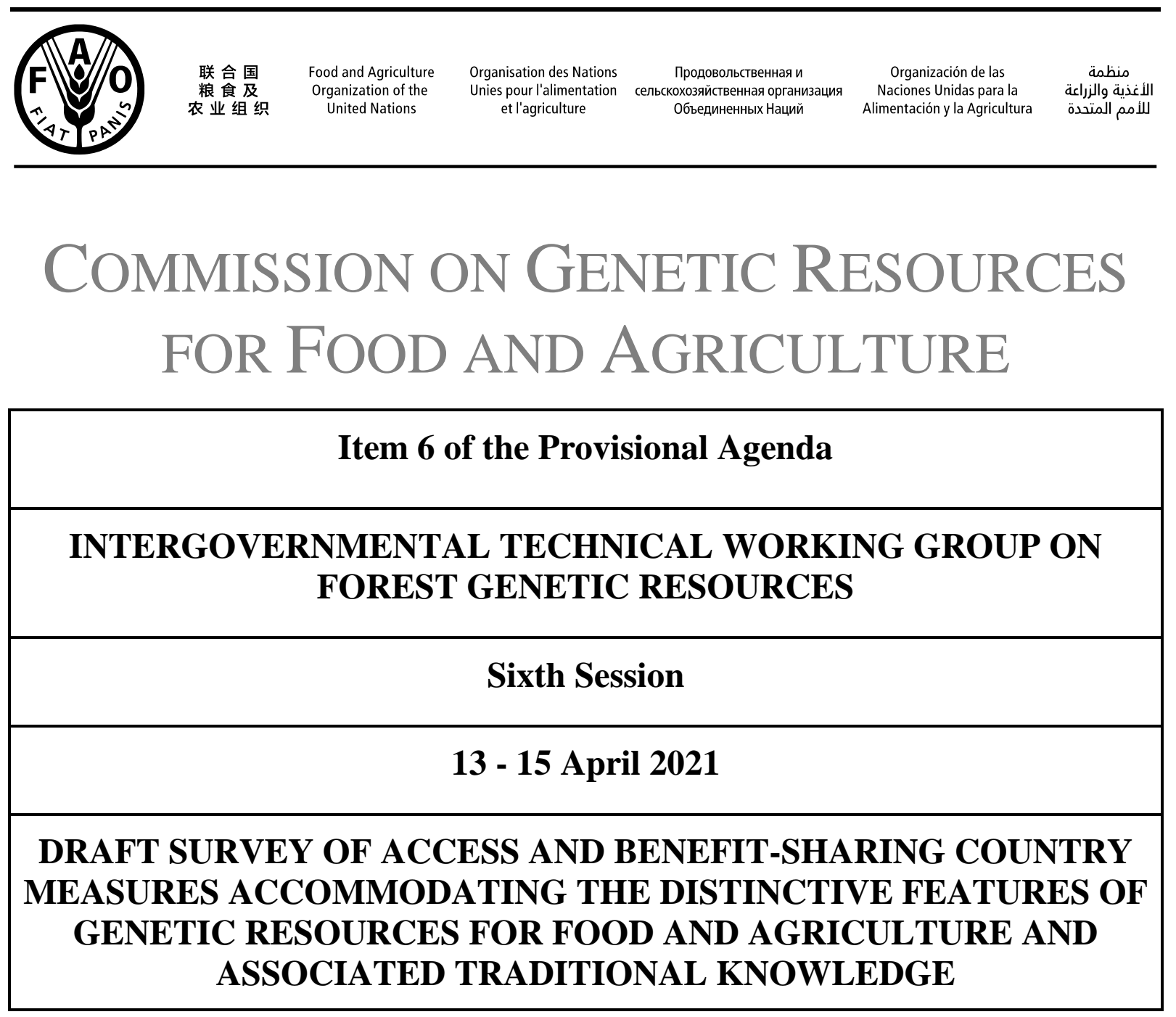

\title{
Note by the Secretariat
}

1. The Commission on Genetic Resources for Food and Agriculture (Commission), at its Seventeenth Regular Session, recalled that its Multi-Year Programme of Work (MYPOW) foresees a review of its work on access and benefit-sharing (ABS) for its Eighteenth Regular Session and requested its Secretary to prepare, for review by the Commission's intergovernmental technical working groups an up-to-date survey of existing legislative, administrative and policy approaches, including best practices, for ABS for the different subsectors of genetic resources for food and agriculture (GRFA) and traditional knowledge associated with GRFA held by indigenous peoples and local communities, with the aim of identifying typical approaches and lessons learned from their implementation, as well as challenges and possible solutions.

2. The Commission requested the Working Groups to review the survey. ${ }^{1}$

3. This document contains the draft Survey of ABS country measures accommodating the distinctive features of GRFA and associated traditional knowledge. The draft Survey has been prepared by Fran Humphries (Griffith University \& Queensland University of Technology, Australia) with contributions from Sarah Laird (People and Plants International, United States of America), Rachel Wynberg (University of Cape Town, South Africa), Clare

${ }^{1}$ CGRFA-17/19/Report, paragraph 19. 
Morrison (Griffith University, Australia), Charles Lawson (Griffith University, Australia) and Anastasia Kolesnikova (Griffith University, Australia).The content of the draft Survey is entirely the responsibility of the authors, and does not necessarily represent the views of FAO or its Members. 
Survey of access and benefit-sharing country measures accommodating the distinctive features of genetic resources for food and agriculture and associated traditional knowledge

Fran Humphries ${ }^{\mathrm{a}}$

With contributions from Sarah Laird ${ }^{\mathrm{b}}$, Rachel Wynberg, ${ }^{\mathrm{c}}$ Clare Morrison, ${ }^{\mathrm{d}}$ Charles Lawson ${ }^{\mathrm{d}}$ and Anastasia Kolesnikova $^{\mathrm{d}}$

a Griffith University \& Queensland University of Technology, Australia

${ }^{\mathrm{b}}$ People and Plants International, United States of America

${ }^{c}$ University of Cape Town, South Africa

${ }^{d}$ Griffith University, Australia

The content of this draft survey is entirely the responsibility of the authors and does not necessarily represent the views of FAO or its Members. 


\section{TABLE OF CONTENTS}

$\begin{array}{lr}\text { Abbreviations } & 7 \\ \text { Executive summary } & 8 \\ \text { Introduction } & 16 \\ \text { Background } & 18 \\ \text { Literature review } & 20\end{array}$

$\begin{array}{lr}\text { Literature review } & 20\end{array}$

I. Element 1: Institutional arrangements $\quad 23$

1.1 Single institutional responsibility for access and benefit-sharing 23

1.2 Shared institutional responsibility for ABS measures $\quad 24$

1.3 Coordination within national governments of ABS activities across sectors and stakeholders

1.4 Information-sharing arrangements 28

$\begin{array}{ll}1.5 \text { Element } 1 \text { Conclusion } & 29\end{array}$

II. Element 2: Access to and utilization of genetic resources for food and agriculture 31

2.1 Categories of genetic resources covered by access and benefit-sharing legislation 31

2.1.1 Temporal scope of access measures for genetic resources for food and agriculture

2.1.2 Genetic resources provided by countries of origin/countries that acquired them in accordance with the Convention on Biological Diversity 33

2.1.3 Privately versus publicly held genetic resources 35

2.1.4 Genetic resources versus biological resources 36

2.1.5 Genetic resources held by Indigenous Peoples and local communities 37

2.1.6 Specific exemptions of genetic resources for food and agriculture subject matter 39

2.2 Intended uses that trigger the application of access and benefit-sharing provisions $\quad 40$

2.2.1 Development of genetic resources in the course of agricultural production $\quad 40$

2.2.2 Research and development for food and agriculture 42

2.2.3 Commercial/non-commercial research and development 42

2.2.4 Exemption of specific activities/user groups 44

2.3 Authorization procedures applicable under access and benefit-sharing legislation $\quad 45$

2.3.1 Prior informed consent 45

2.3.2 Simplified and fast-track prior informed consent 46

2.3.3 Implicit prior informed consent 47

2.3.4 Standardization of prior informed consent and mutually agreed terms 47

2.3.5 Framework prior informed consent and mutually agreed terms 48

2.4 Element 2 Conclusion $\quad 49$

III. Element 3: Access to and utilization of traditional knowledge associated with genetic resources for food and agriculture

3.1 Defining the scope of traditional knowledge associated with genetic resources $\quad 51$

3.2 Identifying the correct traditional knowledge holders $\quad 54$

3.3 Procedures for obtaining traditional knowledge through prior informed consent or approval and involvement of Indigenous Peoples and local communities 55

$\begin{array}{ll}3.4 \text { Element } 3 \text { Conclusion } & 56\end{array}$

IV. $\quad$ Element 4: Fair and equitable sharing of benefits 58

$\begin{array}{ll}\text { 4.1 Scope of benefit-sharing obligations } & 58\end{array}$

4.2 Model contractual clauses, codes of conduct, etc. for negotiating "fair and equitable benefits"

4.3 Identifying the correct beneficiaries with whom benefits should be shared and national benefit-sharing funds

4.4 Monetary and non-monetary benefits

4.5 Sharing benefits through partnerships

4.6 Global multilateral benefit-sharing mechanism $\quad 63$

4.7 Element 4 Conclusion 
V. Element 5: Compliance and monitoring 65

5.1 Monitoring $\quad 65$

5.2 Compliance measures $\quad 65$

$\begin{array}{ll}5.3 \text { Element } 5 \text { Conclusions } & 67\end{array}$

$\begin{array}{ll}\text { Survey conclusion } & 68\end{array}$

\begin{tabular}{lr} 
Primary sources & 69 \\
\hline
\end{tabular}

$\begin{array}{ll}\text { References } & 73\end{array}$

$\begin{array}{ll}\text { Appendix } 1 \text { Methodology } & 83\end{array}$

\section{LIST OF BOXES}

Pages

Box 1: Countries with single competent national authorities that are genetic resources for food and agriculture agencies (CBD, 2020, as of November 2020) 24

Box 2: Examples of 'one-stop-shop' approaches to institutional arrangements 27

Box 3: Examples of coordination through committees and councils on genetic resources 28

Box 4: Approaches to information-sharing arrangements 29

Box 5: Approaches to defining temporal scope 33

Box 6: Approaches to determining where a genetic resource has developed its distinctive properties 33

Box 7: Approaches to privately vs publicly held genetic resources 36

Box 8: Approaches to defining scope by "biological" or "genetic" resources 37

Box 9: Approaches to genetic resources held by Indigenous Peoples and local communities 38

Box 10: Approaches to specific exemptions of genetic resources for food and agriculture subject-matter

Box 11: Approaches to distinguishing uses that fall within scope of access and benefit-sharing from those relating to the production of agricultural products for sale and human consumption 41

Box 12: Research and development for food and agriculture $\quad 42$

Box 13: Approaches for special arrangements for non-commercial research and development 43

Box 14: Approaches for exempting specific activities of relevance to genetic resources for food and agriculture users

Box 15: Approaches to prior informed consent $\quad 46$

Box 16: Approaches to simplified and fast-tracked prior informed consent $\quad 47$

Box 17: Approaches to standardized prior informed consent and mutually agreed terms 48

Box 18: Approaches to framework prior informed and mutually agreed terms 49

Box 19: Approaches to defining the scope of traditional knowledge 53

Box 20: Ascertaining the correct traditional knowledge-holders 55

Box 21: Procedures for prior informed consent in relation to traditional knowledge 56

Box 22: Approaches to the scope of benefit sharing obligations 59

Box 23: Examples of model contractual clauses, codes of conduct and guidelines 60

Box 24: Approaches to identifying the correct beneficiaries 61 
Box 25: Approaches to monetary and non-monetary benefits 62

Box 26: Approaches to sharing benefits through partnerships $\quad 63$

Box 27: Examples of genetic resources for food and agriculture-related checkpoints 65

Box 28: Approaches to compliance with provider-country prior informed consent and mutually agreed terms

\section{LIST OF TABLES}

Pages

Table 1: Countries with ABS measures identified in this survey

Table 2: Shared institutional responsibility examples 


\section{ABBREVIATIONS}

ABS

access and benefit sharing

$\mathrm{ABSCH}$

Access and Benefit-sharing Clearing-House

AnGR

animal genetic resources for food and agriculture

AqGR

aquatic genetic resources for food and agriculture

CBD

Convention on Biological Diversity

CNA

competent national authority

FAO

Food and Agriculture Organization of the United Nations

FGR

forest genetic resources for food and agriculture

GRFA genetic resources for food and agriculture

InGR invertebrate genetic resources for food and agriculture

IPLC Indigenous Peoples and local communities

MAT mutually agreed terms

MoGR micro-organism genetic resources for food and agriculture

NFP national focal point

PGR plant genetic resources for food and agriculture

PIC prior informed consent

Plant Treaty International Treaty on Plant Genetic Resources for Food and Agriculture

SMTA standard material transfer agreement

TKGRFA traditional knowledge associated with genetic resources for food and agriculture

UNCLOS United Nations Convention on the Law of the Sea 


\section{EXECUTIVE SUMMARY}

1. The multiple sectors of food and agriculture globally operate within a rapidly changing environment of legislative, administrative and policy measures on access and benefit-sharing (ABS). These regulate access to, and use and transfer of, genetic resources and traditional knowledge associated with them, including genetic resources for food and agriculture (GRFA) and traditional knowledge associated with them (TKGRFA), as well as the sharing of benefits arising from the use of genetic resources or associated traditional knowledge. ${ }^{2}$ The Food and Agriculture Organization of the United Nations (FAO) commissioned this survey to address the following research question:

What types of legislative, administrative or policy measures have countries taken to accommodate the distinctive features of GRFA and subsectors of GRFA and of traditional knowledge associated with GRFA in their ABS measures?

2. The survey involved a search for ABS measures in all United Nations member countries and examined the administrative, policy and/or legislative measures or draft laws of 47 countries. It also involved a systematic quantitative literature review for research trends and gaps across geographical scales and GRFA subsectors. The majority of articles concerned international ABS agreements generally: the Convention on Biological Diversity (CBD), the Nagoya Protocol on Access to Genetic Resources and the Fair and Equitable Sharing of Benefits Arising from the Utilization to the Convention on Biological Diversity (Nagoya Protocol) and the International Treaty on Plant Genetic Resources for Food and Agriculture (Plant Treaty). Forty-two percent of publications were at the national level, of which almost 80 percent were about countries in Africa, Asia, Europe and Latin America, (dominated by a relatively small number of countries, primarily Brazil, China, India, Norway, the Philippines and South Africa). Most countries with established ABS frameworks were under-represented in the literature. The majority of the articles focused on plant GRFA (39\%) or all GRFA (35 percent), with comparatively few focusing on aquatic (10 percent), animal ( 8 percent), forest ( 6 percent) or microbial ( 2 percent) GRFA. The most common focus of the publications was the challenges associated with implementation of international ABS agreements under national law. However, few provided data or other evidence on how national measures have contributed to the conservation and sustainable use of GRFA or TKGRFA. While food security was often mentioned, only 5 percent of the publications highlighted the role of ABS for GRFA in food security. A key gap was the absence of literature about how ABS measures accommodate or could accommodate the collection, use and movement of, and the sharing the benefits from, GRFA and TKGRFA.

3. The current survey comprises a baseline desk review of legislation, policy and literature. It provides a review of how countries address the distinctive features of GRFA and TKGRFA based on the letter of their ABS legislative, administrative and policy measures rather than on how these measures have been implemented in practice. It therefore does not provide an analysis of the state of implementation, the challenges involved and possible solutions to these challenges. As such, it aims to provide a basis for future empirical research on how ABS measures work in practice for GRFA subsectors. A specific objective is to provide a typology of legislative, administrative and country measures applying to ABS for GRFA and TKGRFA.

4. The survey follows the structure of the five key elements of ABS measures for GRFA identified in FAO's ABS Elements: (1) institutional arrangements; (2) access to and utilization of GRFA; (3) access to and utilization of TKGRFA; (4) benefit-sharing relating to GRFA and TKGRFA; and (5) monitoring and compliance.

\footnotetext{
${ }^{2}$ Genetic resources for food and agriculture include: aquatic, animal, forest, micro-organism and invertebrate and plant genetic resources for food and agriculture.
} 


\section{Element 1: Institutional arrangements}

5. The survey took institutional arrangements to be broader than institutional structures (e.g. governments) and to extend to the distribution of power for decision-making, funding mechanisms and information-exchange mechanisms. It identified three typical approaches.

6. The first approach was single-agency institutional responsibility for ABS (Section 1.1). The survey found that the most common approach of this kind was to have a single competent national authority (CNA), often an environmental or science authority. However, several countries have a single CNA that is primarily food, forest and agriculture focused but which also makes decisions in relation to genetic resources more broadly (e.g. Belgium, Benin, Bhutan, Comoros, Granada, Indonesia, Malta, Nepal, the Netherlands, Portugal, the Republic of Moldova, and Saint Kitts and Nevis). The second approach was shared institutional responsibility for ABS measures where agriculture CNAs are primarily responsible for GRFA/TKGRFA and environmental or other CNAs are responsible for all other genetic resources and traditional knowledge (Section 1.2). Examples include Estonia, Finland, Mexico, Peru, the Republic of Korea, Spain, the Syrian Arab Republic, Viet Nam and Zimbabwe.

7. Establishing coordination mechanisms for ABS activities across sectors and stakeholders is a third approach countries have taken (Section 1.3). This includes "one-stop-shops", where a single agency takes a coordinating role in authorization processes, (e.g. Brazil, Ethiopia, India, Kenya, Mozambique, Nepal and Uganda) and the establishment of national committees and councils on genetic resources (e.g. France and South Africa). There are fewer examples of coordination mechanisms for TKGRFA specifically.

8. Many governments and stakeholder groups have sought to address problems in the development of streamlined, simple, flexible and coordinated institutional approaches to ABS across sectors by raising awareness, building capacity, simplifying procedures and sharing information in real time through established mechanisms (Section 1.4). Some countries have lodged ABS procedures with the ABS Clearing-House, while others have created national clearing-house mechanisms (e.g. Cameroon, Finland, Kenya, Malaysia and Sweden) or created information-sharing portals and platforms (e.g. France and Germany).

\section{Element 2: Access to and utilization of genetic resources for food and agriculture}

9. When developing, adapting or implementing ABS measures dealing with access to GRFA, countries may take into account: (1) categories of resources to be covered by access provisions; (2) intended uses triggering access provisions; and (3) authorization procedures. The survey provided country examples both of measures that do not exclusively apply to GRFA but may be relevant to GRFA and of measures that explicitly provide for special treatment of GRFA.

\section{Categories of resources covered by access provisions (Section 2.1)}

10. For categories of resources covered by access provisions, the survey looked at six key issues raised in the ABS Elements (FAO, 2019a, pp. 47-50). The first was the temporal scope (Section 2.1.1), which has important implications for whether ABS obligations apply to new and continuing uses of GRFA collected or accessed before an ABS law enters into force in a jurisdiction. It was found that typical approaches to determining the date from which ABS obligations apply to genetic resources and/or knowledge were based on the time of:

- a specified date (e.g. European Union, France, Malaysia and Malta);

- “access" (e.g. Antigua and Barbuda, Australia, Bulgaria and Niger);

- "utilization" (e.g. Japan);

- predefined activities (e.g. Brazil and South Africa); or

- various activities as triggers at different temporal scales (e.g. Croatia, Kenya, Mozambique, Nicaragua, Palau, Panama, Rwanda and Zambia). 
11. The second issue was determining with certainty the country of origin in the case of GRFA that have been widely exchanged across time and geographical locations (Section 2.1.2). Parties to the CBD can apply their access measures to genetic resources for which they are the country of origin or those acquired in accordance with the CBD. The survey found examples of measures defining the circumstances in which genetic resources are considered to have developed their "distinctive properties" and thereby clarifying whether ABS obligations apply. The approaches in question were:

- including and defining domesticated resources (e.g. France, Mozambique and Viet Nam);

- specifying the date before which the resources have to have been present in order to be deemed to have developed their distinctive characteristics in the country (e.g. Australia);

- determining origin within cultural contexts (e.g. Uganda); and

- specifying the country of "isolation" for micro-organism genetic resources for food and agriculture (MoGR) (e.g. Brazil, Colombia and Mozambique).

12. The third key issue is the need to clarify whether ABS measures apply to privately held or only to publicly held GRFA and to clarify the hierarchy of different types of rights related to genetic resources, including intellectual property (Section 2.1.3). Clarification is necessary because ABS measures may have a significant impact on the exchange of privately held GRFA, such as breeding materials. The survey found that many laws do not distinguish between privately and publicly held materials and that few laws specify whether privately held genetic resources are excluded. Some laws only apply to public land, waters and collections and by implication exclude privately owned materials (e.g. most of Australia's jurisdictions). Some laws exclude from their scope specific resources, such as plant varieties protected under plant breeders' rights legislation (e.g. Kenya, Portugal's Autonomous Region of the Azores, and Uganda). Some laws recognize and protect Indigenous Peoples and local communities' (IPLCs') rights to communal genetic resources and traditional knowledge (e.g. the Philippines and Uganda).

13. A fourth key issue is whether the measures apply broadly to biological resources or more narrowly to genetic resources so that only the use of a biological resource for its genetic material potential rather than for its other attributes (such as providing a product for consumption) falls within their scope (Section 2.1.4). The survey found that most of the ABS laws reviewed confined their scope to genetic resources but that some used a broader biological resources definition (e.g. Costa Rica and India). Some ABS laws with this broader definition then narrow the scope under other provisions, such as through an exemption for resources used for consumption (e.g. Australia).

14. A fifth key issue is clarifying the scope of genetic resources over which IPLCs have an "established right" to grant access in accordance with the Nagoya Protocol framework (Section 2.1.5). The survey found that "established rights" over resources are often determined outside the ABS context, such as through other legislation (e.g. Australia) and court proceedings (e.g. Vanuatu). Some laws apply to Indigenous Peoples only (e.g. Australia), some to local communities only (e.g. Namibia) and some to Indigenous Peoples and local communities (e.g. Malaysia). Usually it is up to Indigenous Peoples to self-identify, but some ABS laws provide a definition for local communities generally (e.g. Namibia) or specifically in relation to GRFA (e.g. Mozambique). Some laws provide for advisory bodies to coordinate between IPLCs (e.g. Malaysia and Vanuatu). Some laws incorporate customary laws into their ABS measures (e.g. the Philippines and Zambia), while some countries require compliance with community protocols (e.g. Indonesia). Several countries have biocultural or community protocols specific to GRFA (e.g. Peru and Romania). Kenya has procedures for consulting with and obtaining consent from IPLCs in neighbouring countries.

15. A sixth key issue is how to craft specific exemptions for GRFA materials (Section 2.1.6). The survey found that most countries exclude GRFA if they are managed under multilateral ABS arrangements such as the Plant Treaty. Under this approach:

- $\quad$ some countries exclude only materials under the Plant Treaty's Annex 1 (e.g. Peru);

- others more broadly exclude materials under the Plant Treaty multilateral system (e.g. Bhutan); and 
- others have general exclusions for any materials regulated under a specialized international ABS regime (e.g. France).

- Some countries exclude specific categories of genetic resources by definition, for example:

- domesticated/cultivated species (Bhutan, France and Morocco (draft law));

- specific categories of plant genetic resources for food and agriculture (PGR), fisheries resources and animal genetic resources for food and agriculture (AnGR) (Spain);

- GRFA protected under intellectual property (e.g. Kenya, Portugal's Autonomous Region of the Azores, and Uganda).

16. Finally, some countries exclude GRFA on a declaratory (e.g. Australia) or case-by-case basis (e.g. India).

\section{Intended uses triggering access provisions (Section 2.2)}

17. The second part of Element 2 that countries may take into account when accommodating GRFA under national measures is intended uses that trigger the application of ABS provisions. A broad scope in this regard might capture a wide range of GRFA activities and many food and agriculture-related transactions that would otherwise be considered to be managed under sales contracts and not ABS rules. The survey looked for examples that address four key issues raised under the ABS Elements (FAO, 2019a, pp. 50-59).

18. The first issue is the difficulty of distinguishing GRFA falling within the scope of ABS obligations from those used in the supply of agricultural products for sale or human consumption, which generally fall outside the scope of ABS obligations. The survey found that some laws make the distinction based on "intention" and "purpose" of use (e.g. South Africa). Some laws define and exempt resources used as commodities or for consumption (e.g. Bangladesh, India, Malta and the Philippines), while other laws have specific exclusions for GRFA activities that do not amount to "research and development" (e.g. Australia, Malaysia, Spain and the United States of America [Utah]).

19. A second issue is the difficulty involved in drawing a distinction between food/feed and nonfood/feed agricultural products given that the purposes for which the outcome will ultimately be used will often be unknown at the research and development phase. The survey found that while it may be difficult to draw a distinction, some national laws have attempted to facilitate food and agriculture (including aquaculture and forestry) research and development by providing for simplified prior informed consent (PIC) and mutually agreed terms (MAT) arrangements for agrobiodiversity research (e.g. the Philippines) or facilitated access for specific GRFA subsector research (e.g. Ethiopia and Norway).

20. A third issue is how to create conditions that promote non-commercial GRFA research and development. The survey found that several countries make a distinction between commercial and noncommercial research, for example Australia, Bangladesh, India, the Philippines, South Africa, while most do not make a distinction, for example Ethiopia, Thailand and Zambia. Some laws have specific procedures for changes of intent to avoid loopholes that would enable subsequent use of resources or knowledge for commercial purposes without consent (e.g. Australia, France, Kenya and Malaysia). Making a distinction between specifically agricultural commercial and non-commercial research is rare, but there are some countries that attempt to accommodate GRFA activities in their measures. For example, Solomon Islands has a law that excludes GRFA through a narrow definition of commercial research that is restricted to pharmaceutical purposes. Other laws exclude breeding purposes from the definition of commercial use (e.g. Bangladesh and India).

21. Finally, the survey found that some countries exempt specific uses or activities from their ABS measures or offer simplified procedures for them. Examples include research for taxonomic (e.g. Mexico), conservation (e.g. Spain) or animal/plant-health (e.g. France) purposes, exchange of genetic resources within and among local IPLCs (e.g. Guatemala, India and Uganda) or among farmers (e.g. China (draft law) and Malaysia), and exchanges within research networks (e.g. India). 


\section{Applicable authorization procedures (Section 2.3)}

22. The third part of Element 2 that countries may take into account when accommodating GRFA is applicable authorization procedures for their access, use and/or transfer. These procedures often apply to both genetic resources and traditional knowledge. However, Element 3 provides detail on PIC procedures unique to traditional knowledge. The survey looked at five key issues raised in the $A B S$ Elements (FAO, 2019a, pp. 59-62).

23. The first issue concerns PIC procedures (Section 2.3.1). Many countries do not have dedicated ABS legislative frameworks, but most of these manage access under various other types of legislation, for example legislation on fisheries, the environment or agricultural. Some countries do not have access measures for their biological resources but do have PIC measures for traditional knowledge associated with genetic resources within their jurisdictions (e.g. Finland and Indonesia).

24. Most ABS laws have PIC provisions as administrative authorization procedures (e.g. permits) at the time of access, utilization and/or transfer (export). Some have requirements to consider food and agriculture when determining the terms and conditions of approval (e.g. Ethiopia). Other countries have registration systems designed to capture end-users of genetic resources and knowledge rather than consent procedures at the time of collection or use (e.g. Brazil). Some countries extend PIC procedures to intellectual property applications concerning genetic resources and/or traditional knowledge (e.g. India, Malaysia, Norway and Zambia).

25. The second issue concerns considerations for fast-tracked consent procedures for certain situations, for example for research and development for food and agriculture (Section 2.3.2). The survey found that some laws have simplified procedures in the form of a declaration for conservation and emergency situations relating to human, animal or plant health (e.g. France) and for food security in the case of threats to the life and health of humans, animals or plants (e.g. the Republic of Korea). Some laws have a fast-track processes for specific categories of users, for example locals and growers and cultivators of biodiversity (e.g. India).

26. The third issue concerns what are referred to in the ABS Elements as "implicit" consent procedures, under which access and utilization may proceed without explicit PIC (Section 2.3.3). The survey found no examples of such procedures. However, one view of "notification" style procedures (e.g. Brazil) is that they may constitute implicit consent at the time of access.

27. The fourth issue concerns standardization of access procedures when dealing with the high number of transfers in the food, agriculture and aquaculture sectors (Section 2.3.4). The Plant Treaty's multilateral system and standard material transfer agreement (SMTA) is one example. The European Union and the African Union have indicated that their members may choose to use the Plant Treaty's SMTA as a guide for extending a standardized approach to other PGR in the public domain. Some laws prescribe standard terms and conditions for material transfer agreements that apply to genetic resources, including GRFA (e.g. South Africa, the Philippines and Uganda).

28. The fifth issue concerns framework PIC and MAT (e.g. with research centres or universities) that include a specific range of genetic resources and which might be limited to specific purposes (Section 2.3.5). This is still a largely unexplored field, but the survey found a possible example in the case of the application of framework access agreements at the national level in Andean countries such as Ecuador and Peru.

29. One observation that can be made for all of the approaches in Element 2 is that they have a heavy focus on special arrangements for PGR and to a lesser extent AnGR, with very little focus on aquatic (AqGR), forest (FGR) and micro-organism (MoGR) genetic resources for food and agriculture. While the literature review revealed few examples of special arrangements, it did show a similar pattern in terms of subsectors focus, revealing a significant gap in knowledge about the effects of ABS measures on AnGR, AqGR, FGR, invertebrate genetic resources for food and agriculture (InGR) and MoGR in particular. The key finding from the survey is that there is there is no one-size-fits all approach to accommodating GRFA and TKGRFA under authorization procedures and that further research is needed to determine their practical effects and whether options differ across subsectors. 


\section{Element 3: Access to and utilization of TKGRFA}

30. While many of the considerations in Element 2 also apply to Element 3, this element outlines some additional requirements for TKGRFA where there are specific requirements or considerations that apply uniquely to traditional knowledge. Element 4 includes benefit-sharing related to the use of traditional knowledge. The survey found that countries took diverse approaches under their national laws to defining the scope of traditional knowledge that falls within the subject matter of ABS (Section 3.1). The range included traditional knowledge:

- broadly associated with genetic resources (e.g. Zambia);

- broadly associated with biological resources (e.g. Peru);

- broadly associated with ecological knowledge (e.g. Guatemala);

- more narrowly associated with genetic resources (e.g. Japan, Mozambique, Nicaragua, the Republic of Korea and Viet Nam);

- $\quad$ specifically including TKGRFA (e.g. Kenya and Uganda);

- specifically excluding TKGRFA (e.g. France and Morocco (draft));

- defined by the custodians of the knowledge in a specific case (e.g. Australia and Finland); and

- extending to traditional knowledge in the public domain (e.g. Ecuador and South Africa).

31. The survey found diverse approaches to ascertaining the correct traditional knowledge holder (Section 3.2), including prescribed processes for helping with correct identification (e.g. Malawi, South Africa and Uganda). It found that several countries manage TKGRFA differently from other traditional knowledge, for example through specific GRFA biocultural protocols that are complementary to ABS laws (e.g. in Indian and Kenyan communities). It is important for users to be aware that traditional knowledge holders may be different from the IPLCs with an established right to grant access over the physical resources and many rights are held by the collective, not individuals (e.g. Ecuador, Peru and Plurinational State of Bolivia).

32. The survey found that while many of the procedures for PIC and MAT identified in Element 2 were also applicable to access and use of traditional knowledge, there were examples of specific procedures for traditional knowledge (Section 3.3). Some countries have procedures for laws that protect traditional knowledge in a manner similar to intellectual property (e.g. Kenya, Peru, South Africa, Viet Nam and Zambia). Some national laws define PIC under their national laws for traditional knowledge generally (e.g. Nicaragua) or TKGRFA specifically (e.g. Peru). The survey found that there are an increasing number of protocols complementary to ABS that explain the meaning of free, prior and informed consent within a cultural context at the international (e.g. Mo'otz Kuxtal Voluntary Guidelines - Secretariat of the Convention on Biological Diversity, 2019), national or local levels (e.g. Peru). The survey found procedures for government representation in negotiations (e.g. France) and government involvement in obtaining consent from communities in neighbouring countries (e.g. Kenya).

33. On the whole, procedures for involving IPLCs in granting access to traditional knowledge associated with GRFA are diverse. In many countries they are still under development. However, almost all countries include traditional knowledge as an important factor in PIC and MAT processes, which usually enable IPLCs to apply their traditional and customary laws and practices. However, there is a significant gap in the literature of the practical effect of ABS laws on TKGRFA specifically.

\section{Element 4: Benefit-sharing relating to GRFA and TKGRFA}

34. The survey looked for country examples of ABS measures that accommodate the need for sharing the benefits from the use of GRFA for sustainable food, agriculture, aquaculture and forest production, while at the same time promoting the sharing of benefits with providers of GRFA to compensate for the costs of their conservation and/or to meet equity and economic objectives. The survey considered six key issues that the $A B S$ Elements raise concerning the fair and equitable sharing of benefits (FAO, 2019a, pp. 64-69). 
35. The first issue was the scope of benefit-sharing obligations (Section 4.1). ABS measures vary significantly as to the overall design of benefit-sharing obligations, the procedures foreseen for reaching MAT and the level of formality required for the agreement. Some ABS measures (e.g. Rwanda and Solomon Islands) leave it up to the CNA to determine the modalities of benefit-sharing on a case-bycase basis as part of the access permit. Other laws are more prescriptive, with benefit-sharing agreements for intended commercial uses or a statutory declaration for non-commercial uses (e.g. some Australian jurisdictions). In relation to special arrangements for GRFA concerning benefit-sharing categories and processes, some laws exempt from benefit-sharing obligations certain categories of users or products relevant to GRFA, for example farmers (e.g. Brazil), and some laws have simplified benefit-sharing procedures for GRFA research or other activities (e.g. the Philippines).

36. The second issue was the reliance of GRFA sectors on model contractual clauses, codes of conduct, guidelines and best practice developed for GRFA subsectors (Section 4.2). The survey found many examples for the PGR and MoGR subsectors, but fewer examples for the AqGR, AnGR, InGR and FGR subsectors.

37. The third issue was the challenge of identifying the correct beneficiaries with whom benefits should be shared (Section 4.3). Some countries have national benefit-sharing funds to address situations where beneficiaries cannot be identified or there are multiple beneficiaries for GRFA/TKGRFA (e.g. Bangladesh, Bhutan and Brazil). The survey found that few countries address the grey area of intermediaries (neither providers nor users) in relation to ABS obligations and the claiming of benefits, the European Union and Malaysia being exceptions.

38. The fourth issue was benefits that are of particular relevance to the food and agriculture sector (Section 4.4). The survey found that some laws identify such benefits:

- research directed towards food, health and livelihood security (e.g. Belgium (Walloon Region), India, Malaysia and Uganda);

- training to enhance local skills and propagation of GRFA and TKGRFA (e.g. Zambia); and

- mutual exchange of GRFA within or between communities to sustain food or livelihood systems (e.g. India, Kenya and Zambia) and for traditional uses (e.g. Ethiopia and Norway).

39. It found that monetary benefits are not usually GRFA-specific under national laws but that there are some high-profile publicly available benefit-sharing agreements relating to GRFA, including rooibos (South Africa), teff (Ethiopia) and the baobab tree.

40. The fifth issue is how to manage GRFA that are often exchanged in the framework of collaborations and partnerships in which many stakeholders act neither as the original providers nor as end users (Section 4.5). The survey found a large gap in analysis with respect to approaches to sharing benefits through partnerships, with few examples in ABS laws and literature. However, one approach is to create measures that simplify the requirement for subsequent users to enter into benefit-sharing agreements with the original provider (e.g. Queensland, Australia).

41. The sixth key issue is consideration of a global multilateral benefit-sharing mechanism for GRFA in addition to the Plant Treaty mechanism (Section 4.6). The CBD has commissioned a study that is currently under peer-review, and further investigation of the issue is beyond the scope of the present survey.

42. Despite the CBD having been in force for decades, research studies and official ABS ClearingHouse data confirm that very few benefit-sharing agreements have been concluded for genetic resources generally, and even fewer for GRFA purposes specifically.

\section{Element 5: Monitoring and compliance}

43. Parties to the Nagoya Protocol must take measures to monitor and enhance transparency about the "utilization of genetic resources", including by designating checkpoints and providing recognized certificates of compliance (evidence that access procedures were followed) and other relevant nonconfidential information to the ABS Clearing-House (Section 5.1). The survey found that checkpoints vary between countries and often include patent offices (e.g. Kenya), national coordination centres (e.g. 
Belarus), environment protection bodies (e.g. Denmark) and food safety offices (e.g. the Netherlands). Several countries have checkpoints directly relevant to research, development and commercialization of GRFA, including agricultural, forestry and biocontrol institutions, some of which cover also aquaculture (e.g. Bhutan, Estonia, Hungary, Kenya and the Republic of Korea).

44. There are different types of compliance measures for GRFA, but this survey was confined to examples of approaches to so-called "user country measures" under the Nagoya Protocol, which require Parties to take measures to provide that genetic resources and traditional knowledge used within their jurisdiction have been accessed in accordance with PIC and that MAT have been established (Section 5.2). Countries are also required to take measures to address situations of non-compliance and to cooperate in the event of alleged violations. There are few examples of such measures under law (e.g. Japan, Norway, the Republic of Korea and European Union Member States).

45. These compliance "user country" measures only ensure that access procedures have been followed, and not that users have complied with the terms of the MAT (e.g. the terms and conditions of access and use and/or benefit-sharing agreements). The Nagoya Protocol, however, obliges parties to ensure opportunities for recourse under their legal systems in cases of dispute arising from MAT (consistent with jurisdictional requirements). The Philippines provides an example of the inclusion in ABS law of a procedure to be applied in the event of a MAT dispute.

\section{Conclusion}

46. Countries have broad scope to accommodate the distinctive features of GRFA within existing ABS frameworks. Promoting the conservation and sustainable use of genetic resource and associated traditional knowledge need not involve a one-size-fits-all model. If institutional arrangements are coordinated at international, regional, national and local levels, they can develop streamlined, simple and coordinated approaches to ABS measures across sectors. This coordination can promote a shared understanding of how access measures can be varied through exemptions and special arrangements based on GRFA activities and sites of significance. It can promote benefit-sharing options that suit sectors relying on incremental innovation through government and community funds and capacitybuilding specific to the GRFA sectors. The survey found that many national ABS measures apply to commercial as well as small-scale and subsistence food and agriculture activities on paper, but there are significant gaps in research about the positive or negative effects of the measures in practice on various stakeholders and the conservation and sustainable use of GRFA/TKGRFA. The challenge in the coming decades will be for countries to ensure the access, sustainable use and transfer of GRFA and TKGRFA for food/livelihood security and conservation, while ensuring the fair and equitable sharing of benefits from their use with the providers and knowledge holders. 


\section{INTRODUCTION}

The multiple global sectors of food and agriculture operate within a rapidly changing environment of access and benefit-sharing (ABS) laws and policies. These regulate access to, and use and transfer of, genetic resources for food and agriculture (GRFA) and traditional knowledge associated with GRFA (TKGRFA) and the sharing of related benefits with the provider and/or knowledge holder.

The Food and Agriculture Organization of the United Nations (FAO) and its Commission on Genetic Resources for Food and Agriculture (Commission) have a longstanding history of dealing with access to GRFA and the fair and equitable sharing of benefits derived from their utilization. One of the more recent products of the Commission's work on ABS, are the Elements to Facilitate Domestic Implementation of Access and Benefit-Sharing for Different Subsectors of Genetic Resources for Food and Agriculture (ABS Elements), which, following the Commission's Seventeenth Regular Session in 2019 , were complemented by explanatory notes that provide additional information specifically relevant to the different subsectors of GRFA, including plant, animal, aquatic, forest and micro-organism and invertebrate GRFA (FAO 2019a). The ABS Elements aim to assist governments, in their development and implementation of ABS measures, to take into account the importance of GRFA, their special role in food security and the distinctive features of their different subsectors (FAO, 2019a).

The Commission, at its Seventeenth Regular Session, requested its Secretary to prepare, for review by the Commission's intergovernmental technical working groups:

an up-to-date survey of existing legislative, administrative and policy approaches, including best practices, for ABS for the different subsectors of genetic resources for food and agriculture (GRFA) and traditional knowledge associated with GRFA held by indigenous peoples and local communities, with the aim of identifying typical approaches and lessons learned from their implementation, as well as challenges and possible solutions (FAO, 2019b).

This survey was commissioned by FAO in response to the first part of this request and to address the research question "which types of legislative, administrative or policy measures have countries taken to accommodate the distinctive features of GRFA and subsectors of GRFA and of TKGRFA in their ABS measures?" As requested by the Commission, the survey will be submitted to the Commission's intergovernmental technical working groups, the Team of Technical and Legal Experts on Access and Benefit-sharing and the Commission for their consideration.

The GRFA subsectors surveyed are plant (PGR), animal (AnGR), aquatic (AqGR), forest (FGR), microorganism (MoGR) and invertebrate (InGR) genetic resources for food and agriculture and associated TKGRFA. The survey searched for ABS measures in all United Nations member countries and examined the administrative, policy and/or legislative measures or draft laws of 47 countries (see Table 1). The countries were included on a random basis because they had measures relevant to the elements explored in the survey.

This is a desktop baseline survey drawing on three sources - legislation, policy and literature. Literature searches included a systematic quantitative literature review of peer-reviewed articles, book chapters and books in English (see below for further details) and a qualitative review of peer reviewed and grey literature (reports and meeting documents). The legislative review involved interpretation of primary sources (legislation) supported by secondary sources through the literature searches. The review included unofficial translations of non-English legislation. The laws were sourced from the parliamentary websites of the relevant countries and legal databases including WorldLII and Westlaw. The policy review involved government website searches, literature searches and other government sources. The survey was not intended to be an exhaustive review of all countries' measures nor a review of the effectiveness of the arrangements and their implementation in practice. It focused on how country frameworks look on paper, not on how they work in practice, and the survey is not intended to provide legal advice. 
Table 1 Countries with ABS measures identified in this survey

\begin{tabular}{|l|l|l|l|l|}
\hline $\begin{array}{l}\text { Antigua and } \\
\text { Barbuda }\end{array}$ & Costa Rica & India & Nicaragua & South Africa \\
\hline Australia & Croatia & Indonesia & Niger & Spain \\
\hline Bangladesh & $\begin{array}{l}\text { Democratic People's } \\
\text { Republic of Korea }\end{array}$ & Japan & Norway & Uganda \\
\hline Belgium & Denmark & Kenya & Palau & $\begin{array}{l}\text { United States of } \\
\text { America (Utah) }\end{array}$ \\
\hline Bhutan & Ecuador & Malawi & Peru & Viet Nam \\
\hline Brazil & Ethiopia & Malaysia & Philippines & Zambia \\
\hline Bulgaria & Finland & Malta & Portugal & Zimbabwe \\
\hline Cameroon & France & Mexico & Republic of Korea & \\
\hline China & Germany & Morocco & Rwanda & \\
\hline Colombia & Guatemala & Mozambique & Solomon Islands & \\
\hline
\end{tabular}

This survey follows the structure of the five key elements of ABS measures for GRFA identified in Chapter 6 of the ABS Elements (FAO, 2019a):

1. Element 1 - Institutional arrangements;

2. Element 2 - Access to and utilization of GRFA;

3. Element 3 - Access to TKGRFA;

4. Element 4 -Fair and equitable sharing of benefits;

5. Element 5 - Compliance and monitoring.

Under each element, the survey identifies several key topics, which are in turn broken down into subtopics. In each case, country examples of typical approaches to accommodating the distinctive features of GRFA and subsectors of GRFA and of TKGRFA in ABS measures are presented. 


\section{BACKGROUND}

There are three international legally binding ABS frameworks, all of which are relevant to sectors of food and agriculture: ${ }^{3}$ the Convention on Biological Diversity (CBD), the Nagoya Protocol on Access to Genetic Resources and the Fair and Equitable Sharing of Benefits Arising from the Utilization to the Convention on Biological Diversity (Nagoya Protocol), and the International Treaty on Plant Genetic Resources for Food and Agriculture (Plant Treaty). Negotiations of a legally binding instrument under the United Nations Convention on the Law of the Sea (UNCLOS) on the conservation and sustainable use of marine biological diversity of areas beyond national jurisdiction are ongoing and may in the future have relevance for AqGR, including aquatic PGR, MoGR and InGR (UNGA, 2017).

The CBD recognizes the sovereign rights of states over their natural resources and that the authority to determine access to genetic resources rests with national governments and is subject to national legislation. At the same time, contracting parties of the CBD shall endeavour to create conditions that facilitate access to genetic resources for environmentally sound uses by other contracting parties and not to impose restrictions that run counter to the objectives of the CBD. Access, where granted, shall be on mutually agreed terms (MAT) and subject to prior informed consent (PIC) of the contracting party providing resources, unless otherwise determined by that party.

Two core legal and institutional processes have evolved since the CBD entered into force to achieve this in practice:

- an administrative (government) process for regulating access and utilization through PIC and authorization processes (e.g. permits), including the establishment of measures that aim to ensure that genetic resources and associated traditional knowledge used for research and development have been accessed in accordance with PIC and that MAT have been established, as applicable; and

- a contractual process for determining how the benefits arising from the utilization of genetic resources and traditional knowledge are "fairly and equitably" shared between users and providers (e.g. benefit-sharing agreements and/or material transfer agreements).

However, as this survey shows, there are several alternatives to this two-step approach, such as registration and end-user approaches to ABS. The CBD Preamble notes that "conservation and sustainable use of biological diversity is of critical importance for meeting the food, health and other needs of the growing world population, for which purpose access to and sharing of both genetic resources and technologies are essential" (CBD, 1992). However, its provisions do not distinguish between GRFA/TKGRFA and other categories of genetic resources and knowledge.

The Nagoya Protocol implements the ABS provisions of the CBD (Nagoya Protocol, Article 4.4). In addition to the CBD's bilateral measures, this framework provides for additional measures concerning, among others, institutional arrangements (Nagoya Protocol, Articles 13 and 14), monitoring and compliance (Nagoya Protocol, Articles 15-18) and traditional knowledge (Nagoya Protocol, Article 7 and 12). The Nagoya Protocol requires parties to consider, in the development and implementation of their ABS measures, the importance of research and development, cases of present or imminent emergencies that may require expeditious access to genetic resources, and the importance of GRFA and their special role for food security GRFA (Nagoya Protocol, Article 8(c)). In its Preamble, the Nagoya Protocol explicitly recognizes the special nature of agricultural biodiversity, its distinctive features and problems needing distinctive solutions, as well as "the interdependence of all countries with regard to GRFA as well as their special nature and importance for achieving food security worldwide and for sustainable development of agriculture in the context of poverty alleviation and climate change ...".

The Nagoya Protocol addresses its relationship with other ABS instrument by stating that "where a specialized international access and benefit-sharing instrument applies that is consistent with, and does not run counter to the objectives of the Convention and this Protocol, this Protocol does not apply for

\footnotetext{
${ }^{3}$ The World Health Organization's Pandemic Influenza Preparedness: Sharing of Influenza Viruses and Access to Vaccines and Other Benefits (WHO, 2011) is a framework for WHO member countries that relates only to the H5N1 influenza strain.
} 
the Party or Parties to the specialized instrument in respect of the specific genetic resource covered by and for the purpose of the specialized instrument" (Nagoya Protocol, Article 4.4).

The Plant Treaty is a specialized ABS instrument that applies to PGR (Plant Treaty, Article 3). Its Multilateral System of Access and Benefit-sharing covers PGR of crops listed in its Annex 1. In the exercise of their sovereignty, state contracting parties provide access to PGR that are under their management and control and in the public domain (Plant Treaty, Article 11.2). The Multilateral System also comprises CGIAR "in trust" materials, materials held by other international institutions that sign agreements with the Governing Body of the Plant Treaty and materials that individual holders voluntarily make available. Under the Multilateral System, access is provided for the purpose of utilization and conservation for research, breeding and training for food and agriculture, provided that such purpose does not include chemical, pharmaceutical and/or other non-food/feed industrial uses (Plant Treaty, Article 12.3 a). Materials are accessed and benefits shared under conditions set out in the Standard Material Transfer Agreement (SMTA), which binds the initial provider and recipient as well as subsequent users (Plant Treaty, Article 12.4).

The CBD, Nagoya Protocol and the Plant Treaty reflect contracting parties' intentions that each of these agreements should be implemented in mutually supportive ways. For example, the Nagoya Protocol must "be implemented in a mutually supportive manner with other international instruments relevant to this Protocol" (Article 4(3)) ${ }^{4}$ and refers to the Multilateral System of Access and Benefit-sharing established under the Plant Treaty as "developed in harmony with the Convention" (Nagoya Protocol, Preamble). The Plant Treaty states that its objectives are "the conservation and sustainable use of plant genetic resources for food and agriculture and the fair and equitable sharing of the benefits arising out of their use, in harmony with the Convention on Biological Diversity, for sustainable agriculture and food security. These objectives will be attained by closely linking this Treaty to the Food and Agriculture Organization of the United Nations and to the Convention on Biological Diversity" (Plant Treaty, Article 1).

Not all countries have ratified all the instruments, and this is reflected in varying ways in national ABS measures and in the way they accommodate the distinctive features of GRFA. In some cases, national $\mathrm{ABS}$ measures also reflect regional arrangements for ABS. Regional approaches to ABS are varied and have a range of formats. These include the development of shared regulations or frameworks such as the European Union's due diligence framework (EU, 2014) and the Andean Community's Decision 391 Common Regime on Access to Genetic Resources (Andean Community, 1996). The African region has model laws (Adebola, 2019) and guidelines (AU Commission, 2015a, 2015b). Some regions also have institutional coordinating structures that deal with ABS, among other issues, including the African Union, Southern African Development Community Plant Genetic Resource Centre (SADC, 2013) and the Secretariat of the Pacific Community (SPC, 2020).

The Nairobi Final Act of the Conference for the Adoption of the Agreed Text of the Convention on Biological Diversity (1992) accepted that GRFA were different from other genetic resources and needed special treatment. Nevertheless, nearly 30 years later, GRFA other than those that fall within the Plant Treaty Multilateral System, generally fall within the CBD/Nagoya Protocol framework and its bilateral approach. This poses challenges for GRFA and associated TKGRFA developed by humans over varying temporal and geographical scales. Examples of national ABS measures that attempt to accommodate the distinctive features of GRFA and TKGRFA are included within the scope of this survey whether or not the countries concerned are parties to particular international agreements.

\footnotetext{
${ }^{4}$ The Preamble also recognizes "that international instruments related to access and benefit-sharing should be mutually supportive with a view to achieving the objectives of the" CBD.
} 


\section{LITERATURE REVIEW}

This survey aims to fill some of the literature gaps about the types of measures that countries take or propose to take to accommodate the distinctive features of GRFA and GRFA subsectors - PGR, AnGR (taken for the purpose of the literature review to include InGR), FGR, AqGR and MoGR - and TKGRFA. To identify trends and gaps we used a systematic quantitative literature review method that systematically identified peer-reviewed literature (from between 1991 and 2020) from a range of databases and quantified the data so that the results are reproducible (Pickering and Byrne, 2014). The search looked for literature concerning ABS, including traditional knowledge $(n=1201)$ and GRFA/GRFA subsectors $(\mathrm{n}=1165)$ and publications that did not relate to the collection, use or movement of, or benefit-sharing from, genetic resources and/or traditional knowledge were removed. The final library for analysis was 827 publications. A summary of the methodology is provided in Appendix 1.

The overall aim of the review was to assess literature on ABS in relation to GRFA and TKGRFA in order to identify trends and gaps in analysis across geographical areas (global, regional and national scales) and across GRFA subsectors. Out of 827 relevant publications, the review found that the majority of the articles focused on PGR (39 percent) or all GRFA (35 percent), with comparatively few focusing on AqGR (10 percent), AnGR (8 percent), FGR (6 percent) and MoGR ( 2 percent).

Almost half of the publications focused on global-level implementation of international agreements (particularly the CBD, the Plant Treaty and the Nagoya Protocol). There was relatively little discussion about how these agreements could specifically be implemented or enforced by ratifying countries (c.f. Halewood et al., 2018; Morgera, Tsioumani and Buck, 2014; Tvedt, 2013), with the bulk of publications indicating that implementation and/or enforcement would be a challenge for many nations.

Approximately 10 percent of publications examined ABS of GRFA at the regional level, primarily in Europe (e.g. Coolsaet et al., 2015) and Africa (e.g. Mapiye et al., 2019). Regional publications about the Americas focused on South America generally (e.g. Medaglia, 2013) and those from Oceania focused on Pacific island countries generally (e.g. Tuiaa et al., 2015). While articles from Asia dominated the national-level publications, there were very few articles examining ABS of GRFA in multiple Asian countries (Liu et al., 2017) or for the region as a whole.

Forty-two percent of publications were at the national level, of which almost 80 percent were from countries in Asia (35 percent), Europe (25 percent) and Africa (20 percent). There were relatively few national-level articles from the Americas and Oceania, highlighting a large knowledge gap in English ABS literature for GRFA. There were 97 publications about specific national ABS laws. However, this literature was dominated by a relatively small number of countries, primarily India (e.g. Varma, 2017), South Africa (e.g. Wynberg, 2017), Norway (e.g. Rosendal and Andersen, 2016), the Philippines (Smagdi, 2005), Brazil (Muzaka and Serrano, 2019) and China (Zheng, 2019). Many countries that have well-established ABS frameworks, for example Kenya and Malaysia (e.g. Angwenyi, 2009; Nijar, 2018), were under-represented in the literature.

The bulk of articles for each subsector related to international agreements concerning ABS. These comprised between 70 and 80 percent of publications concerning PGR, AqGR and MoGR and around 40 percent of publications concerning AnGR and FGR. The following subsections provide an overview of the trends for each subsector of the review.

\section{PGR Literature}

- Over 40 percent of the literature focused on PGR generally, with the remainder concerning all crops combined, medicinal plants, fruit and grains.

- Most focused on the global level (48 percent) or on African, Asian and European countries.

- PGR publications primarily examined issues of intellectual property (35 percent) and Farmer's Rights (23 percent) and the importance of biobanks for seed storage, conservation and dissemination of PGR (19 percent). Few focused on implications of national law for PGR (8.6 percent). 


\section{AqGR literature}

- Most (60 percent) discussed AqGR generally; where specified the main taxonomic groups covered were fish and crustaceans.

- Most (69 percent) focused on the global level or on Asian countries.

- Key issues examined were intellectual property (35 percent), bioprospecting (30 percent) and marine biodiversity in areas beyond national jurisdiction (20.7 percent). Few focused on implications of national law for AqGR (4 percent).

\section{AnGR literature}

- Most (60 percent) discussed AnGR generally; where specified, the main taxonomic groups covered were cattle, pigs, goats and sheep.

- Most (74 percent) focused on the global level or on African and European countries.

- Key issues examined in the literature were traditional knowledge (32 percent), breeders' rights (32 percent) and the use of biobanks for conservation of AnGR (12 percent). Few publications focused on national-level ABS legislation (3 percent).

\section{FGR literature}

- Most focused on European countries (64 percent).

- Most (47 percent) related to temperate forests (mainly Europe) with fewer referring to FGR in relation to agroforestry (usually in Africa, Asia or Oceania) and silviculture (mainly in Africa or Europe).

- Key issues included conservation of FGR (primarily in situ FGR conservation in European countries, such as Greece, Romania and Serbia) (12 percent); 8 percent focused on national legislation in relation to FGR, again primarily in relation to the conservation of these resources. There were no articles on technical ABS issues such as PIC.

\section{MoGR literature}

- Most (70 percent) discussed micro-organisms in general, with the remainder focused on yeasts, soil microbes and viruses.

- Most focused on the global level (75 percent) or on Europe and North America.

- Key issues for MoGRs related to the use of biobanks (45 percent) to store and disseminate MoGR for research (non-commercial purposes). Twenty-five percent examined intellectual property issues associated with the use and sharing of MoGR - particularly in the United States of America and Europe.

Of the 20 key issues covered in the literature on ABS of GRFA (see Table 1, Appendix 1), relevant international ABS agreements (e.g. the CBD, the Nagoya Protocol and Plant Treaty) and their implementation constituted the most common focus (73 percent) of articles at all geographic scales (e.g. Lawson et al., 2019a; Wang et al., 2019). Many publications discussed these agreements, the importance of ABS for GRFA in general, and challenges with implementation and enforcement of policy and legislation (e.g. Louafi and Manzella, 2018). However, there were far fewer articles providing details of how this could be done in practice (e.g. Vernooy and Ruiz, 2013) or how successful current efforts were (Peña Neira, 2017).

The next most common issues covered were the impacts of intellectual property on ABS of genetic resources and traditional knowledge and farmers'/breeders' rights (e.g. Adebola, 2019). These mainly related to commercial crop species (Mulesa and Westengen, 2020) and, to a lesser extent, livestock species (e.g. Allaire, Labatut and Tesnière, 2018), species used in commercial aquaculture (e.g. Rosendal et al., 2013), marine AqGR (Humphries, 2017) and traditional medicinal plant species for the pharmaceutical, nutraceutical and cosmetic industries (Robinson et al., 2018). This strong focus 
on commercially important species in all subsectors highlights an important gap in ABS research and development for non-commercially important species that are essential for future climate change adaptation, ecosystem services, research and general conservation of GRFA, such as crop wild relatives (e.g. Bhatti et al. 2015).

While food security was often mentioned in the literature, only 5 percent of articles highlighted the role of ABS for GRFA despite the importance of GRFA for food security (Leskien, 2018; Mba et al., 2020). Another surprising result was the relatively limited discussion of traditional knowledge in relation to ABS for GRFA. The articles discussing traditional knowledge typically focused on Farmers' Rights or breeders' rights for commercially important species or the implications of the Nagoya Protocol for these rights (e.g. Andersen and Winge, 2013; Peschard, 2017; Perucho et al., 2019; de Aguiar et al., 2020).

There were relatively few publications (10 percent) on national-level ABS legislation (e.g. Greiber, 2019; Sirakaya, 2019) and very little work on ABS for GRFA required for subsector adaptations to climate change (e.g. Srinivasa et al., 2016; Winge, 2016).

The two biggest gaps were empirical studies or evidence about (1) how ABS as a legal tool contributes in practice to the conservation of GRFA and TKGRFA (there is literature on sustainable use) and (2) how ABS measures accommodate the collection, use and movement of, and the sharing of the benefits from, GRFA and TKGRFA. The current survey offers a desktop review of typical approaches countries take for (2) as a first step towards future empirical research on how ABS measures work in practice for food and agriculture subsectors. 


\section{ELEMENT 1: INSTITUTIONAL ARRANGEMENTS}

The ABS Elements (FAO, 2019a, p. 45) highlight the importance to all GRFA subsectors of clear and transparent institutional arrangements with adequate coordination and information exchange mechanisms. Institutional arrangements are the policies, systems and processes that organizations, including governments, use to legislate, plan and manage their activities efficiently and to effectively coordinate with others in order to fulfil their mandates (UNDP, 2011). They are broader than institutional structures (e.g. governments) and extend to the distribution of power for decision-making, funding mechanisms and information-exchange mechanisms. For the ABS frameworks under the CBD, the Nagoya Protocol and the Plant Treaty, these arrangements may include the linkages between and among organizations at the local, state/provincial and national levels, and between governmental and non-governmental entities, including local communities. There is evidence to suggest that in many countries the "coordination between lead agencies responsible for the implementation of the [Plant Treaty] and CBD/NP is "very limited; or "limited"" (Halewood, 2015, p. 10). The discussion below, focuses on institutional arrangements established by national governments in accordance with the CBD and Nagoya Protocol.

Under Article 13 of the Nagoya Protocol, each party must designate a national focal point (NFP). The NFP shall make information available, including on procedures for obtaining PIC and establishing MAT, to applicants seeking access to genetic resources and associated traditional knowledge. Parties must also have one or more competent national authorities (CNA) responsible for: (a) granting access or issuing written evidence that access requirements have been met; and (b) advising on PIC and MAT procedures. Parties may designate a single entity to fulfil the functions of both the NFP and the CNA.

Country experience has shown that a single CNA for ABS may create consistency and streamline implementation of ABS. On the other hand, taking a GRFA sector- or subsector-specific approach may facilitate accommodation of the special characteristics of GRFA and coordination across ABS and food, agriculture and aquaculture policy areas, and therefore help to promote effective implementation.

This section identifies country approaches to institutional arrangements where: (1) one CNA has single responsibility for all genetic resources; (2) multiple CNAs have shared responsibility; and (3) coordination mechanisms (e.g. one-stop shops) have been created to facilitate greater cooperation and consistency among multiple competent authorities. It also offers examples of how countries make information available, including through their NFPs, on applicable procedures and competent authorities.

\subsection{Single institutional responsibility for access and benefit-sharing}

National interim reports and the ABS Clearing-House for the Nagoya Protocol show that many countries have selected a single CNA for ABS rather than taking a sectoral or subsector approach. These single points of responsibility also often coordinate information-sharing with stakeholders, across government and with users (including managing information clearing houses). They often also provide information on when and what type of PIC is required and who may provide consent and negotiate MAT, and they sometimes provide guidance and frameworks for these arrangements.

The most common approach that countries take is to have a single CNA that is an environmental, natural resources or science/technology authority (see Box 1). There are, however, countries that have a single CNA that is primarily food, forest or agriculture focused (but may include other responsibilities such as the environment). These include (CBD, 2020):

- Belgium - General Directorate for Agriculture, Natural Resources and the Environment (for the Walloon Region) and Agency Nature and Forests (for the Flemish Region);

- Benin - General Directorate of Water, Forests and Hunting/Ministry of the Living Environment and Sustainable Development;

- Bhutan - Ministry of Agriculture and Forests;

- Comoros - General Directorate for the Environment and Forests; 
- Grenada - Ministry of Agriculture, Lands, Forestry, Fisheries and the Environment Botanical Gardens;

- Indonesia - Ministry of Agriculture and Food and Drug Agency (Mardiastuti, 2019);

- Malta - Plant Protection Directorate;

- Nepal - Ministry of Forests and Soil Conservation;

- Netherlands - Ministry of Agriculture, Nature and Food Quality;

- Portugal - Institute for Nature Conservation and Forests;

- Republic of Moldova - Ministry of Agriculture, Regional Development and Environment; and

- Saint Kitts and Nevis - Department of Environment, Ministry of Agriculture, Marine Resources, Cooperatives, Environment and Human Settlement, Government of St. Kitts and Nevis.

Having a GRFA-focused single CNA may help to accommodate the importance of food and agriculture when making decisions about ABS. For example, in Bhutan, according to the Biodiversity Bill, the proposed CNA, the Ministry of Agriculture and Forests, would be mandated to promote in particular:

- biodiversity conservation and sustainable use of genetic resources;

- conservation and sustainable use of agrobiodiversity for food and agriculture, including crop wild relatives; and

- informal seed systems under which farmers save, use, exchange and sell farm-saved seeds or propagating material, including rights to save, use and exchange protected varieties (Bhutan, 2016, Clause 16).

The National Biodiversity Centre within the Ministry, coordinates the access process between the proposed user and the various providers of genetic resources and knowledge, including the Department of Forests and Park Services, Community Forest Management Group and community custodians or individuals, which further integrates GRFA subsectors into the ABS process (Bhutan Government, 2018).

Box 1: Countries with single competent national authorities that are genetic resources for food and agriculture agencies (CBD, 2020, as of November 2020)

Belgium, Benin, Bhutan, Comoros, Granada, Indonesia, Malta, Nepal, Netherlands, Portugal, Republic of Moldova and Saint Kitts and Nevis

Countries with Single CNAs that are environmental and/or science/technology agencies (CBD, 2020, as of November 2020)

Albania, Antigua and Barbuda, Argentina, Austria, Belarus, Bulgaria, Burundi, Cambodia, Costa Rica, Croatia, Czechia, Côte d'Ivoire, Democratic Republic of the Congo, Denmark, Dominican Republic, Eswatini, France, Gambia, Germany, Guatemala, Guyana, Honduras, Hungary, Lao People's Democratic Republic, Madagascar, Malawi, Mauritania, Norway, Panama, Poland, Qatar, Sao Tome and Principe, Serbia, Seychelles, Singapore, Slovakia, South Africa, Sweden, Switzerland, Tajikistan, United Kingdom, Uruguay and Venezuela (Bolivarian Republic of).

\subsection{Shared institutional responsibility for access and benefit-sharing measures}

Examples from the ABS Clearing-House demonstrate that in many cases responsibility for the Plant Treaty and authorization for various subsectors of GRFA falls to agricultural authorities while environmental or natural resource authorities are responsible for ABS measures as they apply to nonGRFA resources and traditional knowledge. Table 2 presents examples of countries that allocate 
institutional responsibility according to the purpose for which access is being sought (CBD, 2020, as of November 2020).

Table 2 Shared institutional responsibility examples

\begin{tabular}{|c|c|c|}
\hline Country & $\begin{array}{l}\text { Responsibility for GRFA and/or } \\
\text { TKGRFA }\end{array}$ & $\begin{array}{l}\text { Responsibility for other genetic resources } \\
\text { and/or traditional knowledge }\end{array}$ \\
\hline Estonia & Ministry of Rural Affairs. & Ministry of the Environment. \\
\hline Finland & $\begin{array}{l}\text { Natural Resources Institute } \\
\text { Finland. }\end{array}$ & Finnish Environment Institute. \\
\hline Mexico & $\begin{array}{l}\text { National Service of Seed } \\
\text { Inspection and Certification. } \\
\text { Secretary of Agriculture. } \\
\text { General Livestock Coordination. } \\
\text { General Directorate of Forest and } \\
\text { Soil Management. }\end{array}$ & $\begin{array}{l}\text { Ministry of Environment and Natural Resources. } \\
\text { National Commission for the Development of } \\
\text { Indigenous Peoples. } \\
\text { National Commission for Protected Natural } \\
\text { Areas. }\end{array}$ \\
\hline Peru & $\begin{array}{l}\text { National Forest and Wildlife } \\
\text { Service. } \\
\text { Ministry of Production -Vice } \\
\text { Ministry of Fisheries and } \\
\text { Aquaculture. } \\
\text { National Institute of Agrarian } \\
\text { Innovation. }\end{array}$ & $\begin{array}{l}\text { Ministry of the Environment. } \\
\text { National Institute for the Defence of Competition } \\
\text { and the Protection of Intellectual Property. }\end{array}$ \\
\hline $\begin{array}{l}\text { Republic } \\
\text { of Korea }\end{array}$ & $\begin{array}{l}\text { Ministry of Agriculture, Food and } \\
\text { Rural Affairs. } \\
\text { Ministry of Oceans and Fisheries. }\end{array}$ & $\begin{array}{l}\text { Ministry of Environment. } \\
\text { Ministry of Science and ICT. } \\
\text { Ministry of Health and Welfare. }\end{array}$ \\
\hline Spain & $\begin{array}{l}\text { General Directorate for } \\
\text { Biodiversity, Forests and } \\
\text { Desertification of the Ministry for } \\
\text { the Ecological Transition and the } \\
\text { Demographic Challenge. } \\
\text { General Directorate of Natural } \\
\text { Heritage and Forest Policy of the } \\
\text { Junta de Castilla y León. }\end{array}$ & $\begin{array}{l}\text { General Directorate for Environmental } \\
\text { Assessment and Natural Environment of the } \\
\text { Valencian Community. } \\
\text { General Directorate of Natural Environment and } \\
\text { Biodiversity of Castilla-La Mancha. } \\
\text { General Directorate of Biodiversity and Natural } \\
\text { Resources of the Community of Madrid. } \\
\text { General Directorate of Natural Environment of } \\
\text { the Region of Murcia. } \\
\text { General Directorate of Natural Environment of } \\
\text { the Principality of Asturias. } \\
\text { General Directorate for the Fight against Climate } \\
\text { Change and the Environment of the Government } \\
\text { of the Canary Islands. } \\
\text { Department of Environment and Territory of the } \\
\text { Balearic Islands. } \\
\text { Directorate of Natural Heritage and Climate } \\
\text { Change of the Basque Government. }\end{array}$ \\
\hline $\begin{array}{l}\text { Syrian } \\
\text { Arab } \\
\text { Republic }\end{array}$ & $\begin{array}{l}\text { General Commission for } \\
\text { Scientific Agriculture Researches. }\end{array}$ & $\begin{array}{l}\text { Ministry of State for Environment Affairs. } \\
\text { Syrian Society for Conservation of Wildlife. } \\
\text { Atomic Energy Commission. }\end{array}$ \\
\hline Viet Nam & $\begin{array}{l}\text { Ministry of Agriculture and Rural } \\
\text { Development. }\end{array}$ & Ministry of Natural Resources and Environment. \\
\hline Zimbabwe & Forestry Commission. & $\begin{array}{l}\text { Environmental Management Agency. } \\
\text { National Parks and Wildlife Management } \\
\text { Authority. }\end{array}$ \\
\hline
\end{tabular}

Some countries have lead agencies responsible for specific categories of genetic resources or traditional knowledge and have established processes for incorporating the expertise and input of other agencies. For example, in Viet Nam, the Ministry of Agriculture and Rural Development is responsible for 
granting and registering licences to access agricultural crop varieties, livestock, aquatic species and forest seedlings. The Ministry of Natural Resources and Environment has responsibility for all other genetic resources and provides guidance on traditional knowledge associated with genetic resources (Viet Nam 2017, Articles $6.1 \&$ 26). For GRFA, the Ministry of Agriculture and Rural Development assesses access applications for non-commercial purposes, but it must set up an appraisal committee for access applications for commercial research, including representatives of other ministries, the Provincial People's Committee for the province where access is proposed to take place and relevant experts. The appraisal committee is responsible for assessing the application (Viet Nam, 2017, Article 13). The Ministry of Agriculture is then responsible for sending the decision to the Ministry of Natural Resources and Environment to publish the information in the national database (Viet Nam, 2017, Article 24). The decree sets out clearly defined roles and responsibilities for each ministry and committee responsible for the respective genetic resources (Viet Nam, 2017, Article 26).

\subsection{Coordination within national governments of access and benefit-sharing activities across sectors and stakeholders}

In countries where multiple government ministries and departments are responsible for the implementation of ABS measures, the division of competencies may at times create confusion and inefficiency within government and among stakeholders, as well as for users, who may find it difficult to determine from whom they have to acquire PIC and with whom they have to negotiate MAT. Communication and coordination across multiple CNAs are often difficult, resulting in some governments seeking to establish a streamlined process involving a single coordination point for ABS for all genetic resources, including GRFA, and traditional knowledge associated with genetic resources, including TKGRFA.

A relatively widespread approach to coordination is to establish a government one-stop shop, i.e. to have a single agency that takes a coordinating role in authorization processes (see Box 2). In Brazil's case, the CNA - the Genetic Heritage Management Council (CGEN) - is responsible for the coordination, development and implementation of policies on access to genetic heritage and associated traditional knowledge (Brazil, 2015, Article 6). CGEN also manages the National System for Genetic Heritage and Associated Traditional Knowledge Management, which is a "one-stop shop" for the registration of ABS activities (Brazil, 2019).

Ethiopia has an autonomous body of the federal government - the Ethiopian Biodiversity Institute - that is the sole CNA. Ethiopia's legal framework (Ethiopia, 2006 \& 2009) addresses ABS as well as the implementation of breeders', farmers' and community rights by combining elements of the CBD and the Plant Treaty (Mulesa and Westengen, 2020). The Ethiopian Biodiversity Institute has established five directorates focusing respectively on (1) genetic resource ABS, (2) crops and horticulture, (3) forests, (4) animals and (5) microbes (Mulesa and Westengen, 2020, p. 92). India has a "single window approval process" for accessing biological resources and/or associated knowledge for commercial or non-commercial use. Its CNA, the National Biodiversity Authority, provides online ABS applications, documents and procedures and consults with local communities to receive PIC and negotiate MAT (National Biodiversity Authority, 2016).

Uganda established the National Environment Management Authority (NEMA) under the National Environment Act of 1995 (Uganda, 1995, Section 4). This semi-autonomous institution is the NFP for $\mathrm{ABS}$, as well as being responsible for coordinating, monitoring, regulating and supervising environmental management more broadly. It also oversees the development of ABS policy and legislative frameworks. The Uganda National Council for Science and Technology (UNCST) is the CNA under the ABS framework. It processes access applications, coordinates the activities of resource access providers and facilitates the agreements that are a prerequisites for access (Uganda, 2005, Sections $6 \& 8$ ). The lead agencies that are responsible for particular categories of genetic resources review access applications and ensure protection of other resource providers' rights, including those of local communities, owners and ex situ collections (Uganda, 2005, Section 7). The Ministry for Agriculture, Animal Industry and Fisheries and its seven agencies, including the National Agriculture Research Organisation (NARO), have responsibility for GRFA. While there are multiple bodies involved in ABS policy and authorizations, in an effort to coordinate responsibilities across government 
departments, NEMA, UNCST and NARO signed a memorandum of understanding in 2015, which details the relationship and division of responsibilities between these core institutions responsible for ABS (Otieno et al., 2017; ABS Initiative, 2019). Kenya also opted for a one-stop-shop approach (Kenya, 2006; NEMA, 2014). Its National Environment Management Authority (NEMA) undertakes permit review in conjunction with a range of government entities with control over different resources and sectors (Kenya 2006, Section 9). NEMA and these entities form the ABS Permit Committee, which evaluates and grants permits (Kamau, 2019).

Nepal has also established structures within government to coordinate across departments and ministries. Its National Biodiversity Coordination Committee (NBCC), chaired by the Minister for Forests and Soil Conservation is responsible for coordinating and mainstreaming all biodiversity-related conventions and programmes under the national development agenda, including sharing information and coordinating all biodiversity-related policies (Ahmed, 2016). Aside from government officials (national focal points for a range of treaties, including the CBD and the Plant Treaty), it includes representatives of the academic sector and non-governmental organizations, as well as independent experts (Halewood, ed, 2015). Implementation of the CBD falls under the Ministry of Forests and Soil Conservation, whereas the Ministry of Agricultural Development is the national focal point for the Plant Treaty and is responsible for its implementation (Halewood, ed, 2015). Domestic implementation of ABS for GRFA is guided by the Agrobiodiversity Policy and the National Biodiversity Strategy and Action Plan 2014-20 (Nepalese Government, 2014). The Action Plan provides that the functions of the NBCC include coordinating and

\section{Box 2 Examples of 'one-stop-shop' approaches to institutional arrangements:}

Brazil - Genetic Heritage Management Council

Ethiopia - Ethiopian Biodiversity Institute

India - National Biodiversity Authority

Kenya - National Environment

Management Authority

Mozambique - Minister for the

Coordination of Environmental Action

Nepal - National Biodiversity

Coordination Committee

Uganda - National Environment Management Authority monitoring the implementation of biodiversity-related policies by different ministries and setting up NBCC thematic subcommittees, including for agrobiodiversity and forest and protected areas (Nepalese Government, 2014, p. 112). Mozambique's ABS law provides that the Minister for the Coordination of Environmental Action is the CNA and presides over the interinstitutional Genetic Resources Management Group, which is comprised of various ministries, including those responsible for agriculture and fisheries (Mozambique, 2007, Article 4).

Either in addition to the one-stop-shop approach or as a separate approach to creating greater coordination across government, some governments have chosen to establish national committees and councils on genetic resources (see Box 3). Such bodies often have a mandate to coordinate research and share information, as well as to support the development and implementation of ABS and other policies. As in the above case of Nepal, they may also include representatives from stakeholder groups such as industry, non-governmental organizations and Indigenous Peoples and local communities (IPLCs). For example, South Africa has developed a coordinating structure through its Bioprospecting Forum that, through regular meetings, aims to bring together a range of different stakeholders. These include IPLCs, industry representatives and research institutions focused on coordinating implementation of ABS policy and sharing relevant information. The forum includes representatives from all affected ministries, including agriculture, environmental affairs and science and innovation. Outside this structure, there are mechanisms for coordination between specific government departments responsible for ABS policy implementation (Wynberg, 2018, pp. 198-218).

Other examples of coordinating bodies include France's Foundation for Research on Biodiversity, a platform that involves the various scientific actors mandated to coordinate actions related to the conservation, study and management of AnGR in France (FRB, 2020). In France, the Ministry of 


\section{Box 3 Examples of coordination through committees and councils on genetic resources:}

South Africa - Bioprospecting Forum

France - Foundation for Research on Biodiversity

Ecology is the CNA for genetic resources, including GRFA. The Foundation for Research on Biodiversity leads an ABS working group set up in 2018 that brings together representatives from various research institutes, the private sector and the ministries in charge of agriculture, environment and research (FRB, 2020).

The issues of coordination, information-sharing and communication across government entities within a country, and regionally across countries, is noted as an important issue by the African Union in the African Union Strategic Guidelines for the Coordinated Implementation of the Nagoya Protocol on Access to Genetic Resources and the Fair and Equitable Sharing of Benefits Arising from their Utilization (AU Commission, 2015a). Many African countries expressed a need for streamlined communications from NFPs and CNAs, and ideally the merging of these roles into a single entity (AU Commission, 2015b). They also proposed possible mechanisms, such as national interagency ABS committees or national multistakeholder committees, for improving collaboration and communication (AU Commission, 2015b, p. 8).

\subsection{Information-sharing arrangements}

Under the Nagoya Protocol, parties must establish a NFP that provides information for applicants seeking genetic resources and traditional knowledge associated with genetic resources concerning procedures for obtaining PIC and establishing MAT, including benefit-sharing and information on CNAs, relevant IPLCs and relevant stakeholders (Article 13).

As of 10 November 2020, the CBD's ABS Clearing-House had 347 records of national legislative, administrative or policy measures (from 74 countries) that provide links to the relevant documents or laws. However, these do not synthesize information about current procedures for obtaining PIC and establishing MAT for the relevant country in a format easy for users to understand. While individual country websites often contain information about specific ABS procedures, only 17 countries have published "ABS procedure" (including forms, fees and PIC and MAT procedures) through the ABS Clearing-House in accordance with Articles 13 and 14 (that require information to be provided for publication through the ABS Clearing-House). Under Article 14, the Conference of the Parties serving as the meeting of the Parties to the Nagoya Protocol may also require information to be made available to the ABS Clearing-House (e.g. CBD, 2018a).

Numerous governments have established websites, portals and virtual platforms linked to national clearing-house mechanisms (see Box 4). The Swedish Environmental Protection Agency, for example, through its ABS clearing-house provides details on ABS laws, directions for Swedish users of genetic resources in other countries and procedures for accessing Swedish genetic resources, including European Commission requirements (SEPA, 2020). In Cameroon, where the Ministry of Environment, Protection of Nature and Sustainable Development serves as the CNA, a national web portal provides information on all environment-related international conventions and related protocols. Embedded within this portal is the national ABS clearing-house, which provides information on ABS laws, the access application form and other information for users (Cameroon MINEPDED, 2020). Although the country is not a party to the Nagoya Protocol, Malaysia's law establishes its own clearing-house mechanism, which is a "web-based information portal established by the National Competent authority" (Malaysia, 2017, Section 4). The Malaysian ABS law requires that details of access permits (excluding confidential information) be posted to the site (Malaysia, 2017, Section 33). The website also includes information on CNAs and ABS in Malaysia (ABS Clearing House Malaysia, 2020).

Costa Rica's virtual platform provides similar information, along with guidance on PIC, MAT and monetary and non-monetary benefit-sharing (CONAGEBIO, 2016). Finland regulates access to the Saami people's traditional knowledge associated with genetic resources and provides details on ABS procedures on a government website (Finland National Clearing-House, 2020). Kenya's Access and Benefit Sharing Information Portal shares information on Kenyan biodiversity and relevant laws and makes available information on ABS to help implement the Nagoya Protocol. Details of "concepts and 
procedures" are included to raise awareness and provide guidance on "management and monitoring of utilization of genetic resources by policy makers, regulators, and checkpoints in Kenya." Documents include an ABS tool kit and PIC, MAT and ABS fact sheets and flyers (ABS Kenya, 2020).

France has established a website providing information on ABS laws and the steps applicants need to follow to request access to genetic resources (Ministry of Higher Education, Research and Innovation, 2020). The registration platform includes details on the scope of the ABS law and specific exclusions from the scope and provides links to forms and contacts. The website also makes reference to the European Union's Regulation No 511/2014 on compliance measures for users from the Nagoya Protocol (EU, 2014) and to the European Commission's DECLARE platform, on which users may file a declaration of due diligence (EU DECLARE, 2020). Germany has established an ABS information platform that includes information on laws, responsibilities, training materials, guidelines, national contact points, links to DECLARE and support for users in complying with the requirements of European Union's Regulation No. 511/2014 (German Government, 2020).

\section{Box 4 Approaches to information-sharing arrangements}

- Lodging ABS procedures with the ABS Clearing-house (17 countries as of 10 November 2020);

- Lodging national legislative, policy and administrative measures with the ABS Clearinghouse (74 countries as of 10 November 2020);

- Creating national clearing-house mechanisms (e.g. Cameroon, Finland, Kenya, Malaysia and Sweden);

- Creating information-sharing portals and platforms (e.g. France and Germany).

\subsection{Element 1 Conclusion}

Institutional arrangements for administering ABS for genetic resources and specifically for GRFA and TKGRFA vary considerably. As the ABS Elements note, given the complexity and variety of conditions under which GRFA are accessed and used, implementation and administration should be simple and flexible and involve an evolutionary approach that "allows improvement of the operation of the ABS system through practice, self-perfection and innovation" (FAO, 2019a, p. 43). Many countries continue to evolve their institutional arrangements in response to changing circumstances, new information and experience with a view to minimizing the transaction costs of implementation. There are an increasing number of initiatives aiming to provide a more coherent approach to sharing information about ABS procedures and institutional arrangements through centralized or decentralized web-based platforms. Interoperability between websites and databases continues to be a challenge for ABS governance (Rhoden et al., 2020).

The examples presented under Element 1 demonstrate a tension between centralization of CNAs through single institutional responsibility for ABS on the one hand and a sectoral or subsectoral approach on the other. One advantage of centralization is that it can apply consistent procedures and information-sharing for genetic resources that may be used for a range of purposes (food and agriculture, pharmaceuticals, etc.). One disadvantage is that the predominance of environmental CNAs may not take into account the special characteristics of GRFA and TKGRFA (see ABS Elements, FAO, 2019a, Annex) and the importance of food and agriculture for food security (Nagoya Protocol, Article 8(c)). One advantage of a sectoral approach (where agencies with experience in the food and agriculture sectors have responsibility for GRFA and TKGRFA) is that there may be a greater understanding of how to accommodate ecologically sustainable development of GRFA subsectors in ABS arrangements. Challenges include potential duplication and an increase in complexity associated with having different ABS measures that apply to the same genetic resources and traditional knowledge depending on the purpose for which they are proposed to be used.

The "one-stopshop" approach (offering a single point for ABS for all genetic resources that is responsible for coordinating between the various CNAs with decision-making responsibilities) may on 
the one hand create a streamlined approach to institutional responsibility but on the other hand may require significant human and financial resources for infrastructure overlaying the CNAs. Further research is necessary into which approach is likely to be more beneficial in specific national contexts in terms of accommodating the collection and use of GRFA and TKGRFA and the sharing of the benefits from their use with providers. 


\section{ELEMENT 2: ACCESS TO AND UTILIZATION OF GENETIC RESOURCES FOR FOOD AND AGRICULTURE}

The ABS Elements (FAO, 2019a, p. 47) highlight that when developing, adapting or implementing ABS measures dealing with access to GRFA, countries must take into account (1) the categories of resources covered by access provisions, (2) intended activities triggering access provisions and (3) applicable authorization procedures. Some subject-matter, activity and procedural arrangements are difficult to distinguish in practice, because ABS laws often rely on a combination of these to determine the scope of their arrangements. However, this section follows the format and subheadings of Chapter 6 of the ABS Elements, which separates these considerations.

The country measures addressed in this section include those that do not exclusively apply to GRFA but may be of relevance to GRFA or GRFA subsectors, as well as those that explicitly provide for special treatment of GRFA materials and activities. In accordance with the ABS Elements, considerations related to access and utilization of TKGRFA are considered separately under Element 3, although most of the considerations discussed under Element 2 apply equally to traditional knowledge that is within scope of national ABS laws.

\subsection{Categories of genetic resources covered by access and benefit-sharing legislation}

Under the CBD and Nagoya Protocol the term "genetic resources" means "genetic material of actual or potential value" and genetic material means "any material of plant, animal, microbial or other origin containing functional units of heredity" (CBD, Article 2). The ABS Elements (FAO, 2019a, p. 47) point out that this definition is mirrored in the Plant Treaty, which defines "plant genetic resources for food and agriculture" as "any genetic material of plant origin or actual or potential value for food and agriculture" (Plant Treaty, Article 2). While Parties to the CBD, Nagoya Protocol and/or the Plant Treaty need to make sure their ABS measures address their treaty obligations, they take a wide variety of approaches to determining the categories of genetic resources covered by ABS legislation in practice, as the sections below demonstrate.

\subsubsection{Temporal scope of access measures for genetic resources for food and agriculture}

The temporal scope of ABS measures varies from country to country (see Box 5), in the sense that ABS obligations apply in some countries to newly accessed genetic resources only whereas in other countries they also apply to new and continuing uses of genetic resources collected or accessed prior to the entry into force of the ABS law. ${ }^{5}$ This is significant not only for established GRFA activities such as plant or animal breeding but also for newer activities, such as the breeding of species used in aquaculture, that may already use genetic materials from a variety of countries that might assert control over them and related information and/or knowledge.

It is important to note that the temporal scope of provisions governing access should be distinguished from the temporal scope of benefit-sharing obligations. Even where a country does not require PIC for access to genetic resources or traditional knowledge accessed prior to the entry into force of the country's ABS legislation, it may require that benefits derived from such material/knowledge within the country's jurisdiction and control are shared. In other words, the trigger for authorization measures may be different from the trigger for benefit-sharing measures.

An international agreement concluded between states that is governed by international law does not bind a country in relation to acts occurring before it comes into force unless it expressly states otherwise (Vienna Convention on the Law of Treaties, Article 28). However, countries have sovereign rights to determine the circumstances that trigger ABS obligations in relation to the biological resources within their jurisdiction and under their control ( $C B D$, Article 15), which might have retrospective reach. The ABS Elements (FAO, 2019a, p. 47) therefore state that the Nagoya Protocol, in the absence of any rules

\footnotetext{
${ }^{5}$ Much literature is dedicated to the question/s of whether the CBD and Nagoya Protocol apply to (new/continued uses of) genetic resources accessed prior to these treaties entering into force (e.g. Glowka et al., 1994; Greiber et al., 2012).
} 
to the contrary, does not prevent its parties from applying their national ABS measures to genetic resources that fall outside the (temporal) scope of the Nagoya Protocol.

\section{Commencement provisions}

Like most national laws, ABS laws may specify the date on which they, or specific provisions in them, apply. However, a key question with regard to ABS laws is whether they cover activity involving ex situ materials collected prior to the law coming into force. Malaysia's law requires that any person in possession of a biological resource or of traditional knowledge within its scope at the date the legislation comes into force must enter into a benefit-sharing agreement with the provider if the biological resource is made subject to a new use or used for the development of a new product arising from the resource or associated knowledge (Malaysia, 2017, Section 63(3)). The EU's Regulation No. 511/2014 specifies that ABS obligations (in this case the due diligence obligations of users of genetic resources) only apply to genetic resources and traditional knowledge accessed after the Nagoya Protocol entered into force (i.e. 2014) (EU, 2014, Article 2(1)). Malta's ABS law does not apply to genetic resources acquired prior to entry into force of the CBD (i.e. 1993) (Malta 2016, Section 2(2)(c)). More commonly, obligations will apply to collections after the entry into force of the national law. For example, French law provides that only activities of collecting genetic resources after the entry into force of the ABS law and every subsequent access or new utilization of these resources after that date (2016) will require PIC (France 2016, Article 37 Art. L. 412-6).

Few laws clarify what they mean by a new or continuing use of genetic resources. One exception is the French ABS law, which defines "new utilization" as "any research and development activity with a direct commercial development objective and for which the activity area stands out from the initial one of the same user with the same genetic resource or associated traditional knowledge". It is not entirely clear, however, to what extent a subsequent utilization has to be different from the original activity to qualify as "new" (France 2016, Article 37 Art. L. 412-6 (2)).

\section{Activities triggering ABS obligations}

National ABS measures may identify several activities that trigger ABS obligations and often define, explicitly or implicitly, the temporal scope of the ABS measures. ABS obligations are typically triggered by (a) access, (b) utilization or (c) a combination of these or other activities such as transfer of genetic resources and/or associated traditional knowledge.

A typical activity that triggers obligations is "access", in the sense of collecting or taking the genetic resources. For example, different jurisdictions in Australia have ABS legislation whose application is triggered by access to genetic materials or traditional knowledge in a specific state or territory (see reference list). These regimes have access as the trigger and include the time of "taking" as the temporal trigger in their definitions (e.g. Australia, 2000, Section 8A.03(1); Australia 2004, Section 3(2)(a)(i)). It appears that most ABS laws qualify access/collection of genetic resources as one important (and sometimes the only) trigger for provisions governing ABS (e.g. Antigua and Barbuda, 2015, Section 68; Bulgaria, 2002, Article 66; Niger, 1998, Article 6).

A second typical activity that triggers obligations is "utilization" (see e.g. Nagoya Protocol, Article 2 definition). Some countries may have utilization as the sole trigger (e.g. Japan, 2017, Chapter 3). Variations of the trigger include utilization after the time of access (or collection) and new uses of materials accessed prior to the existence of the ABS law. In the case of Brazil, for example, ABS obligations are triggered by predefined activities relating to the economic exploitation of products or reproductive materials arising from Brazil's genetic heritage. This focus on the end-product or end user means that materials accessed prior to the implementation of the 2015 legislation (Brazil, 2015) and potentially even the 2001 provisional legislation (Brazil, 2001) may fall within the scope of ABS obligations, subject to clarification from the Government. Other countries specify temporal scope for certain activities. For example, South Africa's law has a set of pre-defined uses that trigger benefitsharing irrespective of when or where the resources were accessed (South Africa, 2004; Robinson and von Braun, 2017). 
Some countries have a variety of activities that may trigger obligations. For example, "access and utilization" are triggers under Croatia's law (Croatia, 2013, Article 88) and Panama's law (Panama, 2009, Article 3). "Bioprospecting activity" and "“access" trigger Nicaragua's obligations (Nicaragua, 2012, Article 57) and "extraction", "utilization" or "study" trigger obligations under Palau's law (Palau, 2018, Section 5004). Mozambique's law has "access and shipping" (in the sense of exporting) as triggers (Mozambique, 2007, Section 12). Under the Zambian ABS legislation various activities such as the collection, acquisition, transfer and utilization of traditional knowledge, genetic resources and expressions of folklore trigger PIC requirements (Zambia, 2016, Section 2). Under Rwanda's law, ABS obligations are triggered by "research, collection and utilization of biological and genetic resources" (Rwanda, 2013, Article 2(4)). Under Kenyan legislation, "access" means "obtaining, possessing and using genetic resources conserved, whether derived products and, where applicable, intangible components, for purposes of research, bio-prospecting, conservation, industrial application or commercial use" (Kenya 2006, Section 2). Prior to the transfer of the biological resources outside Kenya, a material transfer agreement with the relevant lead agency must be negotiated and signed (Kenya, 2006, Section 18). Subject to clarification from governments or courts, a plain reading of these laws suggests that any of the listed activities on their own could trigger ABS obligations rather than that "access" as well as "utilization" and any other listed activities are required before the obligations are triggered.

\section{Box 5 Approaches to defining temporal scope}

The triggers for the application of ABS provisions are highly relevant to the temporal scope of ABS laws. Some countries (e.g. France, Japan and Malta) define temporal scope through commencement provisions. Access to genetic resource may be the most common trigger. However, under the ABS laws of some countries, new uses of resources that have been accessed prior to the entry into force of the laws may trigger certain obligations, too.

Typical triggers for ABS obligations are:

- "access" (e.g. Antigua and Barbuda, Australia, Bulgaria and Niger);

- "utilization" (e.g. Japan);

- predefined activities (e.g. Brazil and South Africa); or

- various activities at various temporal scales (e.g. Croatia, Kenya, Mozambique, Nicaragua, Palau, Panama, Rwanda and Zambia).

\subsubsection{Genetic resources provided by countries of origin/countries that acquired them in accordance with the Convention on Biological Diversity}

The ABS provisions of the CBD apply to genetic resources that are provided by contracting parties that are countries of origin of such resources or by parties that have acquired the genetic resources in accordance with the CBD ( $C B D$, Article 15; Nagoya Protocol, Article 6). The "country of origin" is the country possessing the resources in in situ conditions, which means where they "exist within ecosystems and natural habitats, and, in the case of domesticated or cultivated species, in the surroundings where they have developed their distinctive properties" (CBD, Article 2). "Domesticated or cultivated species" means "species in which the evolutionary process has been influenced by humans to meet their needs" $(C B D$, Article 2). The "country providing genetic resources" means "the country supplying genetic resources collected from in-situ sources, including populations of both wild and domesticated species, or taken from ex-situ sources, which may or may not have originated in that country" ( $C B D$, Article 2).

The ABS Elements (FAO, 2019a, p. 48) acknowledge that it may be difficult to determine with certainty the country of origin in the case of many GRFA that have been widely exchanged across time and geographical locations. They suggest that countries could provide guidance as to the circumstances in which genetic resources are considered to have developed their "distinctive properties". The approaches outlined below for determining whether a genetic resource is considered to originate from a country (or several countries) of origin centre around the distinctions under national legislation between wild and domesticated resources and between domestic and exotic resources (see Box 6). 
Countries vary significantly in terms of the scope of genetic resources to which ABS provisions apply. The ABS laws of some countries, Kenya ${ }^{6}$ for example, imply the inclusion of domesticated species. Others specifically define domestication or cultivation. For example, the ABS laws of France and Mozambique define "domesticated" or "cultivated species" as any species whose evolutionary process has been influenced by humans to meet their needs (France, 2016, Article 37 Art. L. 412-4(6); Mozambique, 2007, Article 2(o), unofficial translations). This definition is similar to the CBD's definition of domesticated or cultured species as a "species in which the evolutionary process has been influenced by humans to meet their needs" ( $C B D$, Article 2). However, these definitions do not quantify the extent of human intervention or "influence" that is necessary to qualify a genetic resource as having developed distinctive properties in a specific country.

Under the ABS law of Viet Nam, "origin of genetic resources" means "locations where the wild genetic resources are collected or where genetic resources have been domesticated and produced for a long time" (Viet Nam 2017, Article 3(10)). It is for the competent authority to determine whether Viet Nam is the country where a genetic resource has developed its distinctive properties, taking into account the location, the extent of human intervention and the time of use. An official guidance document published by the government explains that where a "species has been acclimated for a long time, adaptive to the living conditions as a local variety, and is now widely cultivated in Viet Nam [i]t would thus be covered by ABS requirements" (Vietnamese Government, 2019). Under Uganda's law, domesticated or cultivated species are determined in the "cultural contexts in which their specific properties have been developed" (Uganda, 2005, Section 2).

ABS laws may also simply specify a cut-off date and provide that any genetic resource that has been present in the country since before that date is considered to have developed its distinctive properties in the country. For example, under Australia's Commonwealth ABS legislation any "biological resources of native species" (Australia, 2000, Section 8A.03(1)) "that was present in Australia or an external Territory before 1400 " fall within scope of the ABS obligations, provided they meet the subject matter requirement (Australia, 1999, Section 528).

Determining the country of origin of MoGR, such as viruses, that may develop their distinctive characteristics in a host (e.g. an animal or plant) in a given country may be particularly challenging. For example, does an ABS law apply if the host is simply present in a jurisdiction, or is origin to be determined when the organism is extracted from the host? Brazil has addressed this uncertainty by clarifying that a micro-organism that has been "isolated from the national territory substrates, territorial sea, exclusive economic zone or the continental shelf" is considered to be part of the genetic heritage of Brazil (Brazil, 2015, Article 2). Colombian law appears to have a similar scope for isolated microorganisms (Colombia, 2014, Article 2). Mozambique's law defines "access to genetic resources" as an "activity performed on the genetic resource in order to isolate, identify or utilize information of the genetic origin, or molecules and substances originated from the metabolism of living beings, and from extracts of those same organisms, for research, technological development or bioprospection, industrial use or other purposes" (Mozambique. 2007, Article 1, unofficial translation).

\section{Box 6 Approaches to determining where a genetic resource has developed its distinctive properties:}

- Include and define domesticated resources (e.g. France, Mozambique and Viet Nam);

- Specify date from which the resources are deemed to have developed their distinctive characteristics (e.g. Australia);

- Determine origin within cultural contexts (e.g. Uganda);

- Specify country of "isolation" for MoGR (e.g. Brazil, Colombia and Mozambique).

\footnotetext{
${ }^{6}$ Its legislation does not specifically refer to domesticated resources but the government has clarified that they are within scope (Kenya Government, 2016).
} 


\subsubsection{Privately versus publicly held genetic resources}

The ABS Elements (FAO, 2019a, p. 49) point out that ABS measures may have a significant impact on the exchange of privately held GRFA. They state that measures need to be clear as to whether they apply to privately held or only to publicly held GRFA and to clarify the hierarchy of different types of rights related to genetic resources, including intellectual property.

Interestingly, it appears that many ABS laws do not distinguish between privately owned and publicly held materials. It is unclear whether this means that ABS laws not making this distinction apply equally to both. This could mean that the owner of a genetic resource, for example of a rare breeding animal, may well be allowed to sell it. However, whether the buyer may use and export the breed for research and development may be subject to the relevant ABS law.

Some ABS laws only apply to public lands, waters and collections and by implication exclude privately or community owned materials (see Box 7). For example, in Australia, there are different ABS arrangements in each state and territory (Lawson, Humphries and Rourke, 2019b). In Commonwealth public land, waters and ex situ collections, the providers are (a) the owner of the land for resources in Indigenous Peoples' land under lease by the Commonwealth, (b) native title holders for resources in native title areas and (c) the Commonwealth Government for all other areas (Australia 2000, Section $8 A$.04). In the Northern Territory, the category of resource access provider is far broader and includes private landowners, aboriginal communities and the Government (Australia 2006, Section 6). The legislation of the Australian Capital Territory (Australia, 2014, Sections 169, 206, 207, 209) and Western Australian (Australia, 2018, Section 72(3)) only applies to resources from territory or state (respectively) public lands and waters. Queensland's ABS legislation also only covers public lands and waters, although a recent amendment imposed a traditional knowledge obligation that will create a requirement (once a code is in place) to take all reasonable and practical measures to ensure traditional knowledge is only used for biodiscovery with the agreement of knowledge custodians, regardless of the location of the biological resources to which the knowledge relates (see Section 3.1 below) (Australia, 2004, Section 3, Australia, 2019).

Private rights under intellectual property laws are rarely intertwined with ABS laws other than with regard to disclosure of origin requirements (see Section 2.2.3 below), questions of government permission for intellectual property applications and use as form of benefit-sharing (see Section 4). This is because the two are usually separate areas of law with their own conventions and decision-makers. However, the ABS laws of some countries explicitly exclude from their scope specific genetic resources derived from breeding activities. Under Kenyan law, for example, ABS obligations do not apply to "access to genetic resources derived from plant breeders" in accordance with Kenya's plant variety protection legislation (Kenya, 2006, Section 3(b)). This means that plant varieties protected under Kenyan plant variety protection legislation may be used without an ABS permit and in line with the socalled breeders' exemption as the initial source of variation for the production of a new plant variety. Similarly, Uganda's ABS framework excludes from ABS obligations "access to genetic resources derived from plant breeders as defined by the laws relating to plant breeding and plant variety" (Uganda 2005, Section 4c). Similarly, the ABS Regime of the Autonomous Region of the Azores in Portugal exempts varieties protected by intellectual property (Portugal, 2002, Article 2(1)).

Another area where private proprietary rights intersect with ABS is in relation to the protection of traditional knowledge as intellectual property. In the Philippines, for example, rights to published or unpublished research and documentation, including traditional knowledge associated with genetic resources, belong to the community if the research is conducted solely by the community, or to the community and the research proponent jointly if the research is conducted by non-members of the community, and copyright remains with the community (The Philippines 2012, Section 18). More generally, any memorandum of agreement with IPLCs must have compulsory clauses for measures to protect the community's intellectual property rights and value systems (The Philippines, 2012, Section 32). Uganda's ABS law requires that ownership of commercialization rights and publication rights concerning genetic resources and traditional knowledge that may affect subsequent claims for patents and copyright be clarified in a material transfer agreement with the relevant lead agency and 
passed on in subsequent material transfer agreements with third parties (Uganda, 2007, Part III 3.1.3.(j)).

\section{Box 7 Approaches to privately vs publicly held genetic resources}

- Many ABS measures do not distinguish between privately and publicly owned materials;

- Few ABS measures specify that privately held genetic resources are exempted from ABS obligations;

- Some ABS measures only apply to public land, waters and collections and by implication exclude privately owned materials (e.g. Australia);

- Some ABS measures exclude from scope specific resources, such as plant varieties protected under plant breeders' rights legislation (e.g. Kenya, Portugal [Autonomous Region of the Azores] and Uganda);

- Some laws recognize and protect IPLCs' rights to communal genetic resources and traditional knowledge (e.g. the Philippines and Uganda).

\subsubsection{Genetic resources versus biological resources}

The ABS Elements (FAO, 2019a, p. 49) suggest that governments should reflect on whether including "biological resources" in ABS measures, as opposed to "genetic resources" and their utilization has any effect on the use of and access to GRFA. Box 8 outlines approaches to defining scope by "biological" or "genetic" resources.

By confining the Nagoya Protocol to "genetic resources", negotiators created a framework for the use of a biological resource for their potential as genetic material rather than for their other attributes, for example as sources of products (e.g. fish fillet) for consumption (see Section 2.2.1). However, some national ABS measures apply more broadly to "biological resources", which the CBD defines as including "genetic resources, organisms or parts thereof, populations, or any other biotic component of ecosystems with actual or potential use or value for humanity" ( $C B D$, Article 2). The rationale behind this approach is to ensure that initial access to biological resources for consumptive uses cannot be misused for subsequent use of their genetic or chemical attributes without PIC and MAT (Morgera, Buck and Tsioumani, 2013, p. 72).

Examples of ABS measures that apply to "biological resources" include those of Costa Rica (Medaglia, 2020) and India (India, 2003). However, ABS measures that apply to "biological resources", rather than "genetic resources" are often narrowed down under other provisions. Australian ABS legislation provides an interesting example with respect to the use of GRFA. Although, at the time of writing, legislation in three of Australia's jurisdictions includes an expansive definition of "biological resources", two of the jurisdictions, Commonwealth (Australia, 2000, Section 8A.03(3)) and Northern Territory (Australia, 2006, Section 5) then exclude resources taken for the mere purpose of culture or consumption from the scope of ABS obligations (see Section 2.2.1). This probably means that collecting broodstock from the wild for grow out would not trigger ABS obligations. The situation is less clear for the collection of wild or domesticated biological resources, sponges for example, to farm them to produce chemical compounds of interest to the pharmaceutical sector (Page et al., 2011; Humphries, 2016). 


\section{Box 8 Approaches to defining scope by "biological" or "genetic" resources}

- The scope of many ABS measures is confined to "genetic resources" in the sense of the CBD and Nagoya Protocol rather than biological resources;

- The ABS measures of some countries apply to more than "genetic resources", for example "biological resources", but often narrow down their application through provisions such as exemptions for consumption and/or culture for non-research and development purposes (e.g. Australia).

\subsubsection{Genetic resources held by Indigenous Peoples and local communities}

The ABS Elements (FAO, 2019a, p. 50) point out that national measures should address how PIC or "approval and involvement" of IPLCs may be obtained, taking into account customary laws, community protocols and procedures (Nagoya Protocol, Article 12.1). Differences in country approaches to this question may relate to whether they are parties to the CBD (with no specific framework for resources held by IPLCs) and/or the Nagoya Protocol, under which parties must aim to ensure that users obtain the PIC or "approval and involvement" of IPLCs where they have an "established right to grant access" over genetic resources.

Countries have chosen different ways of recognizing "established rights" of IPLCs to grant access to genetic resources. Some have established or recognized such rights explicitly in ABS legislation. Others have left the decision as to whether or not such rights exist to the discretion of the decision-maker assessing an application. More often, such determinations are made outside the ABS context, for example through native title determinations and land-tenure rights in Australia (Humphries, Robinson and Loban, 2017) and through customary court proceedings in Vanuatu (Robinson et al., 2019). Countries also have different ways of determining the rights of holders, with some ABS laws recognizing the rights of Indigenous Peoples only (e.g. Australia, 1999), some the rights of local communities only (e.g. Namibia, 2017) and some the rights of both Indigenous Peoples and local communities (e.g. Malaysia, 2017, Section 4). Often it is up to the communities themselves to determine who is the correct holder of rights as the "provider" of the communities' resources (Nagoya Protocol, Preamble; UNGA, 2007a, Article 33). ${ }^{7}$

While the meaning of 'Indigenous Peoples' is often clear under a country's laws (ABS or other laws), it is often unclear what an ABS law means by "local community" because the term is rarely defined. However, there are some countries that define the term. Namibia, for example, defines "local community" as a group with rights or interests in a distinct geographical area, including natural resource management organizations such as community forest committees, or a group of persons "with rights in relation to or stewardship over its biological and genetic resources and associated traditional knowledge, governed partially or completely by its own customs, traditions or laws" (Namibia, 2017, Section 1) (Namibia, 2017, Section 1). Mozambique has a definition of particular relevance to GRFA and TKGRFA:

Local community: group of families and individuals, living in a territorial circumscription at local level or inferior, that aims to protect common interests through protection of residential areas, fishing and aquaculture areas, farming areas, either cultivated or fallow, forests, sites of cultural importance, pastures, water source and expansion areas (Mozambique, 2007, Article 2(h), unofficial translation).

Some countries have advisory bodies to determine the correct rights holder, for example Vanuatu (Vanuatu, 2002, Section 29) and Malaysia (Malaysia, 2017, Section 9), particularly if there are multiple IPLCs with rights over the same resources. Kenyan law has procedures for involving IPLCs in the neighbouring countries whose communities have rights over cross-jurisdictional in situ resources (NEMA, 2014).

\footnotetext{
${ }^{7}$ International Labour Organization's International Labour Convention on the Rights of Indigenous and Tribal Peoples in Independent Countries criteria of self-identification.
} 
Customary laws are significant for GRFA and traditional knowledge of relevance to GRFA activities held by IPLCs. Customary laws are the customs, practices, norms and beliefs that found the identity of IPLCs by defining their rights, obligations and responsibilities. They address the social workings of IPLCs by regulating land use and access to natural resources, dispute resolution and the maintenance of knowledge systems.

Some countries not only require PIC to be in accordance with customary law but also incorporate it more broadly into their ABS arrangements. For example, the Philippines' ABS law provides that failure to comply with PIC and MAT provisions may be punished under the customary laws and practices of the concerned IPLC, unless the sanctions are excessive, cruel and degrading (The Philippines 2013, Section 38). In some cases, the ABS law identifies a hierarchy between customary law and ABS law. For example, Zambia's ABS law recognizes the inalienable right of Zambian traditional communities to use or exchange with other Zambian traditional communities their "genetic resources for sustaining [their] livelihood systems in accordance with customary laws and practices". However, where a genetic resource is not being sufficiently exploited by the holder, or the holder refuses to grant a licence on reasonable commercial terms and conditions, the minister may grant a compulsory licence to fulfil a national need, subject to compensation to the holder (Zambia, 2016, Section 30(3)).

Community protocols and the increasing number of biocultural protocols are relevant to the use and exchange of GRFA. Some countries, Indonesia for example, require compliance with community protocols as well as with ABS laws (Indonesia, 2017, Article 24(2)). The amendment, in 2020, of Queensland Australia's ABS law implemented a traditional knowledge obligation to ensure traditional knowledge for biodiscovery (commercial purposes) is only used with the agreement of the knowledge custodians (Australia, 2004, Section 9A; see Section 3.1 below). The Government is currently negotiating with IPLCs and biodiscovery entities a code that outlines steps required to meet the obligation's criteria and guidelines including on how to recognize and respect relevant community protocols (DES, 2020). Some communities may have GRFA-specific biocultural protocols. For example, five Andean communities have agreed on an intercommunity biocultural protocol in relation to indigenous potato genetic resources in an area covering 8240 ha called the "Potato Park". The biocultural protocol incorporates customary laws related to PIC procedures, MAT and benefit-sharing (Argumedo et al., 2012, p. 99). Other, less formal community protocols may be relevant to ABS for GRFA, for example local community management of traditional orchards in Romania concerning the access, use and sharing of FGR in defined community areas with trees well over 100 years old (Antofie et al., 2016). Box 9 summarizes the variety of approaches used to regulate genetic resources held by IPLCs.

\section{Box 9 Approaches to genetic resources held by Indigenous Peoples and local communities}

- "Established rights" over resources are often determined outside the ABS context, for example through other legislation (e.g. Australia) and court proceedings (e.g. Vanuatu);

- Some laws only apply to Indigenous Peoples (e.g. Australia), some only to local communities only (e.g. Namibia) and some to Indigenous Peoples and local communities (e.g. Malaysia);

- Some ABS laws provide a definition of local communities (e.g. Mozambique and Namibia);

- Some laws have advisory bodies that coordinate between IPLCs (e.g. Malaysia and Vanuatu);

- One law has procedures for consulting with neighbouring-country IPLCs (e.g. Kenya);

- Some laws incorporate customary laws into their ABS measures (e.g. the Philippines and Zambia);

- Some countries require compliance with community protocols (e.g. Indonesia); 
- Several countries have biocultural or community protocols specific to GRFA (e.g. Peru and Romania).

\subsubsection{Specific exemptions of genetic resources for food and agriculture subject matter}

Countries take various approaches to exempting GRFA as subject matter from their ABS obligations. It is quite common to exclude specific GRFA from the scope of ABS legislation if they are managed under multilateral ABS arrangements. A common example under this approach is excluding PGR included in the Plant Treaty's multilateral system. ${ }^{8}$ While as of 20 November 2020 there were 148 contracting parties to the Plant Treaty, not all have specifically exempted PGR in the multilateral system from their national ABS legislation. Those that do, recognize that access to specific PGR for research, breeding and training does not require contracting parties of the Treaty to grant PIC or bilaterally negotiate MAT for each transaction, but instead requires the use of the SMTA (with its relevant obligations) for all exchanges (Plant Treaty, Article 10). Countries have chosen various approaches to addressing multilateral system materials. Some, more narrowly, specifically exclude "Annex 1 materials" (e.g. Peru, 2009, Article 5) or those falling under the Plant Treaty more broadly (e.g. Bhutan, 2016, Section $4(d)$ ), while others have exclusions that are more generic, addressing materials regulated under a specialized international ABS regime (e.g. France, 2016, Article 37 Art. L. 412-5II). The advantage of the latter approach is that countries do not need to amend their legislation if they wish to adhere to other specialized international ABS regimes should these be developed.

The ABS measures of some countries exclude specific categories of genetic resources, including certain GRFA, from their scope. For example, the French ABS law exempts from its scope genetic resources (1) arising from domesticated or cultivated species, (2) those of related wild plant species and (3) those that are subject to forestry, among other categories (France, 2016, Article 37 Art. L. 412-5II). Morocco's draft law exempts biological material "cultivated or bred for use as a model in research and development", which is further specified in a regulation (Morocco, undated, Article 5). Bhutan's ABS law excludes wild and domesticated PGR and AnGR that are managed under other legislation (Bhutan, 2003, Section 4(d)). The Spanish ABS law exempts specific PGR, fisheries resources and AnGR (which are governed under other legislation) from its scope (Spain, 2017, Article 3(2)).

The ABS law of the Autonomous Region of the Azores in Portugal exempts plant varieties protected by intellectual property from its scope (Portugal, 2002, Article 2). Similarly, Uganda (Uganda, 2005, Section 4(c)) and Kenya (Kenya, 2006, Section 3(b)) exclude PGR falling in the scope of Plant Variety Protection legislation from the scope of their ABS legislation.

Some national laws allow for the exclusion or accommodation of GRFA on a discretionary case-by-case basis. For example, public ex situ collections in Australia's Commonwealth areas can seek exemptions from ABS legislation where existing regulatory arrangements meet ABS objectives (Australia, 2000, Reg. 8A.05(1)(a)), which happened in the case of resources held by the Australian National Botanic Garden that are exempt from the primary ABS legislation (Australia, 2007, p. 536). India's ABS law mandates the National Biodiversity Authority (the decision-making body) to take certain considerations relating to GRFA into account when processing a foreigner's application to access India's biological resources. Such considerations include whether the resource is cultivated/domesticated or wild, developed or maintained under ex situ conditions or of high value/importance to the livelihoods of local communities (India, 2014, Article 16; India, 2019). ${ }^{9}$ See Box 10 for a summary of the range of approaches laws take to exempting GRFA subject-matter.

\section{Box 10 Approaches to specific exemptions of genetic resources for food and agriculture} subject-matter

- Most countries exclude GRFA if they are managed under multilateral ABS arrangements, such as the Plant Treaty.

\footnotetext{
${ }^{8}$ Annex 1 list of PGR, "in trust" materials in the CGIAR and other materials countries include in the system.

${ }^{9}$ Note the Revised Guidelines in the Form of Draft Notification - Guidelines on Access to Biological Resources and Associated Knowledge and Equitable Sharing of Benefits Regulations, 2019. It is unclear whether the Draft Notification is in force.
} 
○ Some narrowly exclude Annex 1 materials (e.g. Peru);

$\circ$ Others more broadly exclude materials under the Plant Treaty's multilateral system (e.g. Bhutan);

- Others have general exclusions for any materials regulated under a specialized international ABS regime (e.g. France), which could also therefore include the ABS regime under the WHO's Pandemic Influenza Preparedness Framework;

- Some countries exclude specific categories of genetic resources by definition, e.g.

○ Domesticated/cultivated species (Bhutan, France and Morocco);

- Specific categories of PGR, fisheries resources and AnGR (Spain);

- GRFA protected under intellectual property (Kenya, Portugal's Autonomous Region of the Azores and Uganda).

- Some countries exclude GRFA on a discretionary (e.g. Australia) or case-by-case basis (e.g. India).

\subsection{Intended uses that trigger the application of access and benefit-sharing provisions}

The Nagoya Protocol provides that "access to genetic resources for their utilization" shall be subject to PIC and defines "utilization" as "to conduct research and development on the genetic and/or biochemical composition of genetic resources, including through the use of biotechnology ..." (Nagoya Protocol, Article 2(c)).

The ABS Elements (FAO, 2019a, p. 53) point out that a broad definition of "utilization" that triggers ABS obligations combined with a broad scope of application of the ABS measures (e.g. to all "biological resources") may imply that ABS provisions apply to a wide range of activities that typically and regularly happen with agricultural commodities in the course of food production. Some countries have chosen to avoid the application of ABS provisions to typical agricultural practices/products, as outlined below.

\subsubsection{Development of genetic resources in the course of agricultural production}

The ABS Elements (p. 53) highlight that many GRFA are shaped, developed and improved through continued use in agriculture production and that it may therefore be difficult to distinguish those used in the supply of agriculture products for sale and human consumption, which generally fall outside scope of ABS obligations, from those used for purposes to which ABS obligations apply. Countries address this issue in a variety of ways, including through specific exemptions, as outlined below.

Trade in agricultural raw materials such as tea usually serves the ultimate purpose of consumption, and therefore ABS obligations may usually not apply. If, however, agricultural raw materials are collected and sold for other purposes, for instance research and development, ABS obligations apply if they fall within the scope of national laws. For example, the term "bioprospecting" means under South African law "any research on, or development or application of, indigenous biological resources for commercial or industrial exploitation ...", and the legislation provides various examples (South Africa, 2004, Section 1). Guidelines issued by the Government explain that "if rooibos tea is cultivated for the beverage market and sold as a tea, it is not bioprospecting but if the plant is used to make an extract for incorporation into another product this is considered bioprospecting" (South African Government, 2012, p. 3).

Some ABS measures specifically define and exempt resources used as commodities or for consumption (e.g. Malta, 2016, Section 2(2)(b)). The Philippines' ABS regime applies to wild and exotic species located in the Philippines, but with different administrative procedures for commercial and noncommercial uses. Exemptions from the more onerous procedures for accessing resources for commercial purposes include subsistence consumption and conventional commercial consumption (The Philippines, 2005 a, Section 3). Conventional commercial consumption is defined as "the common use of biological 
resources for direct consumption, such as fishing or logging, that does not involve biotechnological processes to develop new commercial products" (The Philippines, 2005a, Section 5). Subject to clarification from the Government, the legislation may exempt not only raw materials for direct consumption but also materials developed through human intervention (other than biotechnology) such as aquaculture grow out for food or feed consumption. India's legislation authorizes the Central Government to exempt by way of declaration "biological resources normally traded as commodities" (India, 2003, Section 40) from ABS obligations. Bangladesh's ABS law gives Government discretionary power to exempt, by notification in the official gazette, certain livestock that are marketed as regular consumer goods from the operation of the law (Bangladesh 2017, Section 35).

Some countries specifically exclude certain GRFA-related activities from ABS obligations. For example, South Africa excludes from the scope of the ABS legislation "aquaculture or mariculture activities involving fresh water and marine species producing specimens for consumption purpose" (South Africa, 2004, GoN R149, G. 30739). Australia's ABS law defines "access to biological resources" as the "the taking of biological resources of native species for research and development on any genetic resources, or biochemical compounds, comprising or contained in the biological resources" (Australia, 2000, Section 8A.03(1)). However, it specifically excludes various GRFA-related activities from this definition (except if they are carried out for research and development). Examples include:

- taking biological resources that have been "cultivated or tended";

- collecting broodstock for aquaculture;

- taking wild animals or plants for food;

- collecting plant reproductive material for propagation; and

- commercial forestry (Australia, 2000, Section 8A.03(1)).

Malaysia takes a similar approach, exempting access to food, as well as agricultural activities that are not for the purpose of research and development, from its ABS law (Malaysia, 2017, Section 5). Box 11 summarizes the different approaches taken to distinguishing uses that fall within scope of ABS from those relating to the production of agricultural products for sale and human consumption.

Spain's ABS law excludes from ABS obligations "activities of production and marketing of seeds and forest plants, regulated by Royal Decree 289/2003 of 7 March, commercialization of forest material for reproduction, provided that there is no use of genetic resources, and provided that there is no transfer to third parties for other use" (Spain, 2017, Article 3(3)). Similarly, the Bioprospecting Act of Utah, United States of America, excludes the following from ABS obligations: horticultural cultivation, except for horticultural genetic engineering; agricultural enterprises; and forest and range-management practice (Utah, 2010, Section 65A 14-102).

\section{Box 11 Approaches to distinguishing uses that fall within scope of access and benefit-sharing from those relating to the production of agricultural products for sale and human consumption}

- Some laws define and exempt resources used as commodities or for consumption (e.g. Bangladesh, India, Malta and the Philippines);

- Some laws have specific exclusions for GRFA activities that do not amount to "research and development" (e.g. Australia, Malaysia, Spain and the United States of America (Utah)).

\subsubsection{Research and development for food and agriculture}

Article 8(c) of the Nagoya Protocol requires parties to consider in the development and implementation of their ABS measures the importance of GRFA and their special role for food security. Parties could therefore consider granting preferential conditions for access to genetic resources if the intention of the applicant is to use them for agricultural/food research and development, for example by excluding such access from ABS obligations or providing simplified procedures for such access. However, it may be 
difficult to draw a distinction between food/feed and non-food/feed agricultural products at the research and development phase.

One approach is to have simplified PIC and MAT arrangements for agricultural research and development (Box 12). For example, the Philippines' law has a two-tier system for PIC - an extensive process for bioprospecting, defined as uses solely for commercial purposes, and a simplified process for scientific research involving conservation breeding or propagation activities. The definition of "bioprospecting" excludes "scientific research on agrobiodiversity", and so the simplified arrangements apply to certain GRFA activities (The Philippines, 2005a, Section 3.1). However, agrobiodiversity research is not defined and would presumably be considered on a case-by-case basis. Importantly, a condition of access under this simplified procedure is that the resource user will not create "spin-off" technology, which is undefined, but could include new strains or products.

Another approach is to have facilitated access for a specific subsector. Ethiopian ABS law has a system of facilitated access to PGR for non-commercial research by national public research institutions (Ethiopia, 2009, Article 15). Norway's ABS law provides that collection of genetic resources for use in public collections or further breeding in agriculture or forestry does not require a permit (Norway, 2009, Section 58).

An important issue to resolve in accommodating the distinctive features of GRFA and TKGRFA is that of uses that do not fall within traditional food and agriculture production, for example the production of nutraceuticals or bioplastics. While countries may wish to adapt ABS obligations to the specificities of the food and agriculture sector, they may also wish to have different arrangements for non-food/feed research and development (Peru 2009, Article 5; Friso et al., 2020, p. 5). ${ }^{10}$

\section{Box 12 Research and development for food and agriculture}

The survey found that while it may be difficult to draw a distinction between food/feed and nonfood/feed agricultural products at the research and development phase, some national laws have attempted to facilitate food and agriculture (including aquaculture and forestry) research and development by simplified PIC and MAT arrangements for agrobiodiversity research (e.g. the Philippines) or facilitated access for specific subsectors (e.g. Ethiopia and Norway).

\subsubsection{Commercial/non-commercial research and development}

Parties to the Nagoya Protocol are obliged to "create conditions to promote and encourage research which contributes to the conservation and sustainable use of biological diversity ... including through simplified measures on access for non-commercial research purposes, taking into account the need to address a change of intent for such research" (CBD, Article 15(2); Nagoya Protocol, Article 8(a)). While the laws of come countries make a distinction between commercial and non-commercial research, for example Australia, Bangladesh, India, the Philippines and South Africa, others do not, for example Ethiopia, Thailand and Zambia. Even if there is a distinction in the legislation, it is often difficult in practice to prove the difference between non-commercial research and research whose purpose is to produce a commercial outcome based on intent (Humphries, 2016).

Given that agricultural research and development aimed at improving production might usually qualify as commercial utilization, simplifications for non-commercial research might be of limited value. However, as stated in the ABS Elements (FAO, 2019a, p. 59), the distinction may be significant for taxonomic research on distinguishing pests and pathogens and alien from indigenous taxa. While making a distinction between agricultural commercial and non-commercial research specifically is rare, some countries attempt to accommodate GRFA and TKGRFA activities, as outlined below.

One approach is to exclude GRFA with a narrow definition of "commercial". Solomon Islands has a two-tier system for PIC whereby a bioprospecting research permit requires prior endorsement of Cabinet

\footnotetext{
${ }^{10}$ Interestingly, Article 5 of Peru's ABS law (Peru, 2009) currently explicitly exempts "research activities involving the use of non-timber natural resources, to produce natural products (nutraceuticals and functional foods)" from its scope. However, the abolition of this exclusion is currently under consideration because it is perceived to provide a loophole that could be used by users of PGR to evade ABS obligations.
} 
as opposed to the simpler arrangements that apply in the case of other types of research (Solomon Islands, 2010, Section 17(2)). The definition of bioprospecting is restricted to medicinal drugs or other commercially valuable compounds (Solomon Islands, 2010, Section 2), which arguably indirectly excludes GRFA research from the more onerous procedures.

Another approach is to exclude breeding purposes from the definition of commercial use. India has different authorization requirements depending on whether access is for (a) research, (b) commercial utilization or (c) biosurvey and bio-utilization for research. The more onerous requirements for "commercial utilization" have exceptions for GRFA activities. "Commercial utilization" means "end uses of biological resources for commercial utilization such as ... genes used for improving crops and livestock through genetic intervention, but does not include conventional breeding or traditional practices in use in any agriculture, horticulture, poultry, dairy farming, animal husbandry or bee keeping" (India, 2002, Section 2(f)). While it is not clear whether the subject matter exclusion also applies to FGR and AqGR, it appears to include PGR, AnGR and MoGR. On the other hand, Bangladesh specifically includes GRFA activities within its definition of commercial use, which means "creating or producing various products through the use of bio-wealth for commercial purpose, such as: medicine, industrial used enzymes, food essence, human body scent, cosmetic colour, emulsifier, oleoresin, etc. This includes micro-organism, crop, fish and animal by-products for the sake of genetic modification gene collection" (unofficial translation) (Bangladesh, 2017, Section 2(10)).

Exemptions or simplified procedures for non-commercial research can create a loophole whereby resources initially accessed for research purposes could subsequently be used for commercial purposes without consent (CBD, 2007, para 31). Some laws therefore do not allow for change of intent. For example, under Kenya's law, a condition of the access permit is that "all agreements entered into with respect to access of genetic resources shall be strictly for the purposes for which they were entered into" (Kenya, 2006, Section 15(d)) and there are no change of intent procedures.

\section{Box 13 Approaches for special arrangements for non-commercial research and development}

- Several countries make a distinction between commercial and non-commercial research, for example Australia, Bangladesh, India, the Philippines and South Africa, while others do not make a distinction, for example Ethiopia, Thailand and Zambia;

- Some laws exclude GRFA through a narrow definition of commercial, such as restricting it to pharmaceutical purposes (e.g. Solomon Islands);

- Some laws exclude breeding purposes form the definition of commercial use (e.g. Bangladesh and India);

- Some laws have specific procedures for changes of intent to avoid loopholes that allow subsequent use of resources or knowledge for commercial purposes without consent (e.g. Australia, France, Kenya and Malaysia).

Other laws, such as those of Malaysia (Malaysia, 2017, Sections 13 and 16) and France (France, 2016, Article 37 Art. L. 412-17 III), require users, in the case of a change of intent, to reapply for government permission to use the resources for a purpose different from the original authorization. Australia's Commonwealth law require users to negotiate a new benefit-sharing agreement with the access provider for any use different from the one originally authorized (Australia, 2000, Sections 17.03A(6) and 8A.13). Box 13 outlines the typical approaches countries take in the case of non-commercial research and development.

\subsubsection{Exemption of specific activities/user groups}

The ABS Elements (FAO, 2019a, p. 59) note that ABS measures may exempt specific activities such as exchange of genetic resources within and among local IPLCs and small-scale farmers and exchanges within research networks (Nagoya Protocol, Article 12(4)). The ABS measures of several countries provide such exemptions for specific activities, specific user groups or both (Box 14). 
Some ABS obligations exclude, or provide for procedural simplifications for, research and development for taxonomic, conservation or biosecurity purposes, which may be relevant to GRFA. Spain's law, for example, excludes from its ABS arrangements the collection and maintenance of samples in genebanks or ex situ collections exclusively for conservation purposes (Spain 2017, Article 3(3)). Under French law, the genetic resources collected by laboratories in the context of prevention, surveillance and combatting risks to animal and plant health and to food safety are excluded from ABS obligations (France, 2016, Article 37 Art. L. 412-5.III(4)). Under Mexico's ABS law, facilitated access applies to taxonomy, collection and prebreeding purposes and research projects (de la Torre, 2016). It should be noted, however, that these types of exclusions, i.e. exclusions for research and development for taxonomic or scientific purposes, usually do not apply to commercial activities, such as breeding activities.

Several countries have special arrangements for exchange of genetic resources within and among local IPLCs. For example, Ugandan law exempts genetic resource exchanges by "a local community among themselves and for their own consumption" or where "the exchange is certified to be purely for food or other consumptive purposes" (Uganda, 2005, Section 4(2)). The government's guidelines clarify that this exemption does not apply if the local community user intends to commercialize or export the resources outside Uganda (Uganda, 2007, Section 3.2). Guatemala's ABS law has a similar exemption (Guatemala, 2020, Article 25). Under India's ABS law, "local people and communities of the area, including growers and cultivators of biological resources" do not require access approval, except for obtaining intellectual property rights (India, 2014, Section 17). This user-based approach is frequently used in ABS laws that recognize the contribution of IPLCs to the development of GRFA over time.

Some ABS measures contain specific provisions for specific agricultural activities, either through exemptions or by ensuring that ABS arrangements do not adversely affect the activities of specific stakeholders. For example, Malaysia's law provides that "Nothing in the [ABS laws] shall be interpreted to limit the right of a small farmer ... to undertake conventional breeding or traditional practices in use in agriculture, horticulture, poultry farming, dairy farming, animal husbandry or bee keeping" (Malaysia, 2017, Section 6). The term "small farmer" is defined in the Protection of New Plant Varieties Act 2004 as "a farmer whose farming operations do not exceed the size of holding as prescribed by the minister", currently a holding of 0.2 hectares or less (Malaysia, 2008, Section 2). Under China's draft (unofficial) ABS legislation, the access to and utilization of genetic resources by farmers, pastoralists and fishermen according to their traditional way of life is not subject to registration and approval procedures, as long as this use does not cause any damage to biological diversity (China, 2017, Article 30).

Other laws have exemptions or simplified ABS arrangements for nationally recognized research organizations. For example, India has simplified ABS procedures with expedited timeframes and no application fees for non-commercial research conducted by Indian Government institutions (India, 2014, Section 13). Foreign research collaborators of such research institutions may benefit from these simplified ABS arrangements, which underlines the need for collaboration among research organizations in the post-Nagoya era. 


\section{Box 14 Approaches for exempting specific activities of relevance to genetic resources for food and agriculture users}

Some countries exempt specific activities from their ABS measures or offer simplified procedures for them. Examples include research for taxonomic (e.g. Mexico), conservation (e.g. Spain) or animal/plant health-risk (e.g. France) purposes, exchange of genetic resources within and among local IPLCs (e.g. Guatemala, India and Uganda) and farmers (e.g. China (draft law) and Malaysia), and exchanges within research networks (e.g. India).

It is noteworthy that the $\mathrm{ABS}$ measures of some countries provide certain exemptions from $\mathrm{ABS}$ obligations or simplifications of them only for a specific group of applicants, for example locals/residents (or foreigners making a joint application with locals/residents). Under South Africa's ABS framework, for example, a bioprospecting permit or notification of discovery research may only be issued to a South African citizen or permanent resident or to foreigners who make an application jointly with a South African citizen (South Africa, 2008, Section 9). Similarly, under the Philippines' law, a foreign collector may benefit from the simplified PIC procedure only if a letter of consent from the head of a collaborating local institution is provided (The Philippines, 2004, Section 15(3)). While these examples are not GRFA specific, they indicate a mechanism some countries use to tailor exemptions so as to align their ABS policies with general research policies, including in the field of food and agriculture.

\subsection{Authorization procedures applicable under access and benefit-sharing legislation}

This section identifies different variations of ABS approval procedures that may all be relevant to activities that fall within scope of ABS laws concerning GRFA and in many cases TKGRFA. Countries use various language for authorization, including "PIC" or "free prior informed consent" or "approval and involvement" (often in relation to traditional knowledge associated with genetic resources - see Nagoya Protocol Article 7). The meaning of "free" and "prior" and "informed" and "consent" varies across countries and is often not specified under the legislation. Various international instruments (UNGA, 2007a, Articles 10, 11, 19, 28, 29, 32) and UN reports and guidelines (Secretariat of the Convention of Biological Diversity, 2002), however, offer guidance on these terms, particularly in relation to access to traditional knowledge associated with genetic resources (CBD, 2016).

\subsubsection{Prior informed consent}

The ABS Elements (FAO, 2019a, p. 59) recognize that there are many variations of authorization procedures and that countries may wish to consider their advantages and disadvantages in terms of accommodating the distinctive features of GRFA. The same applies in the case of the authorization procedures for ABS for traditional knowledge, which are often the same or similar procedures that apply to ABS for genetic resources (see Section 3.3 for additional considerations for traditional knowledge PIC). Some countries do not have access measures for their biological resources but do have PIC measures for traditional knowledge associated with genetic resources within their jurisdictions (e.g. Finland, 2016; Indonesia, 2017). Many countries have established different types of authorization procedures, ranging from explicit PIC to rather simple notification procedures, for different categories of users, uses and genetic resources.

Most countries with dedicated ABS legislation require PIC and MAT as envisaged by the CBD and the Nagoya Protocol. This normally involves an administrative procedure for authorization from the government and/or other providers (such as IPLCs and, in some cases, private providers) involving the application for a permit and evidence that the applicant has agreed to the terms and conditions of collection and/or use and on the benefits to be shared. Some laws require parties to enter a benefitsharing agreement and/or a material transfer agreement. Other laws require a statutory declaration that the materials will only be used for certain purposes (see Element 4 below). Some countries may take food and agriculture into account when determining the terms and conditions of approval. For example, under Ethiopia's law, access permit holders must "not deplete populations of farmers planning stock or 
wild species" or "remove significant genetic variation from local gene pool during collection" (Ethiopia, 2006, Article 17.2).

Other ABS laws require registration or notification instead of PIC and are designed to capture end users of genetic resources. For example, Brazil's law aims to promote and facilitate access and only demands authorization and benefit-sharing once a downstream concrete result has been achieved (Brazil, 2019). There are no PIC requirements at the time of collection of the biological resources (in contrast to the consent requirements for traditional knowledge, which must always be accessed directly through IPLCs with PIC and MAT). Instead, users are required to keep the National System for Genetic Heritage and Associated Traditional Knowledge Management (SisGen) informed of their research activities; once a concrete downstream result has been achieved, they have to negotiate the benefit-sharing conditions before starting commercial exploitation (Brazil, 2015; Brazil, 2019; WIPO, 2020a, p. 19).

While ABS laws are usually separate from intellectual property laws, there may be areas of overlap, particularly in the case of authorization of patent applications. ABS laws may require the government's prior authorization, for example in India (India, 2002, Section 6), or prior notification to the government, for example in Malaysia (Malaysia, 2017, Section 31(1)), or the negotiation of a new access agreement with a local community, for example in Zambia (Zambia, 2016, Section 36(k)), before a person can seek intellectual property protection over a product or process invention that incorporates genetic materials or knowledge derived from these countries' jurisdiction. Under Norwegian ABS legislation, any person receiving genetic materials derived from a public collection must refrain, in Norway or abroad, from claiming intellectual property rights or other rights that would limit the use of the material "such as for food or agriculture" unless the material has been modified resulting in substantial change (Norway, 2009, Section 59). In contrast to the ABS law examples above, an increasing number of countries are including disclosure of origin requirements under their patent legislation, which are sometimes used as a tool for monitoring the movement and use of genetic resources and associated traditional knowledge (WIPO, 2020a) (see Element 4 below). Box 15 outlines various approaches to PIC of relevance to GRFA and TKGRFA.

\section{Box 15 Approaches to prior informed consent}

- Most countries have PIC provisions as administrative authorization procedures at the time of access, utilization and/or transfer (export). However, some have requirements to take food and agriculture into account when determining the terms and conditions of approval (e.g. Ethiopia);

- Some countries have registration systems designed to capture end users of genetic resources and knowledge rather than consent procedures at the time of collection or use (e.g. Brazil);

- Some countries do not have access measures for their biological resources but do have PIC measures for traditional knowledge associated with genetic resources within their jurisdictions (e.g. Finland and Indonesia).

- Some countries' intellectual property regimes require compliance with ABS legislation and/or disclosure of origin as a condition for the granting of intellectual property rights that are related to genetic resources and/or traditional knowledge (e.g. India, Malaysia, Norway and Zambia).

\subsubsection{Simplified and fast-track prior informed consent}

The ABS Elements (FAO, 2019a, p. 59) recognize that governments may wish to establish fast-track procedures for certain situations, such as for research and development for food and agriculture, or for certain stakeholders. Many of these are noted in Section 2.2 above. The purpose of this section is to outline approaches to some of the fast-track procedures (Box 16).

Some simplified procedures take the form of a simple declaration/notification by the user rather than consent procedures for specific activities such as conservation and emergency responses. For example, 
under French law, access to genetic resources for utilization for the purposes of biodiversity knowledge, conservation in a collection or promotion without a direct commercial objective and access in emergency situations relating to human, animal or plant health are subject to a declaration to the competent authority (France, 2016, Article 37 Art. L. 412-7-I). Through the declaration, users provide information on planned activities, on resources to be used and on the modalities of access and the conditions of collection. Users may also choose between different benefit-sharing options (France 2017, Article 1 Art R. 412-13-I). Other activities, in particular those with a commercial objectives, require application for a permit, including an agreement with local authorities and local communities on the terms of access (France 2016, Article 37 Art. L. 412-8-I).

Some countries have simplified notification procedures for authorization purposes concerning GRFA. For example, the Republic of Korea's ABS law requires foreigners seeking access to its resources and/or traditional knowledge to report their intention for access; if approved, the CNA will issue a declaration certificate for access (Republic of Korea, 2017, Article 9). The act also has a deeming provision recognizing approvals that are made in accordance with other legislation, for example for removing agrofishery resources from the country (Republic of Korea, 2017, Article 9). However, a presidential decree may prescribe simplified procedures for reporting access or waive the reporting "where it is deemed that expedited access to or utilization of the genetic resource(s) is required for the development of therapeutic drugs and food security in the event there are threats to the life and health of humans, animals, and plants" (Republic of Korea, 2017, Article 10).

Other countries have introduced fast-track procedures for specific categories of users. For example, India has a fast-track authorization process for locals who seek access to India's biological resources and associated traditional knowledge. Foreigners must follow the normal authorization process for access for commercial and non-commercial purposes and have to negotiate a benefit-sharing agreement with terms and conditions of access with the federal authority in consultation with local and community bodies (India, 2014, Regulation 2). In contrast, locals do not require the National Biodiversity Authority's approval for accessing biological resources and/or traditional knowledge for noncommercial purposes. However, they do need to notify the State Biodiversity Board in the state where the resources or knowledge are being accessed if that is being done for commercial purposes (India, 2002, Section 7). Even this simplified notification procedure is waived for "local people and communities of the area, including growers and cultivators of biodiversity" (India, 2002, Section 7).

\section{Box 16 Approaches to simplified and fast-tracked prior informed consent}

The survey found that some laws have simplified procedures in the form of a declaration for conservation and emergency situations relating to human, animal or plant health (e.g. France) and for food security in the case of threats to the life and health of humans, animals or plants (e.g. Republic of Korea). Some laws have fast-tracked process for specific categories of users, for example for locals and growers and cultivators of biodiversity (e.g. India).

\subsubsection{Implicit prior informed consent}

ABS measures may provide for implicit PIC for specific materials, purposes, stakeholders or other situations. In this case, access to and utilization of genetic resources and/or traditional knowledge may proceed without a CNA having granted a permit prior to the acts of access and utilization. Simple notification procedures of the kind described above (Section 2.3.2) may often qualify as implicit PIC. The Brazilian ABS law may arguably be considered an example of an ABS law that provides for implied PIC given that a notification only has to be made once the user undertakes certain predefined activities with a view to the economic exploitation of products or reproductive materials arising from Brazil's genetic heritage (see Section 2.3.1 above).

\subsubsection{Standardization of prior informed consent and mutually agreed terms}

The ABS Elements point out that standardization of access procedures, terms and conditions could be a way of dealing with the high number of "transfers of GRFA and the recurrent exchange events in the food and agriculture sector" (FAO, 2019a, p. 60). Under such an approach, similarly to under the Plant 
Treaty's SMTA, recipients of specified materials for specified purposes would comply with a set of predefined ABS conditions. The ABS Elements recognize that this may not be practical as a solution for all GRFA given the variety of stakeholders, users and purposes of use involved, but it may under certain circumstances be a viable means of avoiding the need to negotiate access on a case-by-case basis and reducing transaction costs.

Some countries may use existing SMTA infrastructure as a guide for the use and exchange of other GRFA. For example, the European Union and the African Union have indicated that their members may choose to subject PGR in the public domain that are not contained in the Plant Treaty's Annex 1 to the terms and conditions of the SMTA (EU, 2014, Article 4(4); AU Commission, 2015b, p. 23). Several parties to the Plant Treaty have decided that PGR under their management and control and in the public domain, even if not listed in Annex I to the Plant Treaty, are nonetheless to be subject to the terms and conditions of the SMTA for the purposes set out under the Plant Treaty (EU, 2014, Recital 13).

Other countries prescribe the terms and conditions of material transfer agreements that apply to all genetic resources, and not GRFA specifically. For example, South Africa's legislation includes a pro forma material transfer agreement that must be signed by the provider and user if biological resources are being accessed for the purposes of bioprospecting and a pro forma benefit-sharing agreement for cases in which traditional knowledge is being used for bioprospecting (South Africa, 2004, Annexures 7 and 8). Uganda's law prescribes the terms and conditions of a material transfer agreement, including genetic resource specifications, detailed reporting requirements, an obligation to deposit a sample with a Ugandan facility, third-party transfer and intellectual property provisions, and a commitment to pay conservation fees and involve Ugandan citizens or institutions at all stages of access and use (Uganda, 2005, Section 15). The Philippines' ABS law have compulsory minimum terms, mainly in relation to third-party transfers and intellectual property protection, which must be contained in a material transfer agreement for resources obtained for commercial purposes (The Philippines, 2005b, Annex 2). Box 17 summarizes some typical approaches to standardized PIC and MAT.

\section{Box 17 Approaches to standardized prior informed consent and mutually agreed terms}

- The Plant Treaty's multilateral system and standard material transfer agreements (SMTA);

- The European Union and the African Union have indicated that their members may choose to use the Plant Treaty's SMTA as a guide for extending a standardized approach to other PGR in the public domain;

- Some countries prescribe the terms and conditions of material transfer agreements that apply to genetic resources, including GRFA (e.g. South Africa, the Philippines and Uganda).

\subsubsection{Framework prior informed consent and mutually agreed terms}

The ABS Elements (FAO, 2019a, p. 62) suggest that ABS measures may accommodate practices of international exchange that involve close working collaborations and partnerships with many stakeholders by providing for the possibility of concluding framework agreements that authorize access to and utilization of a specific range of genetic resources, possibly limited to specific purposes. This is still a largely unexplored field and the survey found few specific examples (Box 18).

Andean Pact Decision 391 provides for the possibility of "access contracts with universities, research centers or well-known researchers to support the execution of several projects" (Andean Community, 1996, Article 36; Cabrera Ormaza, 2019, p. 84). Peru's law prescribes conditions for the conclusion of such access contracts, including the involvement of local researchers in various collection and research activities (Peru, 2009, Articles 24-26). Ecuador has a simplified procedure for framework agreements on research for exclusively scientific purposes, including the involvement of a national support institution in the research, with a fixed term for the agreement on generally defined research programmes (Carbrera Ormaza, 2019, p. 88). 


\section{Box 18 Approaches to framework prior informed and mutually agreed terms}

This is still a largely unexplored field, but examples may include countries, including Ecuador and Peru, applying Andean Pact Decision 391, Article 36 (on framework access agreements) at the national level.

\subsection{Element 2 Conclusion}

The survey showed that there are many different ways of dealing with authorization procedures for genetic resources and associated traditional knowledge. While most countries appear to treat GRFA like any other genetic resource, there are some ABS laws that accommodate the distinctive features of GRFA at different levels or in different aspects of ABS governance. These laws contain provisions that aim at, or have at least the effect of, accommodating some of the special features of GRFA. These provisions address (a) the categories of resources covered by access provisions, (b) intended activities triggering access provisions and (c) applicable authorization procedures. Due to the existence of the Plant Treaty, many ABS laws provide for special provisions addressing PGR; far fewer laws explicitly address AnGR, and very few provide for AqGR, FGR, ${ }^{11}$ MoGR or InGR. The review of relevant literature on ABS measures shows a similar picture. While there are examples of literature dealing with ABS for PGR, few examples of literature on ABS for GRFA other than PGR could be identified. The ABS literature reveals a significant gap in knowledge about ABS measures as they relate to AnGR, AqGR, FGR, InGR and MoGR (see literature review above).

Country measures identified under this Element demonstrate that there are many ways in which ABS measures can be tailored according to the special characteristics and needs of the particular genetic resources and their users. These options include:

- defining the temporal scope to clarify whether new and continuing uses of materials that have been accessed prior to the entry into force of the ABS measure are captured;

- clarifying the point at which GRFA have sufficiently gained their distinctive characteristics within a country's jurisdiction for the country to qualify as "country of origin" and the GRFA to fall within the scope of the country's ABS measures;

- clarifying whether only publicly or also privately held materials, including breeding materials and materials subject to intellectual property, fall within the scope of the ABS measures;

- clarifying whether IPLCs have an established right to grant access to GRFA and identifying the customary laws and biocultural protocols that apply; and

- clarifying whether specific subsector of GRFA falls within the scope.

Without clarification of the above, users of GRFA/TKGRFA may not know whether ABS laws apply to their activities, which may deter them from research, development and other activities relevant to food and agriculture. Given the short time that most of the laws have been in place, it is premature to evaluate their attempts to accommodate GRFA and TKGRFA and the effects that the various laws have on the conservation and sustainable use of GRFA and TKGRFA generally or GRFA subsectors in particular. It is important to note that there is no one-size-fits all approach to accommodating GRFA and TKGRFA under authorization procedures and that further research is needed to determine their practical effects and whether options vary across subsectors.

\footnotetext{
${ }^{11}$ However, many countries conflate FGR with PGR, so this might not be entirely accurate.
} 


\section{ELEMENT 3: ACCESS TO AND UTILIZATION OF TRADITIONAL KNOWLEDGE ASSOCIATED WITH GENETIC RESOURCES FOR FOOD AND AGRICULTURE}

It is important to note that many of the temporal triggers and procedures for authorization outlined under Element 2 apply equally to genetic resources and to traditional knowledge associated with genetic resources. Element 3 outlines some additional requirements for TKGRFA where there are specific requirements or considerations that apply uniquely to traditional knowledge. Element 4 relates to benefit-sharing related to the use of traditional knowledge.

The Nagoya Protocol provides that:

In accordance with domestic law, each Party shall take measures, as appropriate, with the aim of ensuring that traditional knowledge associated with genetic resources that is held by indigenous and local communities is accessed with the prior and informed consent or approval and involvement of these indigenous and local communities, and that mutually agreed terms have been established (Article 7).

Contracting parties of the Plant Treaty are required, in accordance with their needs and priorities and as appropriate, and subject to their national legislation, to take measures to protect and promote Farmers' Rights, including protection of traditional knowledge relevant to PGR. The Governing Body of the Plant Treaty tasked an Ad Hoc Technical Expert Group on Farmers' Rights with the preparation of an inventory of national measures, best practices and lessons learned from the realization of Farmers' Rights and with the development of options for encouraging, guiding and promoting the realization of Farmers' Rights as set out in Article 9 of the International Treaty (FAO, 2019c).

The review of national legislation presented in this section identifies typical approaches used to address the following key concerns in the various GRFA subsectors (a) defining the scope of knowledge that falls within ABS obligations, (b) determining the knowledge-holders from whom consent or involvement is required and (c) procedures for obtaining the consent and involvement of IPLCs for access and/or utilization of traditional knowledge.

\subsection{Defining the scope of traditional knowledge associated with genetic resources}

The extent to which national laws capture traditional knowledge as the subject matter of ABS obligations varies considerably between countries. At the international framework level, the Nagoya Protocol's obligations are confined to "traditional knowledge associated with genetic resources" (Nagoya Protocol, Article 7). The CBD's obligations are potentially broader in scope, as they address "traditional knowledge, innovations and practices" related to biological diversity at each of the ecosystem, species and genetic levels (CBD, Article 8(j); Morgera, Tsioumani and Buck, 2014, p. 30). The Plant Treaty is confined to "traditional knowledge relevant to plant genetic resources for food and agriculture" (Plant Treaty, Article 9.2(a)). Other current and proposed international agreements (e.g. UNGA, 2007a, Article 31; UNGA, 2018; WIPO, 2018) or regional protocols (ARIPO, 2010) may also shape a country's approach to the scope of traditional knowledge under its ABS framework. Box 19 summarizes the diverse approaches taken to defining the scope of traditional knowledge under ABS laws.

Where national laws define traditional knowledge, it is often broad in scope and not specific to food and agriculture. For example, Peru's law relates to "collective knowledge," which "means the accumulated, transgenerational knowledge evolved by indigenous peoples and communities concerning the properties, uses and characteristics of biological diversity ..." (Peru, 2001, Article 2). This incorporates the broader scope of biological resources (see Section 2.1.4 above). Broad definitions based on genetic resources include Zambia's ABS law, where traditional knowledge means:

any knowledge, not limited to a specific subject area, technical or medical field associated with genetic resources, originating from a traditional community, individual or group that is the result of intellectual activity and insight in a traditional context and where the knowledge is embodied in the traditional lifestyle of a traditional community or is codified in knowledge systems and passed on from one generation to another (Zambia, 2016, Section 2). 
Other laws apply to ecological knowledge more broadly. For example, Guatemala's ABS law defines traditional knowledge as "knowledge, practices, uses, technologies and strategies related to the environment and its resources, developed and energized by indigenous peoples and local communities" (Guatemala, 2020, Article 2(f)).

Other countries have definitions that are more narrowly focused on genetic resources (e.g. Mozambique, 2007, Article $1(b) \&(g)$ ). Under Viet Nam's law, traditional knowledge means "knowledge, experience and initiatives of native people on the conservation and use of genetic resources" (Viet Nam, 2008, Article 3(28)). The Republic of Korea's law defines traditional knowledge as "knowledge, innovation, practices or individuals or local communities embodying traditional lifestyles for the conservation and sustainable use of genetic resources" (Republic of Korea, 2017, Article 2.2). Nicaragua defines traditional knowledge as "knowledge, innovations and practices of indigenous and African descent and local communities related to genetic resources ..." (Nicaragua, 2012, Article 10.9). Japan's measures have a similarly narrow definition, "knowledge related to the utilization of genetic resources ..." (Japan, 2017, 2(3)).

There are also examples of country measures on ABS for traditional knowledge that specifically refer to food and agriculture within the definition of traditional knowledge. Under Kenya's intellectual property legislation, traditional knowledge is any knowledge:

(a) Originating from an individual, local or traditional community that is the result of intellectual activity and insight in a traditional context, including know-how, skills, innovations, practices and learning, embodied in the traditional lifestyle of a community; or

(b) Contained in the codified knowledge systems passed on from one generation to another including agricultural, environmental or medical knowledge, knowledge associated with genetic resources or other components of biological diversity, and know-how of traditional architecture, construction technologies, designs, marks and indications (Kenya, 2016, Section 2). ${ }^{12}$

Under Uganda's ABS law, the intangible components to which ABS obligations broadly apply are the "local knowledge, technology innovations, farming practices and traditional lifestyle" that are associated with resources occurring in, or originating from, Uganda (Uganda, 2005, Section 2).

Some laws exclude some TKGRFA from the scope of their ABS obligations. For example, French ABS law excludes from its scope traditional knowledge associated with genetic resources that:

- cannot be attributed to one or more traditional communities;

- traditional knowledge associated with genetic resources whose properties are well known and have been used for a long time and repeatedly, outside of the traditional communities that share them; and

- traditional knowledge associated with some promotion methods likely to benefit agricultural, forestry or food and seafood products (France, 2016, Article 37 Art. L. 412-5).

Morocco's draft ABS law excludes from the scope of obligations the "traditional knowledge and skills associated with the distinctive signs of origin and quality of agricultural and marine products" (Morocco, undated, Article 5).

\footnotetext{
${ }^{12}$ An authorization to access protected traditional knowledge does not give authorization to access the associated genetic resources, which must be done under the regulation mentioned above.
} 


\section{Box 19 Approaches to defining the scope of traditional knowledge}

Definitions of traditional knowledge may:

- be broadly associated with genetic resources (e.g. Zambia);

- be broadly associated with biological resources (e.g. Peru);

- be broadly associated with ecological knowledge (e.g. Guatemala);

- be more narrowly associated with genetic resources (e.g. Japan, Mozambique, Nicaragua, the Republic of Korea and Viet Nam);

- $\quad$ specifically include TKGRFA (e.g. Kenya and Uganda);

- $\quad$ specifically exclude TKGRFA (e.g. France and Morocco (draft));

- allow definition by the custodians of the knowledge in specific cases (e.g. Australia and Finland); and

- extend to traditional knowledge in the public domain (e.g. Ecuador and South Africa).

Some jurisdictions do not include a definition of traditional knowledge under national legislation and instead leave it, at least to a certain extent, to IPLCs to define it. For example, under Finland's ABS law "traditional knowledge of the Saami people associated with genetic resources means knowledge, skills and competence to be specified in the mutually agreed terms which has evolved and which is being maintained in the Saami culture and which has been passed on from one generation to the next in accordance with the tradition" (Finland, 2016, Section 4(2)).

In some cases, non-ABS law is used to define the scope of traditional knowledge. For example, Australia's Queensland ABS law provides that a person "must take all reasonable and practical measures to ensure the person does not use the traditional knowledge for biodiscovery other than under an agreement with the custodians of the knowledge" (Section 9A). If found lacking, a defence is adherence to "the traditional knowledge code of practice" or being a person who "is employed or engaged by a biodiscovery entity that has complied with the traditional knowledge code of practice" (Section 9A(4)). The code is not yet in place and the legislation does not define "traditional knowledge", leaving interpretation to the Acts Interpretation Act 1954 (Qld), which provides relevant definitions for "Aboriginal people" and "Torres Strait Islanders" and their associated traditions:

(a) "Aboriginal tradition means the body of traditions, observances, customs and beliefs of Aboriginal people generally or of a particular community or group of Aboriginal people, and includes any such traditions, observances, customs and beliefs relating to particular persons, areas, objects or relationships".

(b) "Island custom, known in the Torres Strait as Ailan Kastom, means the body of customs, traditions, observances and beliefs of Torres Strait Islanders generally or of a particular community or group of Torres Strait Islanders, and includes any such customs, traditions, observances and beliefs relating to particular persons, areas, objects or relationships" (Australia, 1954, Section 36(1) and Schedule 1).

The effect of this legislative structure is that the Acts Interpretation Act 1954 (Qld) imposes an obligation into the Biodiscovery Act 2004 (Qld) for "Aboriginal people" and "Torres Strait Islanders" to define their traditions, observances, customs and beliefs relating to particular persons, areas, objects or relationships that are the traditional knowledge associated with genetic resources and that are then subject to MAT.

A significant issue is whether the scope of traditional knowledge extends to knowledge that is already publicly available (e.g. in literature or patent claims). Many countries' laws are silent on the issue, while other countries extend ABS obligations to the exploitation of traditional knowledge that has already entered the public domain. Ecuador's law, for example, recognizes the rights of legitimate ancestral knowledge-holders that has entered the public domain (e.g. located in publications and databases) to a 
just and equitable participation in the benefits derived from exploitation of the knowledge (Jefferson, 2020, p. 163; Ecuador, 2017, Article 526). South Africa similarly requires users to obtain consent from knowledge-holders who developed or discovered traditional knowledge that is in the public domain (South African Government, 2012).

\subsection{Identifying the correct traditional knowledge-holders}

The Nagoya Protocol acknowledges that it is the right of IPLCs to identify the rightful holders of their traditional knowledge associated with genetic resources, within their communities (Nagoya Protocol, Preamble). It is generally accepted that IPLCs can refer to two separate groupings with different substantive interests - Indigenous Peoples and local communities (see, for example, ESC, 2011; CBD, 2013, p. 91 and para. 238; UNGA, 2007b, Annex, Article 31). Countries take a diverse approach to ascertaining the correct traditional knowledge holders (Box 20).

It is important for users to be aware that traditional knowledge-holders may be different from the IPLCs with an established right to grant access over the physical genetic resources (see Section 2.1.5 above). Several countries, including the Plurinational State of Bolivia (Plurinational State of Bolivia, 2009, Articles 2, 26, 30) and Ecuador (Ecuador, 2008), recognize through their constitutions the rights of Indigenous Peoples to the protection and collective ownership of their traditional knowledge. Some laws highlight the collective nature of traditional knowledge. For example, the knowledge protected under Peru's law "shall be that which belongs to an indigenous people and not to particular individuals forming part of that people. It may belong to two or more indigenous peoples. The rights shall be independent of those that may come into being within the indigenous peoples, which may have recourse to their traditional systems for the purposes of the distribution of benefits" (Peru, 2001, Article 10). As acknowledged by the ABS Elements (FAO, 2019a, p.63), it is important for users to ascertain who has authorization to speak or negotiate on behalf of the knowledge-holders.

Some countries have processes to help users identify the knowledge provider (or beneficiary) whose consent or involvement in MAT is required. For example, under Uganda's law, an indigenous community of Uganda or "any clan or sub-clan of the community communally occupying, using or managing land in which the genetic resources are found" may determine access to its genetic resources, including the "intangible components", and the central Uganda National Council for Science and Technology is mandated to oversee the ABS agreement (Uganda, 2005, Section 10). Malawi's law provides that the Government must ensure PIC has been obtained from the "relevant community", but there is little guidance about how this may be achieved (Malawi Government, 2015).

Under South Africa's measures, users must prove to the CNA that they have done adequate research to identify potential knowledge-owners and a media notice may be issued to identify further owners (South African Government, 2012, p. 34). Prior informed consent will only be recognized as genuine if there is an indigenous community resolution confirming that the representative is authorized to enter into benefit-sharing agreements on behalf of the community and that the community consents to the agreement and has full knowledge of the bioprospecting project (South African Government, 2012, p. 34). Other countries have processes for including IPLCs from neighboring countries in community meetings with identified resource access providers to negotiate PIC and MAT (NEMA, 2014).

Several countries manage TKGRFA differently from other traditional knowledge. Countries have taken a variety of approaches to the realization of Farmers' Rights (FAO 2019c). At the international level, the Interlaken Declaration on Animal Genetic Resources adopted together with the Global Plan of Action for Animal Genetic Resources, states:

We affirm the desirability, as appropriate, subject to national legislation, of respecting, preserving and maintaining traditional knowledge relevant to animal breeding and production as a contribution to sustainable livelihoods, and the need for the participation of all stakeholders in making decisions, at the national level, on matters related to the sustainable use, development and conservation of animal genetic resources (ITCAGRFA, 2007; FAO 2017 (Resolution 3/2017)).

Countries take different approaches to addressing Livestock Keepers' Rights under their ABS frameworks at the national and community levels. Some communities address the issue through 
biocultural protocols complementary to ABS laws. For example, in India, the Raika of Rajasthan have developed the Raika Biocultural Protocol, which sets out their claims to a traditional right to be recognized as livestock keepers based on their preserving unique AnGR with associated traditional knowledge and includes procedures for PIC and MAT (Samaj Panchayat, 2009). The Samburu in northern Kenya have developed the Samburu Community Protocol, which sets out procedures for PIC for activities involving breeds or traditional knowledge (Samburu Community Protocol, 2009). This survey did not find literature about the exact legal status of these protocols in relation to compliance with ABS.

\section{Box 20 Ascertaining the correct traditional knowledge-holders}

The survey found diverse approaches to ascertaining the correct traditional knowledge-holder, including prescribed processes for helping with correct identification (e.g. Malawi, South Africa and Uganda). It found that several countries manage TKGRFA differently from other traditional knowledge, for example through specific GRFA biocultural protocols that are complementary to ABS laws (e.g. in Indian and Kenyan communities).

\subsection{Procedures for obtaining traditional knowledge through prior informed consent or approval and involvement of Indigenous Peoples and local communities}

Many laws do not distinguish between PIC procedures for accessing and using genetic resources over which an IPLC has an established right from PIC procedures for access and use of traditional knowledge. In this regard, the procedures outlined in Section 2.3 would in many cases apply to the access and use of traditional knowledge. Similar considerations for protocols and customary law outlined in Section 2.1.5 would apply to traditional knowledge as the subject matter of ABS. However, some countries do have separate, additional or complementary procedures for traditional knowledge specifically, as outlined below and in Box 21.

One approach is to have procedures under separate legislation. This often combines ABS with intellectual property protection. For example, South Africa has ABS legislation that provides for a permit system requiring PIC and MAT for access to traditional knowledge (South Africa, 2004, Sections 81,82 ). It also protects traditional knowledge under separate legislation that establishes the National Indigenous Knowledge Systems Office, issues licences for the use of Indigenous Peoples' knowledge and assists communities in negotiating benefit-sharing agreements (South Africa, 2019). A community that registers the knowledge in the registration system has exclusive rights to benefit from its commercial use, limit its unauthorized use and be acknowledged as its origin (South Africa, 2019, Section 13). Several other countries have registration systems connected to their ABS regimes for traditional knowledge, including Viet Nam (Viet Nam, 2008, Article 64), Zambia (Zambia, 2016, Sections 11-15) and Peru (Peru, 2001, Title VI). There are important differences among the procedures of traditional knowledge registration systems, including whether registration requires PIC and/or public disclosure. For example, under Kenya's law, registration "shall be undertaken willingly by the owners of traditional knowledge upon obtaining prior informed consent but shall not require the public disclosure of the traditional knowledge concerned" (Kenya, 2016, Section 7).

Few countries actually define PIC under their laws. One exception is Nicaragua, which defines it as:

the act by which indigenous and afro descendant peoples, ethnic and local communities or the private owners, where appropriate, after supplying all the required information, agree to allow access to their biological resources or the intangible element associated with them, or the access of the collective knowledge of indigenous and afro descendant communities, ethnic or local, under mutually agreed terms and established in a letter of consent that is then perfected with the access permit contract (Nicaragua, 2012, Article 10(4), unofficial translation).

Peru's law defines PIC specifically in the context of TKGRFA, as follows:

authorization given under this protection regime, by the representative organization of the indigenous peoples possessing collective knowledge and in accordance with provisions recognized by them, for the conduct of a particular activity that entails access to and use of the said collective 
knowledge, subject to the provision of sufficient information on the purposes, risks or implications of the said activity, including any uses that might be made of the knowledge, and where applicable on its value (Peru, 2001, Article 2).

Another typical approach is to have procedures that are complementary to ABS laws in the form of guidelines or protocols explaining the meaning of "free, prior and informed consent" and "approval and involvement" in the context of traditional knowledge. There are various international guidelines on the interpretation of these terms, including the Mo'otz Kuxtal Voluntary Guidelines (CBD, 2016, Annex), where:

- "free" implies consent is given without coercion;

- "prior" implies seeing consent sufficiently in advance of any authorization decision-making process;

- "Informed" implies access to all relevant information including potential risks, impacts, intended purpose and execution of access;

- "consent" or "approval" is the agreement or otherwise of the knowledge holders or authorities of the relevant IPLC; and

- "involvement" refers to the full and effective participation of IPLCs in decision-making.

Despite some examples of protocols at the national level, potential users of TKGRFA may need to ascertain on a case-by-case basis: (a) whether IPLC traditional knowledge holders have a community protocol; (b) when is authorized according to the protocol to grant access to the knowledge; and (c) the circumstances in which the knowledge can be used and benefits (from its use) shared (see for example the community protocol in the Potato Park in Peru in Section 2.1.5 above).

The ABS Elements point out that in the case of TKGRFA, much knowledge may be shared by several communities, and at times across borders (FAO, 2019a, p. 63). This is acknowledged by some countries. For example, in Kenya, the Government invites community leaders from neighbouring countries to be part of the benefit-sharing negotiations under Kenyan law when cross-jurisdictional in situ resources are involved (NEMA, 2014). Some countries have chosen to mandate a public entity to negotiate on behalf of the IPLC with users of their traditional knowledge and to agree with those users on the modalities of ABS. For example, under the French ABS law, a public entity representing the traditional community negotiates PIC and MAT with the user and subsequently the CNA ratifies the agreement (France, 2017, Article 1 Art R. 412-28-I).

\section{Box 21 Procedures for prior informed consent in relation to traditional knowledge}

Procedures may involve:

- the same procedures as used for genetic resources of IPLCs (Section 2.3);

- procedures for laws that protect traditional knowledge as a form of intellectual property (e.g. Kenya, Peru, South Africa, Viet Nam and Zambia)

- laws or community protocols that explain the meaning of free, prior and informed consent (e.g. Nicaragua and Peru);

- public entities representing the IPLC negotiates PIC and MAT with users (e.g. France); and

- procedures for involving neighbouring communities across boarders (e.g. Kenya).

\subsection{Element 3 Conclusion}

The ABS Elements note that procedures for involving IPLCs in granting access to traditional knowledge associated with GRFA are diverse, and in many countries are still under development (FAO, 2019a, paragraph 63). The final texts of the CBD, Nagoya Protocol and Plant Treaty all include language that casts the responsibility for meeting the rights and interests of IPLCs to country laws. The country examples above illustrate the diversity of approaches. Access to traditional knowledge associated with 
genetic resources that is held by IPLC is, in many countries, subject to PIC or approval and involvement of these IPLCs, and MAT have to be established. However, specific arrangements or mechanisms to obtain PIC and MAT for traditional knowledge from the relevant IPLCs are rarely elaborated and the presence of laws recognizing the rights of IPLCs over their traditional knowledge does not mean that they are widely implemented in practice. It is important to remember that traditional knowledge is one of a range of issues of concern to IPLCs with respect to their relations with nation states, including nondiscrimination, protection of cultural integrity, land tenure, rights over lands and natural resources (Humphries, Robinson and Loban, 2017), social welfare for economic well-being and self-government (self-determination) (Bavikatte and Robinson, 2011). This means that a broader range of legislation may be relevant to the activities involved in accessing and using traditional knowledge associated with GRFA.

The literature review above revealed that there are a more articles on traditional knowledge and ABS than on other key GRFA-related topics but that few focus on the practical implications of ABS for TKGRFA. The literature typically has a focus on farmers' or breeders' rights with respect to commercially important species or in general terms in relation to the implementation of the Nagoya Protocol (e.g. Andersen, 2013; Peschard, 2017; Perucho et al., 2019; de Aguilar et al., 2020). However, there is a significant gap in analysis of how countries may specifically accommodate traditional knowledge associated with GRFA under their national measures and the effect of such measures on GRFA subsectors. 


\section{ELEMENT 4: FAIR AND EQUITABLE SHARING OF BENEFITS}

The Nagoya Protocol requires that "benefits arising from the utilization of genetic resources as well as subsequent applications and commercialization shall be shared in a fair and equitable way with the Party providing such resources that is the country of origin of such resources or a Party that has acquired the genetic resources in accordance with the Convention. Such sharing shall be upon mutually agreed terms" (Nagoya Protocol, Article 5(1)). Obligations to share benefits with IPLCs may arise from ABS measures with regard to benefits arising from the utilization of genetic resources that are held by IPLCs (Nagoya Protocol, Article 5(2)) and with regard to benefits arising from the utilization of traditional knowledge associated with genetic resources (Nagoya Protocol, Article 5(5)).

This section analyses examples of country measures that accommodate the need for sharing the benefits derived from the utilization of GRFA, including GRFA held by IPLCs and traditional knowledge associated with GRFA, while at the same time ensuring that benefits are shared on the basis of efficient and practical arrangements - the transaction costs of which do not outweigh the benefits. In accordance with the ABS Elements, this section explores typical approaches to (1) the scope of benefit-sharing obligations, (2) model contractual clauses, codes of conduct, etc. for negotiating "fair and equitable benefits", (3) identifying the correct beneficiaries with whom benefits should be shared, (4) monetary and non-monetary benefits, (5) sharing benefits through partnerships and (6) global multilateral sharing mechanisms.

\subsection{Scope of benefit-sharing obligations}

Some countries accommodate the importance of GRFA and their special role for food and livelihood security through simplified benefit-sharing procedures or exemptions from such procedures rather than through exemptions from, or simplifications of, access procedures (see Elements 2 and 3 above).

ABS measures vary significantly in terms of the overall design of benefit-sharing obligations, the procedures foreseen to reach MAT and the level of formality required for the agreement (Box 22). Some ABS measures, for example those of Solomon Islands (Solomon Islands, 2010) and Rwanda (Rwanda, 2013), leave it up to the CNA to determine the modalities of benefit-sharing on a case-by-case basis as part of the access permit. Other ABS measures require negotiated benefit-sharing agreements for intended commercial uses of genetic resources and/or traditional knowledge but do not require applicants to enter into a benefit-sharing agreement if access is granted for non-commercial purposes (e.g. Australia 2004). Some measures may require only the written permission (or a statutory declaration) of each access provider for non-commercial uses of genetic resources instead of a benefitsharing agreement (e.g. Australia, 2000, Section 8A.12).

Some laws exempt certain categories of users or products relevant to GRFA from benefit-sharing obligations. For example, Brazil's law exempts certain users, including "traditional farmers and their cooperatives, with annual gross income equal to or less than" a prescribed maximum limit (Brazil, 2015, Article 17(5)(II)), from the benefit-sharing obligations applying to the commercial exploitation of products derived from in situ genetic resources or TKGRFA. A "traditional farmer" is a "natural person using local traditional varieties or landraces or locally adapted breeds or creole and maintains and preserves genetic diversity, including family farmers" (Brazil, 2015, Article 2(XXXI)). The law has another benefit-sharing category, which applies to commercial products arising from access to genetic resources or associated knowledge for agricultural activities and must be implemented on the marketing of reproductive material. Domesticated products, other than those that have acquired distinctive features in Brazil and traditional local varieties or Creole races, are exempt from this category (Brazil, 2015, Article 18).

Other countries have simplified procedures for the sharing of benefits arising from GRFA/TKGRFA research or other activities. For example, the Philippines "exempts scientific research on agrobiodiversity" from the benefit-sharing obligations that apply to the collection and use of biological resources for commercial purposes (The Philippines, 2005b). The standard provisions require negotiation of a benefit-sharing agreement with all resource providers, including some compulsory terms relating to a bioprospecting fee, upfront payments and royalties. In the case of "scientific research on agrobiodiversity", simpler legislative arrangements involving a memorandum of agreement and a 
free permit apply, with few conditions attached other than the requirement to collaborate with local researchers as a form of benefit-sharing (The Philippines, 2004, Section 15). There are separate benefitsharing procedures for access to and use of traditional knowledge, with prescribed minimum standards for benefit-sharing (The Philippines, 2016).

\section{Box 22 Approaches to the scope of benefit sharing obligations}

There are many approaches to sharing the benefits of the use of genetic resources and traditional knowledge generally. In relation to special arrangements for GRFA concerning benefit-sharing categories and processes:

- some laws exempt certain categories of users or products relevant to GRFA from benefitsharing obligations (e.g. Brazil); and

- some laws have simplified benefit-sharing procedures arising from GRFA research or activities (e.g. the Philippines).

\subsection{Model contractual clauses, codes of conduct, etc. for negotiating "fair and equitable benefits"}

The ABS Elements (FAO, 2019a, p. 65) note that bilateral case-by-case benefit-sharing negotiations for GRFA may involve high transaction costs and may not be practical and that providers and users may wish to rely on model contractual clauses, codes of conduct, guidelines and best practice developed for GRFA subsectors. It is to be noted, however, that model contracts, codes or guidelines such as those outlined below (see Box 23) are subordinate to the specific rules on benefit-sharing under the provider country's legislation. Model contracts, codes or guidelines may inspire the development of specific ABS practices and facilitate the utilization of GRFA; they do not, however, replace, nor do they supersede ABS laws. Any GRFA transaction must ensure compliance with relevant laws.

Typical monetary and non-monetary benefits to be shared are listed in the Annex to the Nagoya Protocol. For the PGR sector, the Plant Treaty specifies as benefits: exchange of information, access to and transfer of technology, capacity-building and sharing of monetary and other benefits of commercialization (Plant Treaty, Article 13.2). Other guides or best practices for PGR may be found in relevant publications of various institutions such as Botanic Gardens Conservation International (Davis, 2008) and the Swiss Academy of Sciences (IISD, 2006).

MoGR, which are increasingly being used in large-scale agriculture (Sly, 2019), are commonly shared through informal networks set in place by groups of researchers, allowing for strains to be shared without high transaction costs and contractual agreements (Dedeurwaerdere et al., 2009). Various attempts have been made to facilitate the exchange of these resources in line with applicable ABS measures. For example, Belgium introduced the Micro-Organisms Sustainable Use and Access Regulation International Code of Conduct (MOSAICC), which is a voluntary code of conduct intended to facilitate access to MoGR and to help partners to make appropriate agreements when transferring them (BCCM, 2011). Best-practice guidelines and model contractual clauses have been developed for this subsector by various networks and organizations such as the World Federation for Culture Collections (WFCC, 2010).

Regarding InGR, the International Organisation for Biological Control established a Global Commission on Biological Control and Access and Benefit Sharing, whose mission is to "provide scientific advice to oversee and advise the design and implementation of an ABS regime that ensures practical and effective arrangements for the collection and use of biological control agents ..." (Mason, 2008; Mason et al., 2018).

Unlike the situation with PGR and MoGR, there is little coordination between aquatic genebanks and networks (Greer and Harvey, 2004, p. 67), and there are few generally accepted protocols governing access and use of AqGRs (Bartley et al., 2009, p. 24). However, there are some examples of model material transfer agreements with ABS due diligence and benefit-sharing obligations. For example, Europe's Micro B3 ABS Model Agreement for access to marine micro-organisms (MicroB3, 2013) lists 
a variety of benefits, ranging from specific capacity-building for AqGR researchers to benefit-sharing provisions for commercial uses (Von Kries et al., 2013).

A particular issue for a benefit-sharing agreement for FGR, given the long lifespan of trees, is the handling of genetic material after the termination of the agreement. For example, the European Union's project Trees 4 Future project developed a model FGR agreement to tackle these and other issues specific to the sector (Beuker et al., undated).

\section{Box 23 Examples of model contractual clauses, codes of conduct and guidelines}

- Standard Material Transfer Agreement under the Plant Treaty for multilateral materials and best-practice guidelines for other plant networks including botanic gardens;

- Voluntary codes of conduct, including Micro-Organisms Sustainable use and Access regulation International Code of Conduct (MOSAICC), and model contractual clauses, including MicroB3 ABS Model Agreement, Microbial Resource Research Infrastructure (MIRRI), World Federation for Culture Collections (WFCC).

\subsection{Identifying the correct beneficiaries with whom benefits should be shared and national benefit-sharing funds}

According to the Nagoya Protocol, benefits shall be shared with the party providing genetic resources that is the country of origin of the genetic resources or a contracting party that has acquired them in accordance with the Convention (Nagoya Protocol, Article 5(1)). A "country providing genetic resources" means the country "supplying genetic resources collected from in-situ sources, including populations of both wild and domesticated species, or taken from ex-situ sources, which may or may not have originated in that country" ( $C B D$, Article 2).

The ABS Elements point out that it may be difficult to determine with certainty the "country of origin" of GRFA given that many GRFA have been widely exchanged across regions, countries and communities and that many different stakeholders have contributed to their development in different places and at different points in time. Section 2.1.2 examined this issue, but this section focuses on challenges associated with determining the country of origin that is entitled to benefits arising from the utilization of such GRFA (ABS Elements, FAO, 2019a, p.48). Box 24 summarises some of the approaches under national law for identifying the correct beneficiaries.

Often products that are developed with the use of GRFA can be used as genetic resources for further research and development, making it difficult to clearly distinguish providers from recipients of GRFA under the CBD/Nagoya Protocol framework for ABS. The ABS Elements (FAO, 2019a, p. 66) point out that benefits could be decoupled from individual providers, pooled in a national benefit-sharing fund or other cooperative arrangements and distributed in line with agreed policies and criteria. One example is the Plant Treaty Benefit Sharing Fund established to increase resources for investment in crop diversity and therefore to promote increased food security for all (FAO, 2020).

One example for a benefit-sharing fund at the national level is that established by the Government of Bhutan, which aims to support biodiversity, enhance rural livelihoods and offset the costs of conservation. Its funds are derived from a variety of sources, including benefits from the use of genetic resources, ex situ collections, protected areas and community forests (Bhutan Government, 2018). There are several examples of the proceeds of ABS agreements entering the benefit-sharing fund to support local conservation and livelihoods. For example, the Government entered into an agreement with an international company seeking access to processed orchid flowers from a local community-based natural resources management group to produce anti-wrinkle cream. The benefit-sharing fund received monetary benefits, which were used to support community-based conservation initiatives including capacity-building in orchid propagation and management (Bhutan Government, 2018).

Brazil's national benefit-sharing fund set up by the national Government refers to GRFA-specific benefits. It aims to support the efforts of "indigenous peoples, traditional communities and traditional farmers in the sustainable management and conservation of genetic heritage" and "the development and 
maintenance of diverse farming systems that enhance the sustainable use of genetic heritage" (Brazil, 2015, Article 30). Benefit-sharing funds from economic exploitation of traditional knowledge or genetic heritage with unidentifiable origin are set at a negotiable 1 percent of the annual net revenue obtained from their exploitation (da Silva and de Oliveira, 2018). There are various other examples, including Bangladesh (Bangladesh, 2017, Section 36), of countries with benefit-sharing funds that decouple benefits from the original provider and apply benefits to specific purposes including conservation and management of GRFA.

One grey area relates to the fact that between users and the providers to whom benefits are owed there may be intermediaries. The CBD and Nagoya Protocol lack recognition for the role and accountability of intermediaries, and few countries specifically address this gap. The issue is particularly relevant for GRFA, which may pass through collection centres or multiplier centres for distribution to farmers without the intermediary engaging in "utilization" activities that may trigger ABS obligations. Malaysia's law is one example that specifically addresses intermediaries. It has strong penalties that can be imposed if unauthorized intermediaries do not comply with ABS obligations and pass materials to a person that does not have authorization from the Government to use the materials or associated information or traditional knowledge (Malaysia, 2017, Section 21). In the European Union:

In cases where genetic resources are obtained indirectly, through an intermediary such as a culture collection or other specialised companies or organisations with a similar function, the user should ensure that prior informed consent was obtained and mutually agreed terms were established by the intermediary when the resources were originally accessed. Depending on the conditions under which the intermediary accessed the genetic resources, the user may need to obtain new PIC and MAT or modify existing ones, if the intended use is not covered by the PIC and MAT obtained and relied upon by the intermediary. The conditions are originally agreed between the intermediary and the provider country, and hence the intermediaries are best placed to inform the user about the legal status of the material they hold (EU Commission, 2016, Section 2.1.3).

Under the EU framework, "it does not matter where the intermediary is located (in a Party to the Nagoya Protocol or not), as long as the provider of the resource in question is a Party" (EU Commission, 2016, Section 2.1.3). In this case, it is clear that the provider to whom benefits must flow is not the intermediary but the country providing the resources to the intermediary.

\section{Box 24 Approaches to identifying the correct beneficiaries}

- Some countries have national benefit-sharing funds to address situations in which providers cannot be distinguished from recipients and/or there are multiple beneficiaries for GRFA/TKGRFA (e.g. Bangladesh, Bhutan and Brazil);

- Few countries address the grey area of intermediaries (neither providers nor users) for the purpose of ABS obligations and the claiming of benefits. Exceptions include the EU and Malaysia.

\subsection{Monetary and non-monetary benefits}

The ABS Elements (FAO, 2019a, p. 67) point out that ABS measures may identify benefits that are of particular relevance to the food and agriculture sector, for example research directed towards food and livelihood security. Several biodiversity-rich countries take this approach (see Box 25). For example, India's non-monetary benefit-sharing options include "conducting research directed towards priority needs in India including food, health and livelihood security focusing on biological resources" (India, 2014, Annexure 1). Uganda's law recognizes that benefits can vary on a case-by-case basis but that they "shall include ... benefits relating to food security" (Uganda, 2005, Section 20(2)(h)). The Government of Uganda recognizes that benefit-sharing agreements could include "contributions to local economy and at the village level, e.g. livelihoods improvement such as infrastructure and food security" (Uganda, 2007). ABS laws in Malaysia (Malaysia, 2017, Section 11(2)(14)) and the Walloon Region in Belgium (Belgium, 2020, Annexes 1 and 2) specify similar benefits for food security. Zambia includes, as an 
optional form of non-monetary benefit-sharing, training to enhance local skills and the "conservation, evaluation, development, propagation and use" of genetic resources and traditional knowledge (Zambia, 2016, Section 43(k)).

The ABS Elements (FAO, 2019a, p. 67) also point out that access to GRFA is a benefit in itself and that ABS measures may consider the mutual exchange of GRFA, allowing for access without the necessity of negotiating the sharing of monetary benefits. Country examples identified in Section 2.2.1 above include exemptions for mutual exchanges of GRFA within or between communities to sustain food or livelihood systems (e.g. India, Kenya and Zambia) and for traditional uses (e.g. Ethiopia and Norway).

Many laws refer to voluntary monetary benefits. Monetary contributions may be mandatory under certain circumstances under some laws, for example in Brazil (Brazil, 2015, Article 30) and India (India, 2014), and are usually negotiated on a case-by-case basis. One high-profile case of monetary benefitsharing is that of rooibos tea, one of South Africa's oldest and most successful indigenous natural product industries. This benefit-sharing agreement centres on the fact that the industry is based on traditional use and knowledge, with the agreement specifying a 1.5 percent levy on farm-gate price, to be split between indigenous groups (Wynberg, 2020). In the case of the Ethiopian cereal teff, a benefitsharing agreement with the Ethiopian Government specified a lump sum, calculated as gross net income for a number of years and an annual payment of 30 percent of the profit obtained from the sale of basic and certified seeds (Gebreselassie, 2009). A number of benefit-sharing agreements are also in place for the iconic baobab tree, the fruits of which are used both as a novel food ingredient and as a source of cosmetic oil. The agreements foresee upfront payments for community-development projects based on the quantities of fruits provided.

\section{Box 25 Approaches to monetary and non-monetary benefits}

Some laws identify benefits of particular relevance to GRFA including:

- research directed to towards food, health and livelihood security (e.g. Belgium (Walloon Region), India, Malaysia and Uganda);

- training to enhance local skills and propagation of GRFA and TKGRFA (e.g. Zambia); and

- mutual exchange of GRFA within or between communities to sustain food or livelihood systems (e.g. India, Kenya and Zambia) and for traditional uses (e.g. Ethiopia and Norway).

Monetary benefits are not usually GRFA specific under national laws, but there are some highprofile experiences relating to GRFA, including rooibos (South Africa), teff (Ethiopia) and the boabab tree.

\subsection{Sharing benefits through partnerships}

The ABS Elements (FAO, 2019a, p. 67) point out that GRFA are often exchanged in the framework of collaborations and partnerships, with many stakeholders acting as neither original providers nor endusers. They suggest that ABS measures may allow for benefit-sharing arrangements to be part of broader research partnership agreements. There is a large gap in analysis for this approach, with few examples in ABS laws and the literature (see Box 26).

One approach is to create measures that simplify the requirement for subsequent users to enter into benefit-sharing agreements with the original provider. For example, the ABS law in Queensland, Australia, provides for benefit-sharing agreements between the state and biodiscovery entities, but allows other entities to enter into subsequent use agreements with a party to a benefit-sharing agreement (Australia, 2004, Section 35A). Each subsequent use agreement must include the prescribed minimum terms included in the head agreement. 


\section{Box 26 Approaches to sharing benefits through partnerships}

There is a large gap in analysis for approaches that involve sharing benefits through partnership arrangements, with few examples in ABS laws and literature. However, one approach may be to allow for "subsequent use agreements", whereby an entity that has entered into a benefit-sharing agreement with the original provider has authority to enter into subsequent agreements with other entities (research partners) under specified conditions (e.g. Queensland, Australia).

\subsection{Global multilateral benefit-sharing mechanism}

The ABS Elements (FAO, 2019a, p. 69) point out that parties to the Nagoya Protocol have agreed on a process for considering the need for, and modalities of, a global multilateral benefit-sharing mechanism (Nagoya Protocol, Article 10). This mechanism could be relevant to benefit-sharing for GRFA, because of the nature of the domestication/innovation process and the resulting difficulties in determining countries of origin, the interdependence of countries with regard to GRFA and the high number of international exchanges of GRFA. The Plant Treaty's Multilateral System of Access and Benefit-sharing offers such a mechanism for specific categories of PGR. Discussions are ongoing about establishing similar mechanisms for specific (sectors of) genetic resources (Schloen, Louafi and Dedeurwaerdere, 2011; Louafi and Schloen 2013), genetic resources that are outside the scope of the Nagoya Protocol (African Group Submission, 2012) or genetic sequence information (Lawson, Humphries and Rourke, 2019a).

In 2018, parties to the CBD requested the Executive Secretary to commission a peer-review study identifying specific cases of genetic resources and traditional knowledge that occur in transboundary situations or for which it is not possible to grant or obtain PIC (CBD, 2018b). The survey identifies examples of PGR endemic in multiple countries and migratory AqGR species and notes that such cases may allow users to avoid benefit-sharing by making inaccurate claims about the provider country and raise questions as to which country has the more legitimate claim to share in benefits from use of the respective genetic resources (Bagley and Perron-Welch, 2020, p. 9). It draws attention to a range of scenarios in which traditional knowledge is held by multiple IPLCs within and across national boundaries, including the Rooibos tea example of benefit-sharing negotiations that were delayed by a dispute over whether the San and Khoi people of South Africa were entitled to benefits as first users of Rooibos as tea (Bagley and Perron-Welch, 2020, p. 12). These and other examples such as genetic resources of untraceable origin in ex situ collections make a case for considering a global multilateral benefit-sharing mechanism to accommodate the distinct features of GRFA.

\subsection{Element 4 Conclusion}

Countries have multiple options for addressing the modalities of benefit-sharing in their ABS measures and implementing them in practice. It is still quite common for benefit-sharing arrangements to be negotiated on a case-by-case basis, either as part of the access permit or in a separate agreement (MAT). However, quite a number of initiatives have aimed to harmonize the modalities of benefit-sharing with the aim of facilitating the exchange of genetic resources and research and development based on them. Some countries that continue to take a bilateral approach to benefit-sharing have attempted to accommodate the important role of food and agriculture through exemptions (e.g. for traditional farmers and cooperatives) from the ABS measures that apply to other categories of genetic resources or simplified arrangements (e.g. for agrobiodiversity researchers).

The incremental nature of the development of GRFA makes it difficult to determine the country with which benefits need to be shared. Discussions on multilateral systems (in contrast to the bilateral approach of benefit sharing between the provider and user) that would apply to GRFA beyond PGR are ongoing. In the meantime, several countries have initiated benefit-sharing funds that decouple access from benefit-sharing to reduce transaction costs and facilitate research and support development in the agricultural sectors. The ABS measures of some countries explicitly aim to ensure that non-monetary benefits such as those relating to capacity-building and technology transfer are also directed towards achieving food and livelihood security benefits. Model contractual clauses, codes of conduct and 
guidelines for GRFA may help to harmonize ABS practices across specific subsectors of GRFA, which could also help lower the transaction costs of benefit-sharing negotiations.

Despite the CBD having been in force for decades, official data on the ABS Clearing-House and research studies confirm (e.g. Young and Tvedt, 2017) that relatively few benefit-sharing agreements have been concluded for genetic resources generally, and even fewer for GRFA purposes specifically. It is unclear whether this is because relevant contracts are subject to commercial-in-confidence and not publicly available or whether contractual negotiations have been unsuccessful. The food and agriculture sector would benefit from further investigation into why ABS mechanisms appear to have produced so few benefit sharing arrangements. 


\section{ELEMENT 5: COMPLIANCE AND MONITORING}

The ABS Elements (FAO, 2019a, p. 69) note that there are different types of compliance measures for GRFA including (1) compliance of countries with international agreements (e.g. the Nagoya Protocol or the Plant Treaty), (2) compliance of users with PIC and MAT (e.g. traceability and penalty provisions under national laws) and (3) arrangements for compliance with domestic legislation of the provider country, often called "user country measures". This section focuses on the third category, first providing examples of country measures and infrastructure for key elements of the monitoring and compliance framework, namely disclosure of origin/source and checkpoints and second explaining approaches to "user country measures".

\subsection{Monitoring}

Under Article 17 of the Nagoya Protocol, parties must take measures to monitor and enhance transparency about the "utilization of genetic resources". These measures include (1) the designation of one or more so-called check-points and (2) the issuance of internationally recognized certificates of compliance (access permits or equivalents made available to the ABS Clearing-House, which serve as evidence that the genetic resources they cover have been accessed in accordance with PIC and that MAT have been established).

According to the Protocol, checkpoints shall collect or receive, as appropriate, relevant information related to PIC, to the source of the genetic resource, to the establishment of MAT and/or to the utilization of genetic resources. The information collected/received will be provided to relevant national authorities, to the party providing PIC and the ABS Clearing-House.

The type of checkpoint varies from country to country. They include patent offices (e.g. Kenya), national coordination centres (e.g. Belarus), environment protection bodies (e.g. Denmark) and food safety offices (e.g. the Netherlands) (CBD, 2020). Several countries have designated entities whose mandates are closely related to the food and agriculture sector as checkpoints (see Box 27).

\section{Box 27 Examples of genetic resources for food and agriculture-related checkpoints}

- Republic of Korea - Ministry of Agriculture, Food and Rural Affairs and the Ministry for Trade, Industry and Energy for agricultural bio-resources; and the Ministry for Oceans and Fisheries for marine bio-resources (Republic of Korea, 2017, Article 13(2));

- Kenya - Kenya Agriculture and Livestock Research Organisation and the Kenya Forest Service (Kenya Government, 2017);

- Bhutan - Bhutan Agriculture and Food Regulatory Authority (Bhutan Government, 2018);

- Estonia - Ministry of Rural Affairs (ABSCH); and

- Hungary - Pest County Government Office (ABSCH).

\subsection{Compliance measures}

An increasing number of countries, including Ethiopia, Malaysia, Norway, Uganda and the Republic of Korea, along with the EU, have adopted compliance measures, as required by Articles 15 and 16 of the Nagoya Protocol:

1. to take measures to provide that genetic resources and traditional knowledge used within its jurisdictions have been accessed in accordance with PIC and MAT have been established, as required by the ABS measures of the other Party;

2. to take measures to address situations of non-compliance with ABS measures of other Parties; and

3. to cooperate with other Parties, as far as possible and appropriate, in cases of alleged violation of national ABS measures. 
These measures require those who utilize genetic resources to be able to provide evidence that they have accessed the genetic resources with the PIC of the providing party and that MAT have been established as required under the law of the providing party (see Box 28). For example, Japan's law has detailed reporting, information and compliance requirements for importers, including requirements to supply unique identifiers of internationally recognized certificates of compliance (Japan, 2013, Chapter 2).

The EU's due diligence measures are compliance measure, as required under Articles 15 and 16 of the Nagoya Protocol (EU, 2014, Article 4). The measures also deal with circumstances in which a user obtains the resources indirectly through an intermediary such as a culture collection, requiring in such cases that the user ensure that the intermediary obtained PIC from the original provider and established MAT; if this is not the case, the user may need to obtain new authorization (EU Commission, 2016, Section 2.1.3). Users will be compliant with the due-diligence obligation if they take reasonable measures in keeping and analysing all necessary information relating to the resources and relevant permissions (EU, 2014, Article 4). If, notwithstanding a user's exercise of due diligence, it turns out that a genetic resource has not been accessed legally, the user will not be in breach of the relevant law but will have either stop utilization or obtain the necessary PIC and MAT (EU Commission, 2016, Section 3.1).

Norway's law (Norway, 2009, Section 60) requires that import of genetic material for utilization in Norway from a country that requires consent for collection or export may only take place in accordance with such consent and must be accompanied by evidence that consent has been obtained. The provider country "may enforce the conditions by bringing legal action on behalf of the person that set them". If the provider country is a country other than the country of origin where the materials was collected in situ, then the consent of the country of origin must also be obtained. When genetic materials covered by the Plant Treaty Multilateral System of Access and Benefit-sharing are utilized in Norway for research or commercial purposes, they must be "accompanied by information to the effect that the material has been acquired in accordance with" the Plant Treaty's SMTA. Norway's traditional knowledge law, including requirements to obtain PIC and MAT, applies to traditional knowledge of Norwegian IPLCs and to "traditional knowledge relating to genetic material developed, used, sustained and passed on by indigenous and local communities in other countries, provided that access to or use of such knowledge requires consent under the legislation of the state in question" (Norway, 2016, Section 7).

\section{Box 28 Approaches to compliance with provider-country prior informed consent and mutually agreed terms}

Few countries have overt provisions for compliance with provider-country measures, but there are an increasing number of such "user measures", for example Japan, Norway, the Republic of Korea and European Union Member States.

Everyone who wishes to access foreign genetic resources for "utilization" in the Republic of Korea must follow the procedures established by the provider country and must "endeavour to fairly and equitably share the benefits" with the providers (Republic of Korea, 2017, Article 14). The head of the national checkpoint may monitor compliance with the ABS measures of the party that provided the genetic resources and is authorized to initiate investigations where there is reason to believe that a user does not comply with the law (Republic of Korea, 2017, Article 16). Similarly, Japan requires the cooperation of users in cases of alleged violation of the legislation of the party that provided the genetic resources (Japan, 2017, 4(1)).

These compliance "user country" measures only ensure that access procedures have been followed, and not that users have complied with the terms of the MAT (e.g. the terms and conditions of access and use and/or benefit-sharing agreements). The Nagoya Protocol, however, obliges parties "to ensure that an opportunity to seek recourse is available under their legal system, consistent with applicable jurisdictional requirements, in cases of disputes arising from mutually agreed terms." (Nagoya Protocol, Article 18(2)). Parties are also required to encourage providers and users of genetic resources and traditional knowledge to include dispute resolution provisions in their MAT (Article 18). Private law (e.g. contract law) and private international law largely govern MAT, yet there is surprisingly little research about how ABS has operated in practice under these areas of law (c.f. Young and Tvedt, 2017). 
This survey found few examples in ABS laws specifically providing procedures for seeking recourse in the event of disputes over compliance with MAT, and fewer still about how to resolve conflict in relation to the use of traditional knowledge. One example was found under the Philippines law, which requires that any complaints involving interpretation and implementation of a memorandum of agreement must be addressed first in the community, using the community's traditional conflict-resolution process, and that if that is unsuccessful then the complaint must be made to a specific regional hearing office for resolution (The Philippines, 2005b, Section 37).

\subsection{Element 5 Conclusion}

The scope of this survey was restricted to arrangements for monitoring and compliance in accordance with Nagoya Protocol Articles 15-18. Countries are increasingly establishing infrastructure for monitoring the access, use and movements of genetic resources and traditional knowledge across national boundaries, including checkpoints and internationally recognized certificates of compliance. However, the survey found relatively few examples of laws, infrastructure and procedures concerning compliance with the domestic legislation of the provider country and requiring that genetic resources and traditional knowledge used within a country have been accessed in accordance with the ABS measures of the other country. . There were few examples of countries taking measures to address situations of non-compliance with the ABS measures of other parties and cooperating with other parties in cases of alleged violation of national ABS laws, and even fewer examples of procedures for addressing disputes over the terms of MAT. This is surprising given the international nature of ABS transactions and that these are the measures that "support the integrity of domestic access and benefitsharing frameworks of other Parties" (Buck and Hamilton 2011, p. 51). There is a significant gap in empirical research about monitoring and compliance of ABS measures in practice and whether the infrastructure above accommodates the use and movements of GRFA and TKGRFA. 


\section{SURVEY CONCLUSION}

Countries have broad scope to accommodate the distinctive features of GRFA within existing ABS frameworks. Promoting the conservation and sustainable use of genetic resource and associated traditional knowledge need not involve a one-size-fits-all model. If institutional arrangements are coordinated at international, regional, national and local levels, they can develop streamlined, simple and coordinated approaches to ABS measures across sectors. This coordination can promote a shared understanding of how access measures can be varied through exemptions and special arrangements based on GRFA activities and sites of significance. It can promote benefit-sharing options that suit sectors relying on incremental innovation through government and community funds and capacitybuilding specific to the GRFA sector. The survey found that many national ABS measures apply to commercial as well as small-scale and subsistence food and agriculture activities on paper, but there are significant gaps in research about the positive or negative effects of the measures in practice on various stakeholders and the conservation and sustainable use of GRFA/TKGRFA. The challenge in the coming decades will be for countries to ensure the access, sustainable use and transfer of GRFA and TKGRFA for food/livelihood security and conservation, while ensuring the fair and equitable sharing of benefits from their use with the providers and knowledge holders. 


\section{PRIMARY SOURCES}

\section{ABS legislation and measures}

Antigua and Barbuda (2015) Environmental Protection and Management Act, 2015

Australia (1954) Acts Interpretation Act 1954 (Qld)

Australia (1999) Environment Protection and Biodiversity Conservation Act 1999 (Cth)

Australia (2000) Environment Protection and Biodiversity Conservation Regulation 2000 (Cth)

Australia (2004) Biodiscovery Act 2004 (Qld)

Australia (2006) Biological Resources Act 2006 (NT)

Australia (2007) Commonwealth of Australia Gazette No. 6, 14 February 2007

Australia (2014) Nature Conservation Act 2014 (ACT)

Australia (2018) Biodiversity Conservation Regulation 2018 (WA)

Australia (2019) Biodiscovery and Other Legislation Amendment Bill 2019 (Qld).

Bangladesh (2017) Biodiversity Act 2017

Belgium (2020) Décret relatif à l'accès aux ressources génétiques et au partage juste et équitable des avantages découlant de leur utilisation

Bhutan (2003). Biodiversity Act of Bhutan 2003

Bhutan (2016) Biodiversity Bill of Bhutan 2016

Bulgaria (2002) Biological Diversity Act State Gazette No. 77/9.08.2002

Brazil (2001) Provisional Act No 2,186-16, Dated August 23, 2001 (former legislation)

Brazil (2015) Law n ${ }^{\circ}$ 13,123 of May 20, 2015 (Access and Benefits Sharing of Genetic Resources and Associated Traditional Knowledge)

China (2017) Regulation of Access to Genetic Resources and Benefit-sharing (draft law)

Colombia (2014) Resolution No. 1348 Por la cual se establecen las actividades que configuran acceso a los recursos geneticos y sus productos derivados para la aplicacion de la Decision Andina 391 de 1996 en Colombia y se toman otras determinaciones, 14 August 2014

Croatia (2013) Nature Protection Act 2013

Ecuador (2008) Constitución de la República del Ecuador de 2008

Ecuador (2017) Organic Code for the Social Economy of Knowledge, Creativity and Innovation (Código Orgánico de la Economía Social de los Conocimientos, Creatividad e Innovación)

Ethiopia (2006) Proclamation No. 482/2006 Access to Genetic Resources and Community Knowledge, and Community Rights Proclamation

Ethiopia (2009) Regulation No. 169/2009 Access to Genetic Resources and Community Knowledge, and Community Rights

EU (2014) Regulation (EU) No 511/2014 of the European Parliament and of the Council of 16 April 2014 on the compliance measures for users from the Nagoya Protocol on Access to Genetic Resources and the Fair and Equitable Sharing of Benefits Arising from their Utilisation in the Union

Finland (2016) Act on the Implementation of the Nagoya protocol to the Convention on Biological Diversity 2016

France (2016) Loi n 2016-1087 du 8 aout 2016 pour la reconquete de la biodiversite, de la nature et des paysages (1) Titre V: Accés aux ressources genetiqués et partage juste et equitable des avantages 
France (2017) Décret $n^{\circ}$ 2017-848 du 9 mai 2017 relatif à l'accès aux ressources génétiques et aux connaissances traditionnelles associées et au partage des avantages découlant de leur utilisation

Guatemala (2020) Normativo de Investigaciones e Investigadores de la Diversidad Biológica 2020

India (2002) The Biological Diversity Act, 2002

India (2004) Biological Diversity Rules, 2004

India (2014). Guidelines on Access to Biological Resources and Associated Knowledge and Benefits Sharing Regulations 2014

India (2019) Guidelines on Access to Biological Resources and Associated Knowledge and Equitable Sharing of Benefits Regulations, 2019 (Draft Notification)

Indonesia (2017) Regulation of the Minister of Environment No. 34/MenLHK/Setjen/Kum.1/2017 on Recognition and Protection of Local Wisdom in The Management of Natural Resources and the Environment

Japan (2017) Guidelines on Access to Genetic Resources and the Fair and Equitable Sharing of Benefits Arising from Their Utilization 2017 (not legally binding)

Kenya (2006) Environmental, Management and Coordination (Conservation of Biological Diversity and Resources, Access to Genetic Resources and Benefit Sharing) Regulation, 2006

Kenya (2016) Protection of Traditional Knowledge and Cultural Expressions Act 2016

Malaysia (2008) Protection of New Plant Varieties (Prescribed Size of a Holding) Regulations 2008

Malaysia (2017) Access to Biological Resources and Benefit Sharing Act 2017

Malta (2016) Access to Genetic Resources and the Fair and Equitable Sharing of Benefits arising from their Utilisation Regulations, 2016

Morocco (undated) Avant Projet de loi $n^{\circ}$ 56-17 sur l'accès aux ressources génétiques et le partage juste et équitable des avantages découlant de leur utilisation article 5 (draft law, unofficial translation).

Mozambique (2007) Regulamento sobre Acesso e Partilha de Benefícios Provenientes de Recursos Genéticos e Conhecimento Tradicional Associado 2007

Namibia (2017) Access to Biological and Genetic Resources and Associated Traditional Knowledge Act (No 2. of 2017)

Nicaragua (2012) Ley No 807 Ley De Conservación Y Utilización Sostenible De La Diversidad Biológica

Niger (1998) Loi n98-56 du 29 décembre 1998 portant loi cadre relative à la gestion de l'environnement

Nicaragua (2012) Ley No. 807: Ley De Conservación Y Utilización Sostenible de La Diversidad Biológica

Norway (2009) Nature Diversity Act - Act of 19 June 2009 No.100 Relating to the Management of Biological, Geological and Landscape Diversity

Norway (2016) Regulations Relating to the Protection of Traditional Knowledge Associated with Genetic Material 2016

Palau (2018) Palau National Code Title 24 Chapter 50 Act on Access and Benefit Sharing (RPPL No. 10-28 of 2018)

Panama (2009) Decreto Ejecutivo No. 25 De 29 de abril de 2009. "Por el cual se reglamenta el Artículo 71 de la Ley 41 de 1 de julio de 1998, General de Ambiente" 
Peru (2009). Decreto Supremo $N^{\circ}$ 003-2009-MINAM. Eleva al rango de Decreto Supremo la Resolución Ministerial $N^{\circ}$ 087-2008-MINAM y ratifican la aprobación del Reglamento de Acceso a los Recursos, efectuada por dicha Resolución

Peru (2001) Ley No. 27811, Ley de Proteccion Al Acceso A La Diversidad Biologica Persuana Y los Conocimentos Colectivos De Los Pueblos Indigenas

Plurinational State of Bolivia (2009) Constitución Politica del Estado Plurinacional de Bolivia 2009 Portugal (2002) Decree-Law No. 118/2002 of 20 April

Republic of Korea (2017) Act on Access to and Utilization of Genetic Resources and Benefit Sharing, Act No. 14533, Jan. 17, 2017

Rwanda (2013) Official Gazette No 38 of 23/09/2013 Law No. 70/2013 of 02/09/2013 Governing Biodiversity in Rwanda

Solomon Islands (2010). Protected Areas Act 2010

South Africa (2004) No. 10 of 2004: National Environmental Management: Biodiversity Act, 2004

South Africa (2008) NEM Biodiversity Act: Regulations on Bio-prospecting, Access and Benefit Sharing (No. R 138 of 2008)

South Africa (2019) Act No. 6 of 2019: Protection, Promotion, Development and Management of Indigenous Knowledge Act, 2019

Spain (2017) Real Decreto 124/2017 de 24 de febrero, relativo al acceso a los recursos genéticos procedentes de taxones silvestres y al control de la utilización

The Philippines (2004) Joint DENR-DA-PCSD Administrative Order No. 1, May 18, 2004 Joint Implementing Rules and Regulations (IRR) Pursuant to Republic Act No. 9147

The Philippines (2005a) Joint IPOPHL-NCIP Administrative Order No. 01, 2016: Rules and Regulations on Intellectual Property Rights Application and Registration Protecting the Indigenous Knowledge Systems and Practices of the Indigenous Peoples and Indigenous Cultural Communities

The Philippines (2005b) Joint DENR-DA-PCSD-NCIP Administrative Order No. 01, Series of 2005: Guidelines for Bioprospecting Activities in the Philippines

The Philippines (2012) NCIP Administrative Order No. 1 Series of 2012: The Indigenous Knowledge Systems and Practices (IKSPs) and Customary Laws (CLs) Research and Documentation Guidelines of 2012.

The Philippines (2016) Joint IPOPHL-NCIP Administrative Order No. 01, 2016: Rules and Regulations on Intellectual Property Rights Application and Registration Protecting the Indigenous Knowledge Systems and Practices of the Indigenous Peoples and Indigenous Cultural Communities

Uganda (1995) National Environment Act of 1995

Uganda (2005) National Environment (Access to Genetic Resources and Benefit Sharing) Regulations, 2005

Uganda (2007) Guidelines for Accessing Genetic Resources and Benefit Sharing in Uganda 2007

Utah (2010) Utah Bioprospecting Act 2010

Vanuatu (2002) Environmental Management and Conservation Act No. 12 of 2002

Viet Nam (2008) Law No. 20/2008/QH12 Biodiversity Law 2008

Viet Nam (2017) Decree No. 59/2017/ND-CP On The Management Of Access To Genetic Resources And The Sharing Of Benefits Arising From Their Utilization

Zambia (2016) Protection of Traditional Knowledge, Genetic Resources and Expressions of Folklore Act 2016 


\section{International agreements}

Convention on Biological Diversity, opened for signature 5 June 1992, 1760 UNTS 79 (entered into force 29 December 1993).

International Labour Convention on the Rights of Indigenous and Tribal Peoples in Independent Countries No 169 (1989) 1650 UNTS 383.

International Treaty on Plant Genetic Resources for Food and Agriculture, opened for signature Nov. 3, 2001, in force June 26, 2004, 2400 U.N.T.S. 303.

Nagoya Protocol on Access to Genetic Resources and the Fair and Equitable Sharing of Benefits Arising from Their Utilization to the Convention on Biological Diversity, opened for signature 29 October 2010, [2012] ATNIF 3 (entered into force 12 October 2014).

Nairobi Final Act of the Conference for the Adoption of the Agreed Text of the Convention on Biological Diversity (1992)

United Nations Convention on the Law of the Sea (UNCLOS)

Vienna Convention on the Law of Treaties, opened for signature 23 May 1969, 1155 UNTS 331 (1980). 


\section{REFERENCES}

ABS Clearing House Malaysia. 2020. References [online]. Malaysia [cited 11 October 2020]. https://www.myabs.gov.my/resources.php?menu=50\#content

ABS Initiative. 2019. Report of the 12th Pan African Workshop on Access and Benefit-Sharing, 9-14 September 2019. Cape Town, South Africa, ABS Capacity Development Initiative \& Department of Environmental Affairs.

ABS Kenya. 2020. Access and Benefit Sharing Information Portal for Kenya [online]. Nairobi. [cited 11 October 2020]. http://meas.nema.go.ke/abs/

Adebola, T. 2019. Access and benefit sharing, farmers' rights and plant breeders' rights: Reflections on the African model law. Queen Mary Journal of Intellectual Property, 9(1): 105-121.

African Group Submission. 2012. The need for and modalities of a Global Multilateral BenefitSharing Mechanism (Article 10) [online]. [cited 11 October 2011]. https://www.cbd.int/abs/submissions/icnp-2/african-group-en.pdf

Ahmed, H. 2016. Enhancing cooperation and synergies among Nepal's biodiversity related conventions. NBSAP Forum 1 December 2016. National Biodiversity Strategy and Action Plans, $\mathrm{CBD} / \mathrm{UNDP} / \mathrm{UNEP}$.

Allaire, G., Labatut, J. \& Tesnière, G. 2018. Complexity of commons and property right regimes: The case of animal genetic resources. Revue d'Economie Politique, 128(1): 109-135.

Andean Community. 1996. DECISION 391: Common Regime on Access to Genetic Resources (available at https://www.iatp.org/sites/default/files/ANDEAN_COMMUNITY_DECISION_391_Common_Re gime_on.htm).

Andersen, R. 2013. Norway's path to ensuring farmers' rights in the European context. In: R. Andersen \& T. Winge, eds. Realising farmers' rights to crop genetic Resources. Success Stories and Best Practices, pp. 41-57. New York, USA, Routledge.

Andersen, R. \& Winge, T. 2013. Realising farmers' rights to crop genetic resources: Success stories and best practices. New York, USA, Routledge.

Angwenyi, A.N. 2009. The law-making process of access and benefit-sharing regulations-the case of Kenya. In: E.C. Kamau \& G. Winter, eds. Genetic resources, traditional knowledge and the law: solutions for access and benefit sharing. New York, USA, Taylor \& Francis.

Antofie, M.M., Barbu, I., Sand, C.S. \& Blaj, R. 2016. Traditional orchards in Romania: Case study Fântânele, Sibiu County. Genetic Resources and Crop Evolution, 63(6): 1035-1048.

Argumedo, A. 2012. Decolonising action-research: the Potato Park biocultural protocol for benefitsharing In: K. Swiderska, H. Shrumm, W. Hiemstra, M.J. Oliva, K. Kohli, H. Jonas, H. Ashley, N. Kenton \& A.Milligan, eds. Biodiversity and culture: exploring community protocols, rights and consent, Participatory Learning and Action 65, pp. 91-101I. London, IIED.

ARIPO (African Regional Intellectual Property Organization). 2010. Swakopmund Protocol on the Protection of Traditional Knowledge and Expressions of Folklore (available at https://www.wipo.int/edocs/lexdocs/treaties/en/ap010/trt_ap010.pdf).

AU Commission (African Union Commission). 2015a. African Union Strategic Guidelines for the Coordinated Implementation of the Nagoya Protocol on Access to Genetic Resources and the Fair and Equitable Sharing of Benefits Arising from their Utilisation. Addis Ababa (available at https://absch.cbd.int/api/v2013/documents/41AF3096-D001-62ED-32DA-

5A253287A8AF/attachments/English-Strategic\%20Guidelines\%20for\%20ABS\%20-for\%20print1.pdf)

AU Commission. 2015b. African Union Practical Guidelines for the Coordinated Implementation of the Nagoya Protocol in Africa. African Union Commission, Department of Human Resources, 
Science and Technology. (available at https://absch.cbd.int/api/v2013/documents/ACA06BA72ED4-19C0-F096-

883C14068E94/attachments/AUPracticalGuidelinesOnABS_20150215_Druck.pdf).

Bagley, M. \& Perron-Welch, F. 2020. Study to identify specific cases of genetic resources and traditional knowledge associated with genetic resources that occur in transboundary situations or for which it is not possible to grant or obtain prior informed consent. Subsidiary Body on Implementation. $3^{\text {rd }}$ meeting, item 13 of the provisional agenda. CBD/SBI/3/15/Add.1, 13 July 2020.

Bartley, D., Benzie, J.A.H., Brummett, R.E., Davy, F.B., De Silva, S.S., Eknath, A,E., Guo, X. et al. 2009. the use and exchange of aquatic genetic resources for food and agriculture. Background Study Paper No. 45. Commission on Genetic Resources for Food and Agriculture. Rome (available at https://www.cbd.int/doc/meetings/abs/abswg-09-2nd/information/abswg-09-2nd-abswg-09-inf12-en.pdf).

Bavikatte, K. \& Robinson, D. 2017. Towards a People's History of the Law: Biocultural jurisprudence and the Nagoya Protocol on Access and Benefit Sharing. Law, Environment and Development Journal, 7: 35-51.

BCCM (Belgian Co-ordinated Collections of Micro-organisms). 2011. MOSAICC MicroOrganisms Sustainable use and Access regulation International Code of Conduct [online]. Belgium. [cited 11 October 2020]. https://bccm.belspo.be/projects/mosaicc\#introduction

Beuker, E., Buiteveld, J., Pacques, L., Tremberth, C., Aliouat, M. \& Fluch, S. (undated) ABS: $a$ model Model Transfer Agreement for forest genetic material [online]. Trees4Future [cited 11 October 2020]. http://www.trees4future.eu/uploads/Final\%20conference/Presentations/Session4/1\%20\%20Beuker.pdf

Bhatti, S., Marino, M., Manzella, D., Borring, J. P. \& Toledo, A. 2015. CWR and the prebreeding in the Context of the International Treaty on Plant Genetic Resources for Food and Agriculture. In: L. Guarino, M.E. Dulloo, N. Maxted, P. Smith, R.J. Redden \& S.S. Yadav, eds. Crop wild relatives and climate change, pp. 350-356. New York, USA, Wiley.

Bhutan Government. 2018. Access and benefit sharing toolkit for the management of genetic resources and associated traditional knowledge in Bhutan. National Biodiversity Centre, Ministry of Agriculture and Forests.

Brazil. 2019. Brazil's position on DSI (Notification 2019-012) 03 June 2019 [online]. https://www.cbd.int/abs/DSI-views/2019/Brazil-DSI.pdf

Buck, M. \& Hamilton, C. 2011. The Nagoya Protocol on Access to Genetic Resources and the Fair and Equitable Sharing of Benefits Arising from their Utilization to the Convention on Biological Diversity. Review of European Community and International Environmental Law, 20(1): 47-61.

Cabrera Ormaza, M.V. 2019. ABS in Ecuador and Peru: Between the Andean sub-regional regime and the Nagoya Protocol, In: E.C. Kamau, ed. Implementation of the Nagoya Protocol: Fulfilling new obligations among emerging issues, pp. 83-89. Germany, Bundesamt fur Naturschutz.

Cameroon MINEPDED. 2020. Designation of the ABS Clearing-House Publishing Authority and National Authorised Users [online] MINEPDED Cameroun [cited 12 November 2020] (available at https://portailchm.sie.cm/abs/en/procedure/designation-abs-clearing-house-publishing-authorityand-national-authorised-users).

CBD (Convention on Biological Diversity). 1992. Convention on Biological Diversity. United Nations (available at https://www.cbd.int/doc/legal/cbd-en.pdf).

CBD. 2007. Analysis of gaps in existing national, regional and international legal and other instruments relating to access and benefit sharing. Executive Secretary of the Convention on Biological Diversity. UNEP/CBD/WG-ABS/5/3 (8-12 October 2007) (available at https://www.cbd.int/doc/meetings/abs/abswg-06/official/abswg-06-abswg-05-03-en.pdf). 
CBD. 2013. Report of the Twelfth Meeting of the Conference of the Parties to the Convention on Biological Diversity. Conference of the Parties to the Convention on Biological Diversity. $\mathrm{UNEP} / \mathrm{CBD} / \mathrm{COP} / 12 / 29$, Decision XII/12(F) (available at https://www.cbd.int/doc/meetings/cop/cop-12/official/cop-12-29-en.pdf).

CBD. 2016. Decision adopted by the Conference of the Parties to the Convention on Biological Diversity. Conference of the Parties to the Convention on Biological Diversity. $13^{\text {th }}$ meeting, Agenda Item 14, CBD/COP/DEC/XIII/18, 17 December 2016 (available at https://www.cbd.int/doc/decisions/cop-13/cop-13-dec-18-en.pdf).

CBD. 2018a. Decision Adopted by the Parties to the Nagoya Protocol on Access and Benefit Sharing: 3/3 The Access and Benefit-sharing Clearing House and information sharing (Article 14). Conference of the Parties to the Convention on Biological Diversity Serving as the Meeting of the Parties to the Nagoya Protocol on Access to Genetic Resources and the Fair and Equitable Sharing of Benefits Arising from their Utilization. $3^{\text {rd }}$ meeting, Agenda Item 10. CBD/NP/MOP/DEC/3/3, 30 November 2018 (available at https://www.cbd.int/doc/decisions/np-mop-03/np-mop-03-dec-03en.pdf).

CBD. 2018b. Decision adopted by the parties to the Nagoya Protocol on Access and Benefit Sharing: 3/13 Global multilateral benefit-sharing mechanism (Article 10). Conference of the Parties to the Convention on Biological Diversity Serving as the Meeting of the Parties to the Nagoya Protocol on Access to Genetic Resources and the Fair and Equitable Sharing of Benefits Arising from their Utilization. $3^{\text {rd }}$ meeting, Agenda Item 19. CBD/NP/MPO/DEC/3/13, 30 November 2018 (available at https://www.cbd.int/doc/decisions/np-mop-03/np-mop-03-dec-13-en.pdf).

CBD. 2020. The Access and Benefit-Sharing Clearing House [online]. Secretariat of the Convention on Biological Diversity. [cited 11 October 2020]. https://absch.cbd.int/

CONAGEBIO (Comisión Nacional para la Gestión de la Biodiversidad). 2016. Research and use of biodiversity resources [online]. Costa Rica. [cited 11 October 2020] https://www.conagebio.go.cr/Conagebio/public/permisosInfo.html

Coolsaet, B., Batur, F., Broggiato, A.. \& Dedeurwaerdere, T. 2015. Implementing the Nagoya Protocol: Comparing Access and Benefit-Sharing Regimes in Europe. Leiden, Belgium, Brill-Nijhoff.

da Silva, M. \& de Oliveira, D.R. 2018. The new Brazilian legislation on access to the biodiversity (Law 13,123/15 and Decree 8772/16). Brazilian Journal of Microbiology, 49(1): 1-4.

Davis, K. 2008. A CBD manual for botanic gardens. Richmond, UK, Botanic Gardens Conservation International (also available at https://www.bgci.org/resources).

de Aguiar, A.L., da Silva, R.R., Alves, S.M., da Silva, L.P., de Morais, O.R., \& Lobo, R.N.B. 2020. Breeding objectives and selection criteria of a participatory community-based breeding programme of goats and sheep. Tropical Animal Health and Production. doi:10.1007/s11250-02002209-6

de la Torre, J.F. 2016. The role of native indigenous communities of Mexico in the access of genetic resources and the fair and equitable benefit sharing. In: Agriculture and Agri-Food Canada. Conservation and Development of Ancestral/Indigenous Plant Genetic Resources: Challenges, Tools and Perspectives. Sharing Canadian, Mexican and American Experiences. Workshop Report, Quebec, Canada (available at https://www.procinorte.net/Documents/Workshop_Report_Conservation_Plant_Genetic_Resources _May_10-11_2016.pdf).

Dedeurwaerdere, T., Iglesias, M., Weiland, S. \& Halewood, M. 2009. The use and exchange of microbial genetic resources for food and agriculture. Background Study Paper No. 46. Commission on Genetic Resources for Food and Agriculture, October 2009. Rome. 
DES (Department of Environment and Science). 2020. Reform of the Biodiscovery Act 2004 [online]. Queensland [cited 10 October 2011]. https://environment.des.qld.gov.au/licencespermits/plants-animals/biodiscovery/biodiscovery-act-reform

ESC (Economic and Social Council). 2011. Permanent Forum on Indigenous Issues. Report on the Tenth Session. E/2011/43-E/C.19/2011/14.

EU (European Union). 2014. Regulation (EU) No 511/2014 of the European Parliament and of the Council of 16 April 2014 on the compliance measures for users from the Nagoya Protocol on Access to Genetic Resources and the Fair and Equitable Sharing of Benefits Arising from their Utilization in the Union (available at https://eur-lex.europa.eu/legalcontent/EN/TXT/PDF/?uri=CELEX:32014R0511\&from=EN).

EU Commission. 2016. Guidance document on the scope of application and core obligations of Regulation (EU) No 511/2014 of the European Parliament and of the Council on the compliance measures for users from the Nagoya Protocol on Access to Genetic Resources and the Fair and Equitable Sharing of Benefits Arising from their Utilisation in the Union European Commission (available at https://eur-lex.europa.eu/legalcontent/EN/TXT/PDF/?uri=CELEX:52016XC0827(01)).

EU DECLARE. 2020. European Commission DECLARE Platform [online]. European Union [cited 11 October 2020]. https://webgate.ec.europa.eu/declare/web/domain

FAO. 2007. Global Plan of Action for Animal Genetic Resources and the Interlaken Declaration. Rome (available at http://www.fao.org/3/a1404e/a1404e00.pdf).

FAO. 2017. Report of the Conference of FAO. Fortieth Session (C2017). (Resolution 3/2017). Rome.

FAO. 2019a. ABS Elements: Elements to facilitate domestic implementation of access and benefitsharing for different subsectors of genetic resources for food and agriculture - with explanatory notes. Rome (available at http://www.fao.org/3/ca5088en/ca5088en.pdf).

FAO. 2019b. Seventeenth Regular Session of the Commission on Genetic Resources for Food and Agriculture. Rome, 18-22 February 2019. Commission on Genetic Resources for Food and Agriculture, CGRFA-17/19/Report. Rome (available at http://www.fao.org/3/mz618en/mz618en.pdf).

FAO. 2019c. Inventory of national measures, best practices and lessons learned from the realization of Farmers' Rights, as set out in Article 9 of the International Treaty, Second Meeting of the Ad Hoc Technical Expert Group on Farmers' Rights, 20-23 May 2019. IT/GB-8/AHTEG-FR-2/19/3. Rome.

FAO. 2020. Benefit sharing fund [online]. Rome [cited 11 October 2020]. http://www.fao.org/planttreaty/areas-of-work/benefit-sharing-fund/overview/en/

FAO, IFAD, UNICEF, WFP \& WHO. 2020. The State of Food Security and Nutrition in the World 2020: Transforming Food Systems for Affordable Healthy Diets. Rome, FAO (also available at https://doi.org/10.4060/ca9692en).

Finland National Clearing-House. 2020. Use of genetic resources [online]. Finland. [cited 11 October 2020]. http://www.biodiversity.fi/geneticresources/home.

FRB (Fondation pour la recherche sur la biodiversité). 2020. FRB Focus on ABS (Access and Benefit Sharing) [online]. France. [Cited 11 October 2020].

https://www.fondationbiodiversite.fr/en/biodiversity-challenges/biodiversity-and-regulation/acessbenefit-sharing/

Friso, F., Mendive, F., Soffiato, M., Bombardelli, V., Hesketh, A., Heinrich, M., Menghini, L. \& Politi, M. 2020. Implementation of Nagoya Protocol on Access and benefit-sharing in Peru: Implications for researchers. Journal of Ethnopharmacology, 259: advanced online copy September 2020. 
Gebreselassie, A.T. 2009. Material Transfer Agreements on teff and vernonia - Ethiopian plant genetic resources. Journal of Politics and Law, 2(4): 77-89.

German Government. 2020. Allgemeine Handlungsempfehlungen (General Recommendations for Action) [online]. Germany. [cited 11 October 2020].

https://www.bfn.de/fileadmin/ABS/documents/ABS_Dokumente_ab_September_2015/20170322_ Handlungsempfehlungen_01.pdf

Glowka, L., Burhenne-Guilmin, F., Synge, H., McNeely, J.H., \& Gündling, L. 1994. A Guide to the Convention on Biological Diversity. Environmental Policy and Law Paper No. 30. Gland, Switzerland, International Union for Conservation of Nature.

Greer, D. \& Harvey, B. 2004. Blue genes: sharing and conserving the world's aquatic biodiversity. London, Earthscan.

Greiber, T., Moreno, S.P., Åhrén, M., Carrasco, J.N., Kamau, E.C., Medaglia, J.C., Oliva, M.J. et al. 2012. An Explanatory Guide to the Nagoya Protocol on Access and Benefit-sharing. Environmental Policy and Law Paper No. 83, Gland, Switzerland, International Union for Conservation of Nature.

Greiber, T. 2019. Implementation of the Nagoya Protocol in the European Union and in Germany. Phytomedicine, 53: 313-318.

Halewood, M., ed. 2015. Baseline survey on the state of coordination between CBD/NP and ITPGRFA focal points. In: M. Halewood, ed. Mutually supportive implementation of the Plant Treaty and the Nagoya Protocol - A report on 'The International Treaty and the Nagoya ProtocolA tandem workshop for National Focal Points'. Rome, Biodiversity International.

Halewood, M., Chiurugwi, T., Hamilton, R. S., Kurtz, B., Marden, E., Welch, E., Michiels, F. et al. 2018. Plant genetic resources for food and agriculture: opportunities and challenges emerging from the science and information technology revolution. New Phytologist., 217(4): 1407-1419.

Humphries, F. 2016. Technology transfer of aquatic genetic resources under the Convention on Biological Diversity and Nagoya Protocol: "Sponging" off Patent Law Defences. University of NSW Law Journal, 39(1): 234-272.

Humphries, F. 2017. A patent defence approach to sharing aquaculture genetic resources across jurisdictional areas. Journal of World Intellectual Property, 20(5-6): 221-238.

Humphries. F., Robinson, D. \& Loban, H. 2017. Implications of Northern Land Tenure Changes for Accessing Indigenous Genetic Resources. Environmental and Planning Law Journal, 34: 560-579.

IISD. 2006. Access and Benefit Sharing Good Practice for Academic Research on Genetic Resources [online]. Geneva. [cited 11 October 2020].

https://nbsapforum.net/sites/default/files/abs_swiss_abs_good_practice.pdf

Jefferson, D. 2020. Towards and ecological intellectual property: reconfiguring relationships between people and plants in Ecuador. Abingdon, UK, Routledge.

Kamau, E.C. 2019. Implementation of the Nagoya Protocol: Fulfilling new obligations among emerging issues. Germany, BfN (available at: https://www.bfn.de/fileadmin/BfN/service/Dokumente/skripten/Skript564.pdf).

Kenya Government. 2016. Report to the CBD's ABS Clearing House (available at https://absch.cbd.int/database/record/ABSCH-MSR-KE-208067/3).

Kenya Government. 2017. Biological authorisation procedures (available at https://absch.cbd.int/database/record/ABSCH-MSR-KE-238497).

Lawson, C., Humphries, F. \& Rourke, M. 2019a. The future of information under the CBD, Nagoya Protocol, Plant Treaty, and PIP Framework. Journal of World Intellectual Property, 22(3-4): 103-119. 
Lawson, C., Humphries, F. \& Rourke, M. 2019b. Legislative, administrative and policy approaches to access and benefit sharing (ABS) genetic resources: Digital sequence information (DSI) in New Zealand and Australian ABS laws. Intellectual Property Forum, 118: 38-50.

Leskien, D. 2018. Elements to Facilitate Domestic Implementation of Access and Benefit-Sharing for Different Subsectors of Genetic Resources for Food and Agriculture. Paper presented at the Proceedings of the International Workshop on Access and Benefit-sharing For Genetic Resources For Food And Agriculture, Rome (available at http://www.fao.org/3/CA0099EN/ca0099en.pdf).

Lidder, P. \& Sonnino, A. 2011. Biotechnologies for the management of genetic resources for food and agriculture. Commission on Genetic Resources for Food and Agriculture. Background Study Paper No. 52. Rome, FAO.

Liu, W., Xu, J., Yin, S., Tian, Y. \& Li, J. 2017. Mechanisms of benefit-sharing of medicinal plants found in China and neighboring countries. Biodiversity Science, 25(8): 907-913.

Louafi, S. \& Manzella, D. 2018. The benefit-sharing mechanisms under the international treaty: Heterogeneity and equity in global resources management. In: F. Girard \& C. Frison, eds. The commons, plant breeding and agricultural research: challenges for food security and agrobiodiversity, pp. 257-271. New York, USA, Routledge.

Louafi, S. \& Schloen, M. 2013. Practices of exchanging and utilizing genetic resources for food and agriculture and the access and benefit sharing regime. In: E.C. Kaman \& G. Winter, eds. Common pools of genetic resources: equity and innovation in international biodiversity law, pp. 193-223. Abingdon, UK, Routledge.

Malawi Government. 2015. Procedures and guidelines for access and collection of plant and animal genetic resources in Malawi. National Commission for Science and Technology (available at https://www.ncst.mw/wp-content/uploads/2020/01/REVISED-Procedures-and-Guidelines-forAccess-and-Collection-of-Genetic-Resources-in-Malawi.pdf).

Mapiye, C., Chikwanha, O C., Chimonyo, M. \& Dzama, K. 2019. Strategies for sustainable use of indigenous cattle genetic resources in Southern Africa. Diversity, 11(11). doi:10.3390/d11110214

Mardiastuti, A. 2019. Implementation of access and benefit sharing in Indonesia: Review and case studies. Jurnal Manajemen Hutan Tropika, 25(1): 35-43.

Mason, P. 2008. Commission on Biological Control and Access and Benefit Sharing. [online]. https://www.iobc-global.org/global_comm_bc_access_benefit_sharing.html

Mason, P.G., Cock, M.J.W., Barratt, B., Klapwijk, J.N., Van Lenteren, J.C., Brodeur, J., Hoelmer, K.A. \& Heimpel, G.E. 2018. Best practices for the use and exchange of invertebrate biological control genetic resources relevant for food and agriculture BioControl, 63(1): 149-154.

Mba, C., Abang, M., Diulgheroff, S., Hrushka, A., Hugo, W., Ingelbrecht, I., Jankulowski, L. et al. 2020. FAO supports countries in the implementation of the Second Global Plan of Action for Plant Genetic Resources for Food and Agriculture. Acta Horticulturae, 1267: 197-208.

Medaglia, J.C. 2013. The iImplementation of the Nagoya Protocol in Latin America and the Caribbean: Challenges and opportunities. Legal Studies on Access and Benefit-sharing, 1: 332-368.

Medaglia, J.C. 2020. Case study: CONAGEBIO (Costa Rica) permitting and contractual approach to control DSI benefit-sharing. In: M. Bagley, F. Perron-Welch, E. Karger, \& L. de Souza, eds. Factfinding study on how domestic measures address benefit-sharing arising from commercial and non-commercial use of digital sequence information on genetic resources and address the use of digital sequence information on genetic resources for research and development. CBD/DSI/AHTEG/2020/1/5 29 January 2020. Ad Hoc Technical Expert Group on Digital Sequence Information on Genetic Resources, Montreal, Canada, March 2020.

MicroB3. 2013. Micro B3 ABS Model Agreement released [online]. MicroB3 Consortium. [cited 11 October 2011]. https://www.microb3.eu/news/micro-b3-model-agreement-0.html 
Ministry of Higher Education, Research and Innovation. 2020. Use of genetic resources of associated traditional knowledge [online]. Paris. [cited 11 October 2020]. https://www.enseignementsup-recherche.gouv.fr/cid127438/les-plates-formes-d-enregistrementpour-l-utilisation-de-ressources-genetiques-et-de-connaissances-traditionnelles-associees.html

Moher, D., Shamseer, L., Clarke, M., Ghersi, D., Liberati, A., Petticrew, M., Shekelle, P., Stewart, L.A. \& PRISMA-P Group. 2015. Preferred reporting items for systematic review and meta-analysis protocols (PRISMA-P) 2015 statement. Systematic Reviews, 4(1).

Morgera, E., Buck, M. \& Tsioumani, T. 2013. Introduction. In: E. Morgera M. Buck \& E. Tsioumani, eds. The 2010 Nagoya Protocol on Access and Benefit-sharing in Perspective: Implications for International Law and Implementation Challenges, pp. 1-18. Leiden, Netherlands, Martinus Nijhoff.

Morgera, E., Tsioumani, E. \& Buck, M. 2014. Unraveling the Nagoya Protocol: a commentary on the Nagoya Protocol on access and benefit-sharing to the Convention on Biological Diversity. Leiden, Netherlands, Martinus Nijhoff.

Mulesa, T.H. \& Westengen, O.T. 2020. Against the grain? A historical institutional analysis of access governance of plant genetic resources for food and agriculture in Ethiopia. Journal of World Intellectual Property, 23: 82-120.

Muzaka, V. \& Serrano, O.R. 2019. Teaming Up? China, India and Brazil and the Issue of BenefitSharing from Genetic Resource Use. New Political Economy. doi:10.1080/13563467.2019.1584169

National Biodiversity Authority. 2016. ABS e-filing [online]. India [Cited 11 October 2020]. http://absefiling.nic.in/NBA/login/auth

NEMA (National Environment Management Authority). 2014. Kenya's Access and Benefit Sharing Toolkit for genetic resources and associated traditional knowledge. Nairobi.

Nepalese Government. 2014. National Biodiversity Strategy and Action Plan 2014-20. Government of Nepal Ministry of Forests and Soil Conservation, Singhadurbar, Kathmandu.

Nijar, G.S. 2018. Access and benefit-sharing Legislation in Malaysia. In: FAO. Proceedings of the International Workshop on Access and Benefit-Sharing for Genetic Resources for Food and Agriculture. Rome, CGRFA.

Oiteno, G., Mulumba, J.W., Namulondo, B. \& Halewood, W. 2017. Climate-resilient seed systems \& access and benefit-sharing in Uganda. ISSD Africa.

Page M.J., Handley, S.J., Northcote, P.T., Cairney, D. \& Willan, R. 2011. Successes and pitfalls of the aquaculture of the sponge Mycale hentscheli. Aquaculture, 312: 52-61.

Peña Neira, S. 2017. Interpretation and application of international legal obligation in a national legal system: Taking seriously benefit sharing from the utilization of genetic resources in India. Anuario Mexicano de Derecho Internacional, 17(1): 652-695.

Perry, M. 2013. Accessing accessions, biobanks and benefit-sharing. In: G. Pascuzzi, U. Izzo, \& M. Macilotti, eds. The governance of research biobanks, pp. 267-279. New York, USA, Springer.

Perucho, L., Hadjigeorgiou, I., Lauvie, A., Moulin, C.H., Paoli, J.C. \& Ligda, C. 2019. Challenges for local breed management in Mediterranean dairy sheep farming: insights from Central Greece. Tropical Animal Health and Production, 51(2): 329-338.

Peschard, K. 2017. Seed wars and farmers' rights: comparative perspectives from Brazil and India. Journal of Peasant Studies, 44(1): 144-168.

Pickering, C. \& Byrne, J. 2014. The benefits of publishing systematic quantitative literature reviews for $\mathrm{PhD}$ candidates and other early career researchers. Higher Education Research and Development, 33: 534-548. 
Rhoden, F., Huang, S., Droge, G. \& Hartman Schoz, A. 2020. Combined study on digital sequence information (DSI) in public and private databases and traceability. CBD/DSI/AHTEG/2020/1/4 31 January 2020. Ad Hoc Technical Expert Group on Digital Sequence Information on Genetic Resources, Montreal, Canada, March 2020.

Robinson, D. \& von Braun, L. 2017. New challenges for the Nagoya Protocol: Diverging implementation regimes for access and benefit-sharing. In: C. Correa \& X. Seuba, eds. Intellectual property and development: Understanding the Interfaces, pp. 377-403. Singapore: Springer.

Robinson, D., Raven, M. \& Hunter, J. 2018. The limits of ABS laws: Why gumbi gumbi and other bush foods and medicines need specific indigenous knowledge protections. In: K. Adhikari \& C. Lawson, eds. Biodiversity, genetic resources and intellectual property: developments in access and benefit sharing, pp. 185-207. Milton Park, UK, Taylor and Francis.

Robinson, D., Raven, M. Tari, T., Hickey, F. \& Kalfatak, D..2019. Kava, Kastom and indigenous knowledge: Next steps under the Nagoya protocol. Griffith Law Review, 702: 728.

Rosendal, K. \& Andersen, S. 2016. Realizing access and benefit sharing from use of genetic resources between diverging international regimes: the scope for leadership. International Environmental Agreements: Politics, Law and Economics, 16(4): 579-596.

Rosendal, G.K., Olesen, I., \& Tvedt, M.W. 2013. Balancing ABS and IPR governance in the aquaculture sector. In: S. Oberthur \& G.K. Rosendal, eds. global governance of genetic resources: access and benefit sharing after the Nagoya Protocol, pp. 196-212. New York, USA, Routledge.

SADC (Southern African Development Community). 2013. Plant genetic resources for food and agriculture policy guidelines. (available at http://www.spgrc.org.zm/images/PGRFAPolicy/PGRFA_Policy_Guidelines_English.pdf).

Samaj Panchayat, R. 2009. Raika Biocultural Protocol (available at www.pastoralpeoples.org/docs/Raika_Biocultural_Protocol.pdf).

Samburu Community Protocol. 2009. Samburu Community Protocol about the samburu indigenous livestock breeds and their rights to their indigenous livestock genetic resources and role in global biodiversity management (available at http://community-protocols.org/wpcontent/uploads/documents/Kenya-Samburu_Community_Protocol.pdf).

Schloen, M., Louafi, S. \& Dedeurwaerdere, T. 2011. Access and benefit-sharing for genetic resources for food and agriculture - current use and exchange practices, commonalities, differences and user community needs. Report from a multi-stakeholder expert dialogue. Background Study Paper No. 59 (available at http://www.fao.org/3/mb720e/mb720e.pdf).

Secretariat of the Convention of Biological Diversity. 2002. Bonn Guidelines on Access to Genetic Resources and Fair and Equitable Sharing of the Benefits arising out of their Utilization. Montreal, Canada.

Secretariat of the Convention on Biological Diversity. 2019. Mo' otz Kuxtal Voluntary Guidelines for the development of mechanisms, legislation or other appropriate initiatives to ensure the "prior and informed consent", "free, prior and informed consent" or "approval and involvement", depending on national circumstances, of indigenous peoples and local communities for accessing their knowledge, innovations and practices, for fair and equitable sharing of benefits arising from the use of their knowledge, innovations and practices relevant for the conservation and sustainable use of biological diversity, and for reporting and preventing unlawful appropriation of traditional knowledge. Montreal, 9 p. (CBD Guidelines Series).

SEPA (Swedish Environmental Protection Agency). 2020. Utilizing genetic resources. Guidance on the utilization of genetic resources in research and product development [online]. Stockholm. [cited 11 October 2020]. http://www.swedishepa.se/Guidance/Guidance/SpeciesProtection/Genetic-resourses/

Sirakaya, A. 2019. Balanced options for access and benefit-sharing: stakeholder insights on provider country legislation. Frontiers in Plant Science, 10: 1175. 
Sly, L. 2019. Historical perspectives and new opportunities for Australian collections of microorganisms in the microbiome era. Microbiology Australia, 40(3): 140-143.

Smagdi, A. 2005. National measures on access to genetic resources and benefit sharing - the case of the Philippines. Law, Environment and Development Journal, 1: 50-70.

South African Government. 2012. South Africa's Bioprospecting, Access and Benefit Sharing Regulatory Framework - Guidelines for providers, users and regulators. Department of Environmental Affairs (available at https://www.environment.gov.za/sites/default/files/legislations/bioprospecting_regulatory_framew ork_guideline.pdf).

SPC. 2020. Secretariat of the Pacific Community [online] Fiji [cited 13 November 2020]. https://www.spc.int/

Srinivasa Rao, C., Gopinath, K.A., Prasad, J.V.N.S., Prasannakumar, \& Singh, A.K. 2016. Climate Resilient villages for sustainable food security in tropical India: Concept, process, technologies, institutions, and impacts. Advances in Agronomy, 140: 101-214.

Tuiaa, V.S., Waqainabete, L.M., Sukal, A.C., Shandil, A.S., Lutu, U., Baiculacula, S., Cakaunitavuki, S. et al. 2015. Facilitating access to resilient crop diversity in the Pacific. Acta Horticulturae, 1101: 21-26.

Tvedt, M.W. 2013. Disentangling rights to genetic resources illustrated by aquaculture and forest sectors. Law, Environment and Development Journal, 9(2): 127-[iii].

UNDP (United Nations Development Programme). 2011. Towards human resilience: sustaining $M D G$ progress in an age of economic uncertainty (available at https://www.undp.org/content/undp/en/home/librarypage/povertyreduction/inclusive_development/towards_human_resiliencesustainingmdgprogressinanageofecono micun.html).

UNGA (United Nations General Assembly). 2007a. United Nations Declaration on the Rights of Indigenous Peoples, A/RES/61/295, Annex. New York, USA.

UNGA. 2007b. Report of the Human Rights Council, United Nations General Assembly A/61/L.67. New York, USA.

UNGA. 2017. International legally binding instrument under the United Nations Convention on the Law of the Sea on the conservation and sustainable use of marine biological diversity of areas beyond national jurisdiction. 72nd session, Agenda Item 77. Resolution A/RES/72/249.

UNGA. 2018. United Nations Declaration on the Rights of Peasants and Other People Working in Rural Areas. Resolution A/HRC/RES/39/12. New York, USA.

Varma, R.V. 2017. Access and benefit sharing in India: challenges ahead. In: K.P. Laladhas, P. Nilayangode \& O.V. Oommen, eds. Biodiversity for sustainable development: environmental challenges and solutions, pp. 87-96. Switzerland, Springer.

Vernooy, R. \& Ruiz, M. 2013. Access to and benefit sharing of plant genetic resources: Novel field experiences to inform policy. Resources, 2(2): 96-113.

Vietnamese Government. 2019. Guidance Document for the Implementation of Decree No. 59/2017/ND-CP on the Management of Access to Genetic Resources and the Sharing of Benefits Arising from their Utilization (Ha Noi, May 2019). Ministry of Natural Resources and Environment.

Von Kries, C., Broggiato, A., Dedeurwaerdere, T. \& Winter, G. 2013. MICRO B3 Model Agreement on Access to Marine Microorganisms and Benefit Sharing (MICRO B3 WP8, version 1.0, 10 June 2013, updated 17 December 2013) (available at https://www.microb3.eu/sites/default/files/pdf/MICRO_B3_ABS_model_agreement_17122013\%2 0explanatory\%20notes.pdf). 
Wang, S. W., Lee, W. K., Brooks, J. \& Dorji, C. 2019. Awareness of the Convention on Biological Diversity and provisions regarding access and benefit sharing among multiple stakeholder groups in Bhutan. ORYX. doi:10.1017/S0030605318000819

WFCC (World Federation for Culture Collections). 2010. Guidelines for the establishment and operation of collections of cultures of microorganisms (available at http://www.wfcc.info/guidelines/).

WHO. 2011. Pandemic influenza preparedness: sharing of influenza viruses and access to vaccines and other benefits. WHA64/8 (available at https://apps.who.int/gb/ebwha/pdf_files/WHA64/A64_R8-en.pdf).

Winge, T. 2016. Linking access and benefit-sharing for crop genetic resources to climate change adaptation. Plant Genetic Resources: Characterisation and Utilisation, 14(1): 11-27.

WIPO (World Intellectual Property Organization). 2018. The Protection of Traditional Knowledge: Draft Articles. Intergovernmental Committee on Intellectual Property and Genetic Resources, Traditional Knowledge and Folklore, Thirty-seventh Session, Geneva, 27-31 August 2018. WIPO/GRTKF/IC/37/4.

WIPO. 2020a. Key questions on patent disclosure requirements for genetic resources and traditional knowledge, 2nd edition. Geneva, Switzerland.

WIPO. 2020b. World Intellectual Property Organization [online]. [Cited 11 November 2020]. (https://www.wipo.int/about-ip/en/)

Wynberg, R. 2020. Rooibos: A testing ground for access and benefit sharing in South Africa and beyond. University of Cape Town, Voices for Biojustice.

Wynberg, R. 2017. Making sense of access and benefit sharing in the rooibos industry: Towards a holistic, just and sustainable framing. South African Journal of Botany, 110: 39-51.

Wynberg, R. 2018. One step forward, two steps back? Implementing access and benefit-sharing legislation in South Africa. In: C R. McManis \& B. Ong, eds. Routledge Handbook of Biodiversity and the Law. New York, USA, Routledge.

Young, T.R \& Tvedt, M.W. 2017. Drafting successful access and benefit-sharing contracts. Leiden, Netherlands, Brill Nijhoff.

Zheng, X.O. 2019. Key legal challenges and opportunities in the implementation of the Nagoya Protocol: The case of China. Review of European Comparative \& International Environmental Law, 28(2): 175-184. 


\section{APPENDIX 1: METHODOLOGY}

For this systematic quantitative literature review we conducted two separate searches for literature relating to ABS and GRFA. Both searches targeted journal articles, books, book chapters and early access papers (excluding grey literature, editorials, comments, reviews, white papers and conference proceedings) published in English between 1991 and 2020. The first search was of all literature relating to genetic resources, traditional knowledge, access and benefit-sharing and intellectual property $(n=1201)$. After applying exclusion criteria (e.g. publications that only mention ABS without analysis), 577 articles remained. The second searched for literature relating to GRFA and all of the GRFA subsectors $(n=1165)$. This excluded duplicates and those that did not relate to ABS or informal sharing of the genetic resources, which left us with 362 publications. The final library (searches 1 and 2 combined) contained 827 references relating to ABS and GRFA (see Figure 1).

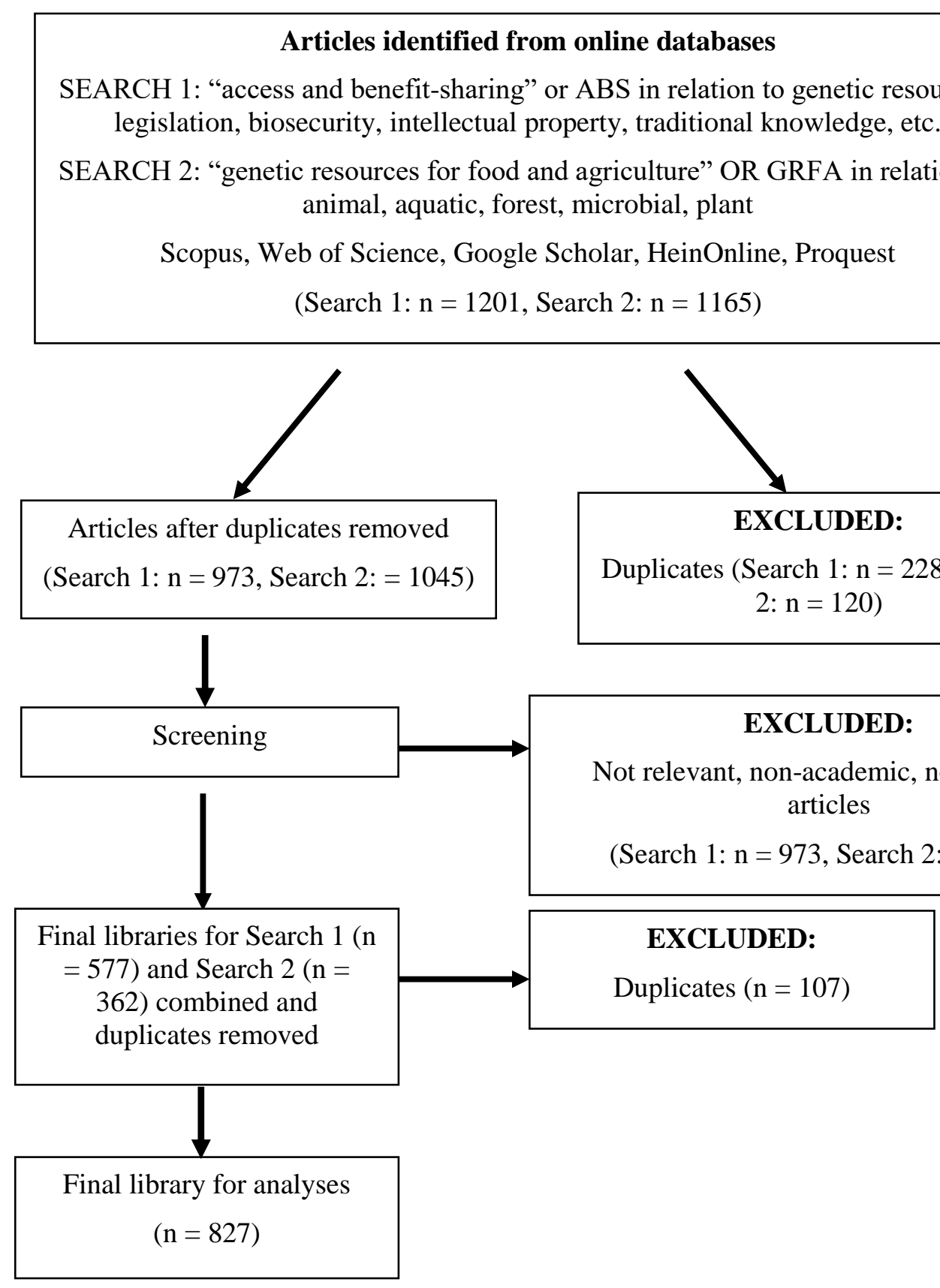

Figure 1. Preferred reporting items for systematic review recommendations (PRISMA) flowchart outlining the process for compiling this review (modified from Moher et al., 2015). $\mathrm{n}=$ number of articles. 


\section{Data analysis}

We classified the final dataset into the five main subsectors: PGR, AnGR, AqGR, FGR and MoGR and a sixth group that included articles relevant for all subsectors. Due to the low number of articles for InGR, we included this category in AnGR. We labelled each of the 827 articles based on geographic and taxonomic focus, and key ABS-related issues for all subsectors (see Table 1).

Table 1 Description of geographic regions, subsectors and key ABS category themes used in analyses of the final dataset $(n=827$ articles)

\begin{tabular}{ll}
\hline Label & Description \\
\hline Region & \\
Africa & All countries on continental Africa, Madagascar and the Seychelles \\
Asia & All countries in eastern, southern and southeastern Asia and the Middle \\
& East (only 4 Middle East publications, but probably more not in \\
& English. We did not want to give an inaccurate picture of the region by \\
& treating it separately) \\
Europe & All countries in Europe \\
Oceania & Australia, New Zealand and Pacific Island Nations \\
North America & Canada and the United States of America \\
South America & All countries in the Americas outside of North America \\
ABNJ & Areas beyond national jurisdiction \\
Global & Global scale \\
\hline
\end{tabular}

\section{Key themes \\ Biobank}

Bioprospecting

Biotechnology

Breeders' rights

Conservation

Farmers' Rights

Food security

Intellectual property

International agreements

National law

Research

Traditional knowledge
Specifically related to GRFA and:

"Any collection of biological materials, including those from ...plant, animal, fungi, bacteria, microorganisms and other living families, as well as bioinformatics data on such organic materials" (Perry 2013). This includes tissue banks, seed banks, biobanks and CGIAR Centres for any taxa

The search for genetic resources that can be developed into products or processes for commercialization, mainly for high-value products such as pharmaceuticals

"Any technological application that uses biological systems, living organisms, or derivatives thereof, to make or modify products or processes for specific use" (CBD Article 2; see Lidder and Sonnino (2011) for GRFA context)

Rights of farmers associated with livestock breeding

Conservation of GRFA diversity including agrobiodiversity

Rights of farmers associated with crops, seeds, etc.

"When all people, at all times, have physical and economic access to sufficient, safe and nutritious food to meet their dietary needs and food preferences for an active and healthy life" (FAO, IFAD, UNICEF, WFP and WHO, 2020). The search included crops/aquaculture/livestock relevant for food security.

"Creations of the mind, such as inventions; literary and artistic works; designs; and symbols, names and images used in commerce" (WIPO, 2020b). the search was confined to IP in relation to ABS of GRFA International or regional treaties, policies, instruments relating to ABS of GRFA

Country-specific legislation or policies in relation to ABS of GRFA Transfer of GRFA for research (non-commercial) purposes Traditional knowledge held by Indigenous Peoples and local communities within the scope of the CBD and the Nagoya Protocol 